\title{
Mineralização bruta de nitrogênio em um Molisol do sudeste da Província de Buenos Aires (Argentina)
}

\author{
CECILIA DEL CARMEN VIDELA \\ Engenheiro Agrônomo
}

Orientador: Prof. Dr. PAULO CESAR OCHEUZE TRIVELIN

Tese apresentada ao Centro de Energia Nuclear na Agricultura, da Universidade de São Paulo, para obtenção do título de Doutor em Ciências: Área de

Concentração: Energia Nuclear na Agricultura

P I R A C I C A B A

Estado de São Paulo - Brasil

Dezembro - 2004 
Dados Internacionais de Catalogação na Publicação (CIP)

\section{Seção Técnica de Biblioteca - CENA/USP}

Videla, Cecilia del Carmen

Mineralização bruta de nitrogênio em um Molisol do sudeste da província de Buenos Aires (Argentina) / Cecilia del Carmen Videla. - - Piracicaba, 2004.

124p. : il.

Tese (doutorado) - - Centro de Energia Nuclear na Agricul tura, 2004.

1. Lavoura 2. Manejo do solo 3. Matéria orgânica do solo 4. Nitrogênio 15 5. Pastagens 6. Plantio direto I. Título

CDU $631.452(821.1)$ 
A Deus, pelo milagre da vida.

Aos meus queridos pais, Magdalena Alvarez e Ramón Videla, pela dedicação e amor de toda a vida e ajuda nestes anos de doutorado.

Aos meus irmãos Gustavo e Lucy, pelo apoio e carinho, apesar da distância.

À memória dos meus avos José, Petrona, Ramón e a ultima a partir, minha querida nona Ramona, pelas lembranças do tempo compartido e a nossa história, que nunca esquecerei.

\section{Ofereço.}

A meu esposo Guillermo Pablo Almeida, pelo amor e apoio contínuos. A meus amados filhos Anita e Bernardo, por alegrar cada dia da minha vida.

Dedico. 


\section{AGRADECIMENTOS}

Ao Prof. Dr. Paulo Cesar Ocheuze Trivelin, pela confiança depositada, pela excelente orientação, pelos ensinamentos que contribuíram a minha formação acadêmica e humana e pela dedicação e capricho com que conseguiu tornar mais inteligível o meu "portunhol".

Aos Professores do Laboratório de Isótopos Estáveis: José Albertino Bendassolli, Jefferson Mortatti e Helder de Oliveira, pelo convívio e amizade.

Aos meus colegas Prof. Hernán E. Echeverría e Guillermo A. Studdert da Faculdade de Ciências Agrárias da Universidade Nacional de Mar del Plata, pela grande contribuição na realização desse projeto.

Ao amigo Dr. Glauber José de Castro Gava pela sua orientação e auxílio constantes durante todo o período de trabalhos no CENA e pelas frutíferas discussões sobre a mineralização bruta.

Aos funcionários e estagiários do Laboratório de Isótopos Estáveis: Hugo e Miguel pelas análises isotópicas, Raquel, Juliana e Carlão pelo auxílio nas realizações das atividades de laboratório, Neusa e Magda, pelo apóio administrativo à pesquisa e pela amizade, Bento e seu Luis, Pingin, pelos "Buenos dias, como estás?" que tanto ajudaram a minha inserção no grupo e os ensinos sobre como deve funcionar um laboratório. A todos eles por tornarem tão humano e agradável o ambiente de trabalho.

A meus colegas pós-graduandos do grupo de Isótopos Estáveis, Billy, Renato, André pela amizade e aquela virada de ano em Santana, Everaldo pela amizade e a preocupação naquele terrível final de 2001, Alexssandra, pela sua alegria e as risadas das que tantas saudades terei; Glauco, pelas suas carinhosas brigas e seus "odeio aos argentinos", Claudineia, pela sua carinhosa amizade, Mandai, o meu "Menino maluquinho", todos eles deixaram um ensinamento maravilhoso na minha vida.

Aos novos colegas do grupo de Isótopos Estáveis, Anderson, Faro e Henrique pela sua ajuda na etapa de redação e especialmente a Isabela pelo auxílio na etapa de copiado.

À minha colega Ana Carla Fernandes Gomes, cuja amizade levarei sempre no coração e ao Proff. Dr. Virgílio F. do Nascimento Filho, pela "adoção" no seu grupo.

Às senhoras Sandra Maria Genaro Nicolete pelo seu auxílio nos fracionamentos das amostras de solo e Marília Ribeiro Garcia Henyei, pela normatização das referências bibliográficas, às duas pela sua excelente disposição e amabilidade. 
A meu colega e amigo Engo. Germán Dominguez, da Faculdade de Ciências Agrárias da Universidade Nacional de Mar del Plata, pela condução dos experimentos em campo e pela informação histórica do experimento.

Ao Sr. Oscar Bastarrechea pela excelente colaboração com os trabalhos de campo e as enriquecedoras conversas, ao Sr. Tito García pela construção dos injetores, a Ana María, Sergio, Luis, Mara, Elsita e Carlitos pela colaboração com os trabalhos de laboratório e campo na Argentina; todos eles funcionários do grupo de Solos da Unidade Integrada INTA Balcarce - Faculdade de Ciências Agrárias da Universidade Nacional de Mar del Plata.

Ao Centro de Energia Nuclear na Agricultura, da Universidade de São Paulo (CENA-USP) que possibilitou a realização do curso de Doutorado em Ciências e todo o corpo docente da CPG/CENA, pelos ensinamentos na minha formação.

A Coordenação de Aperfeiçoamento do Pessoal de Nível Superior (CAPES) pela bolsa de estudo concedida.

À Fundação Antorchas e a Universidade Nacional de Mar del Plata, pelo auxílio financeiro à pesquisa.

Agradeço também a todos aqueles que de uma maneira ou de outra contribuíram para a realização deste trabalho. 


\section{SUMÁRIO}

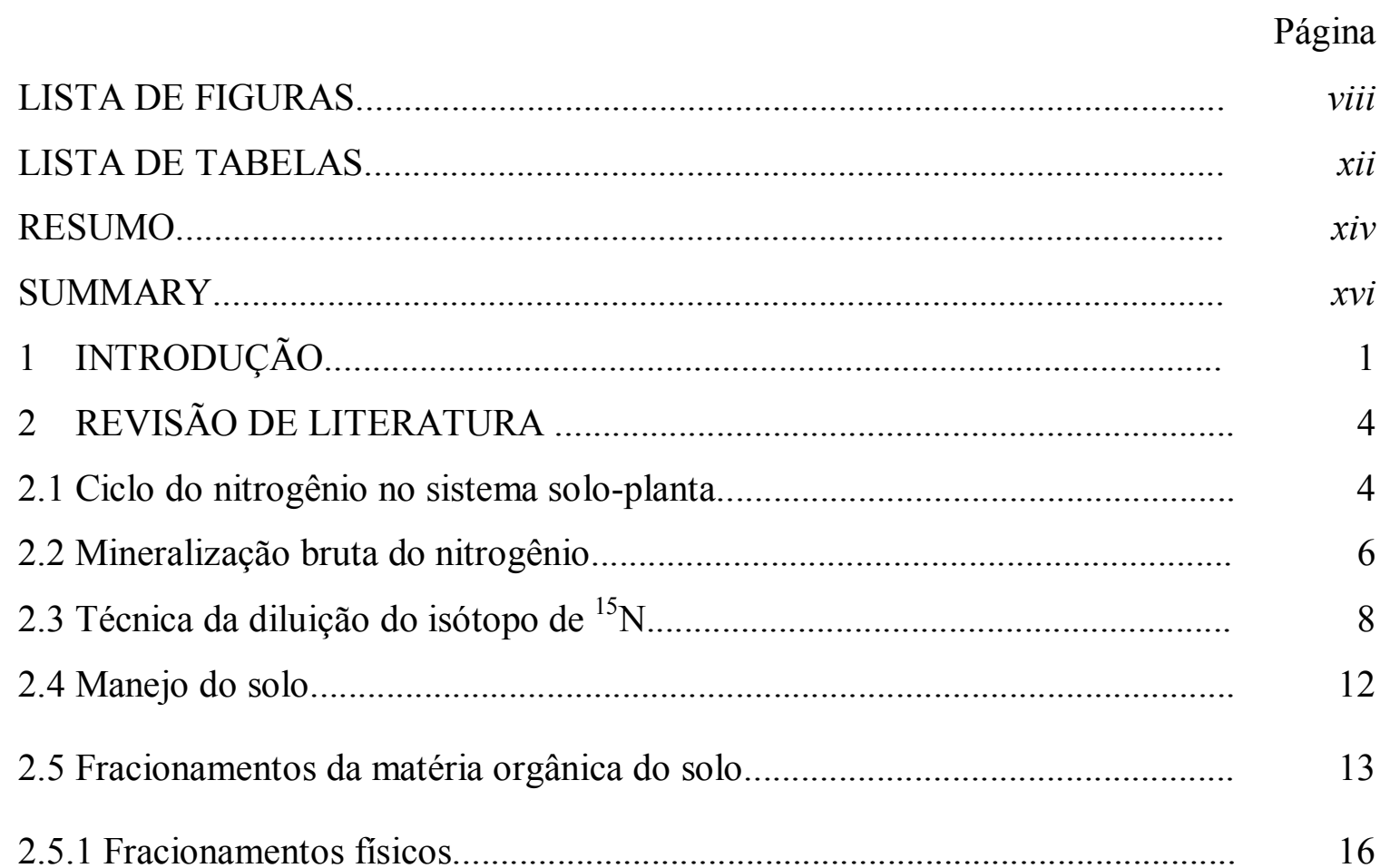

2.5.2 Dinâmica da matéria orgânica do solo associada às frações

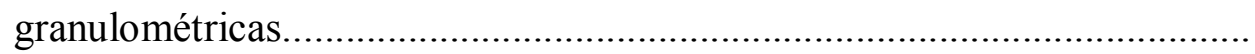

3 MINERALIZAÇÃO BRUTA DO NITROGÊNIO NO SUDESTE DE BUENOS AIRES (ARGENTINA): EFEITO DO MANEJO E A PROFUNDIDADE DE AMOSTRAGEM ..................................................... 21

Resumo ......................................................................................... 21

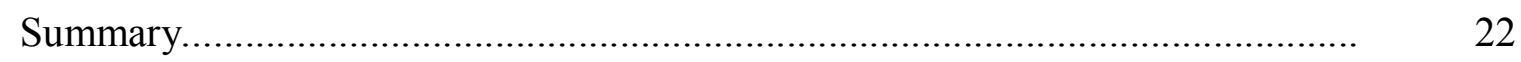

3.1 Introdução.............................................................................................. 23

3.2 Material e Métodos.............................................................................. 25

3.3 Resultados e Discussão .............................................................................. 28

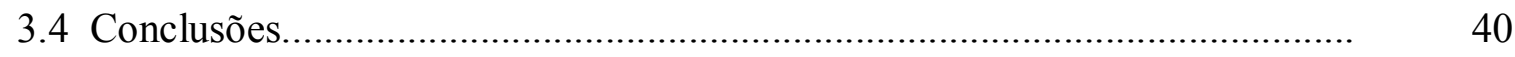


4 FRACIONAMENTO GRANULOMÊTRICO DA MATÉRIA ORGÂNICA DE UM MOLISOL DO SUDESTE DE BUENOS AIRES (ARGENTINA) SOB PASTAGEM, LAVOURA CONVENCIONAL E SEMEADURA DIRETA

Resumo

Summary.

4.1 Introdução

4.2 Material e Métodos.

4.3 Resultados e Discussão.

4.4 Conclusões

5 RELAÇÕES ENTRE OS CONTEÚDOS DE C E N NAS FRAÇÕES DA MATÉRIA ORGÂNICA DO SOLO E OS PROCESSOS BRUTOS DO CICLO DO NITROGÊNIO.

Resumo 55

Summary. 56

5.1 Introdução. 57

5.2 Material e Métodos. 58

5.3 Resultados e Discussão. 59

5.4 Conclusões. 66

6 EFEITO DA TEMPERATURA E DA UMIDADE NAS TAXAS DE MINERALIZAÇÃO E DE CONSUMO BRUTO DE NITROGÊNIO DE UM MOLISOL DO SUDESTE DE BUENOS AIRES (ARGENTINA) SOB PASTAGEM, LAVOURA CONVENCIONAL E SEMEADURA DIRETA

Resumo

Summary...... 70

6.1 Introdução. 71

6.2 Material e Métodos. 72

6.3 Resultados e Discussão. 


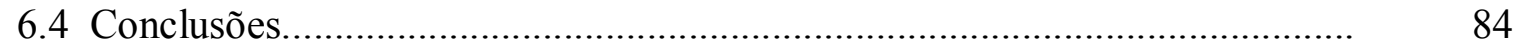

7 VARIAÇÕES TEMPORAIS NA MINERALIZAÇÃO BRUTA DE NITROGÊNIO EM UM MOLISOL DO SUDESTE DE BUENOS AIRES

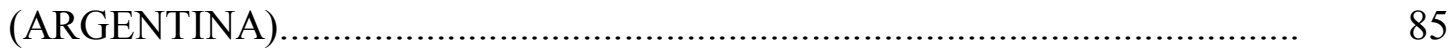

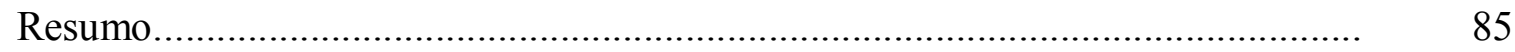

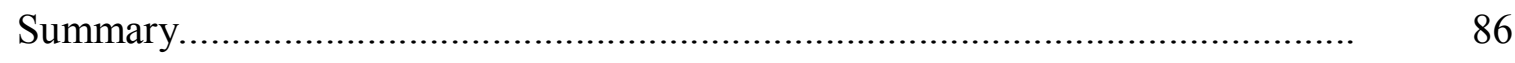

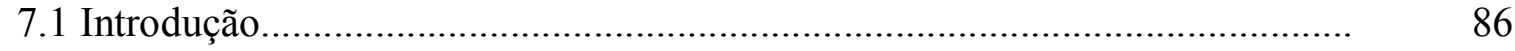

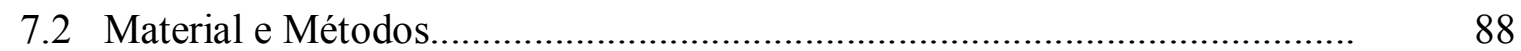

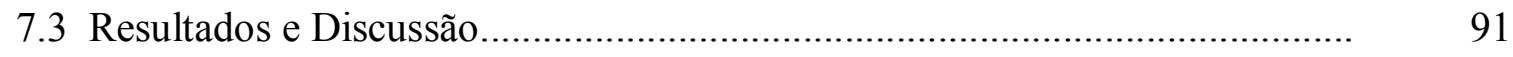

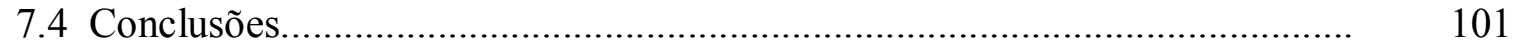

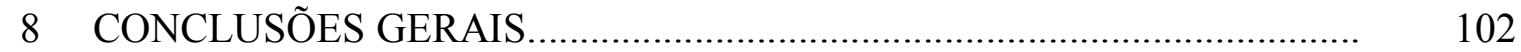

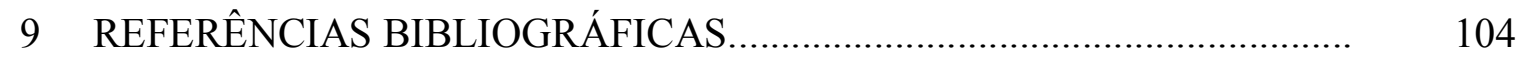

ANEXO A: CARACTERIZAÇÃO DA ÁREA EXPERIMENTAL E DO SOLO 119 ANEXO B: AJUSTE METODOLÓGICO PARA A DETERMINAÇÃO DO TEMPO DE AMOSTRAGEM NA DETERMINAÇÃO DA TMB ... 121 


\section{LISTA DE FIGURAS}

Figura

Página

1 Ciclo simplificado do nitrogênio em sistema solo-planta......................... 4

2 Esquemas do processo de mineralização líquida em duas situações

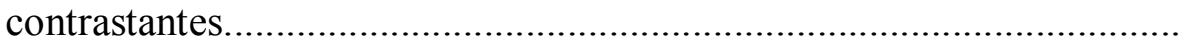

3 Fracionamento granulométrico (organo-mineral) proposto por Sá (2001)

4 Dispositivo utilizado para a adição de ${ }^{15} \mathrm{NH}^{+}{ }_{4}$ no solo das parcelas experimentais, contendo sete seringas e agulhas hipodérmicas.

5 Conteúdo do $\mathrm{N}$ inorgânico (amônio e nítrico) e abundância em excesso de ${ }^{15} \mathrm{~N}$ na profundidade de $0-10 \mathrm{~cm}$ em solos do Sudeste de Buenos Aires sob pastagem (P), lavoura convencional (LC) e semeadura direta (SD)

6 Conteúdo de $\mathrm{N}$ inorgânico (amônio e nítrico) e abundância em excesso de ${ }^{15} \mathrm{~N}$ na profundidade de $10-20 \mathrm{~cm}$ em solos do Sudeste de Buenos Aires sob pastagem (P), lavoura convencional (LC) e semeadura direta (SD)

7 Taxas de mineralização bruta em solos com pastagem (P), lavoura convencional (LC) e semeadura direta (SD), de 0-10 cm (A) e de 10-20 $\mathrm{cm}(\mathrm{B})$

8 Taxas de nitrificação bruta em solos com pastagem (P), lavoura convencional (LC) e semeadura direta (SD), de 0-10 cm (A) e de 10-20 $\mathrm{cm}(\mathrm{B})$

9 Taxas de consumo bruto de amônio em solos com pastagem (P), lavoura convencional (LC) e semeadura direta (SD), em amostras de solo colhidas nas profundidades de $0-10 \mathrm{~cm}$ (A) e de $10-20 \mathrm{~cm}$ (B)........ 
10 Relações entre taxas de mineralização bruta (TMB), consumo bruto (TCB) e nitrificação bruta (TNB) de todos os manejos, profundidades e tempos de adição de ${ }^{5} \mathrm{NH}^{+}{ }_{4}$

11 Acumulação de $\mathrm{N}$ mineralizado $(\mathrm{M})$ e consumido $(\mathrm{C})$ durante o período experimental para pastagem (P), lavoura convencional (LC) e semeadura direta (SD).

12 Distribuição da massa seca, nitrogênio e carbono total nas frações do solo de pastagem depois da destruição da matéria orgânica com $\mathrm{H}_{2} \mathrm{O}_{2} \ldots$.

13 Distribuição da massa da fração mineral do solo de pastagem com a matéria orgânica destruída $\left(\mathrm{H}_{2} \mathrm{O}_{2}\right) \mathrm{e}$, sem destruição da $\mathrm{MO}$, com dispersão em água $\left(\mathrm{H}_{2} \mathrm{O}\right)$ e hexametafosfato de sódio (HMP)

14 Nitrogênio, carbono e $\delta{ }^{13} \mathrm{C}$ nas frações do solo de pastagem do SE da província de Buenos Aires (Argentina) disperso com HMP.

15 Distribuição da massa do solo depois do fracionamento nos tratamentos pastagem $(\mathrm{P})$, lavoura convencional (LC) e semeadura direta $(\mathrm{SD})$ às

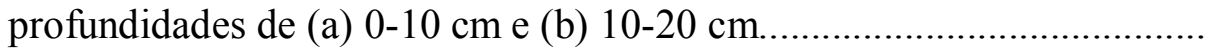

16 Mineralização bruta (TMB) e consumo bruto (TCB) de nitrogênio de solos sob lavoura convencional (LC), semeadura direta (SD) e pastagem (P) nas profundidades do solo de 0-5, 5-10 e 10-20 cm...

17 Variação da taxa de mineralização bruta (TMB) com a umidade do solo expressa como porcentagem da máxima capacidade de retenção de água (\%MCR), na profundidade de $0-5 \mathrm{~cm}$, para pastagem $(\mathrm{P})$, semeadura direta (SD) e lavoura convencional (LC).

18 Variação da taxa de mineralização bruta (TMB) com a umidade do solo, expressa como porcentagem da máxima capacidade de retenção de água (\%MCR), na profundidade de $5-10 \mathrm{~cm}$, para pastagem $(\mathrm{P})$, semeadura direta (SD) e lavoura convencional (LC) 
19 Variação da taxa de mineralização bruta (TMB) com a umidade do solo expressa como porcentagem da máxima capacidade de retenção de água (\%MCR), na profundidade de $10-20 \mathrm{~cm}$, para pastagem $(\mathrm{P})$, semeadura direta (SD) e lavoura convencional (LC).

20 Mineralização bruta (TMB) e consumo bruto (TCB) de nitrogênio de solo sob lavoura convencional (LC), semeadura direta (SD) e pastagem (P) a profundidades de solo de 0-5, 5-10 e 10-20 cm.

21 Distribuição dos cilindros para as determinações das taxas de mineralização bruta na pastagem e detalhe do disco de acrílico, contendo agulhas do tipo espinhal inseridas no solo.

22 Adição de ${ }^{15} \mathrm{NH}^{+}{ }_{4}$ ao solo dos cilindros com injetor múltiplo e agulhas espinhais para a determinação das taxas de consumo e de mineralização bruta.

23 Precipitações e temperatura ambiente no período setembro-abril históricos (período 1970-2000) e em 2003-2004.

24 Precipitações (em colunas) e dinâmica de acumulação de água no solo para o cultivo de milho (linha continua) no período outubro de 2003 a março de 2004.

25 Temperatura de solo a 7,5 $\mathrm{cm}$ de profundidade nos tratamentos lavoura convencional (LC), semeadura direta (SD) e pastagem (P)

26 Conteúdo de água do solo no período de outubro 2003 a março 2004, nas parcelas sob lavoura convencional (LC), semeadura direta (SD) e pastagem $(\mathrm{P})$......

27 Taxa de mineralização bruta nos manejos lavoura convencional (LC), semeadura direta (SD) e pastagem (P) durante o ciclo agrícola do milho 2003-2004.

28 Taxa de consumo bruto nos manejos lavoura convencional (LC), semeadura direta $(\mathrm{SD})$ e pastagem $(\mathrm{P})$ durante o ciclo agrícola do milho 2003-2004 
29 Acumulação de $\mathrm{N}$ mineralizado $(\mathrm{M})$ e consumido $(\mathrm{C})$ durante o período experimental outubro 2003 a março 2004 nos manejos lavoura convencional (LC), pastagem (P) e semeadura direta (SD)....................

30 Conteúdo e enriquecimento em ${ }^{15} \mathrm{~N}$ da fração amônio após a adição de sulfato de amônio- ${ }^{15} \mathrm{~N}$

31 Taxas de mineralização bruta do solo sob pastagem, incluindo o tempo de 1 dia (a) e com eliminação desse tempo (b). 


\section{LISTA DE TABELAS}

Tabela

Página

1 Acumulação bruta de $\mathrm{N}$ mineralizado, consumido e diferenças entre consumo e mineralização para pastagem, semeadura direta e lavoura convencional durante 35 dias de incubação

2 Recuperação da massa, carbono e nitrogênio total no solo de pastagem disperso com água $\left(\mathrm{H}_{2} \mathrm{O}\right)$ ou hexametafosfato de sódio (HMP)

3 Carbono, nitrogênio, $\delta^{13} \mathrm{C}$ e relação $\mathrm{C}: \mathrm{N}$ nas frações granulométricas, à profundidade de $0-10 \mathrm{~cm}$, nos tratamentos com pastagem $(\mathrm{P})$, lavoura convencional (LC) e semeadura direta (SD)..........................

4 Coeficientes de correlação de Pearson e significância das correlações entre as taxas de mineralização e consumo bruto, e os conteúdos de C, $\mathrm{N}$ e relações $\mathrm{C}: \mathrm{N}$ do solo sem fracionar (total) e das frações de matéria orgânica.

5 Modelos de regressão linear múltipla para as taxas de mineralização (TMB) e de consumo bruto (TCB), influenciadas pelos conteúdos de $\mathrm{C}, \mathrm{N}$ e relações $\mathrm{C}: \mathrm{N}$, no solo total e nas frações granulométricas...........

6 Modelos de regressão linear múltipla para a variação das taxas de mineralização bruta (TMB) influenciadas pelos conteúdos de $\mathrm{C}, \mathrm{N}$ e relações $\mathrm{C}: \mathrm{N}$ no solo total e nas frações granulométricas, nos manejos lavoura convencional, pastagem e semeadura direta...........................

7 Modelos de regressão linear múltipla para a variação das taxas de consumo bruto (TCB) influenciadas pelos conteúdos de $\mathrm{C}, \mathrm{N}$ e relações $\mathrm{C}: \mathrm{N}$ no solo total e nas frações granulométricas, nos manejos lavoura convencional, pastagem e semeadura direta. 
8 Conteúdo de água na máxima capacidade de retenção (MCR), Carbono orgânico e Nitrogênio total do solo nos manejos com pastagem (P), semeadura direta (SD) e lavoura convencional (LC), nas

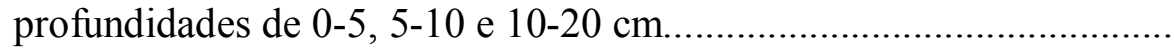

9 Taxas de mineralização e de consumo de amônio do solo, sob lavoura convencional (LC), semeadura direta (SD) e pastagem (P), nas profundidades de $0-5,5-10$ e $10-20 \mathrm{~cm}$ e à temperatura de $35^{\circ} \mathrm{C}$, com as umidades de $25,55,65$ e $80 \%$ da máxima capacidade de retenção de água (\% MCR).

10 Taxas de mineralização e de consumo de amônio de solo sob lavoura convencional (LC), semeadura direta $(\mathrm{SD})$ e pastagem $(\mathrm{P})$ medidas às temperaturas de $5,15,25$ e $35^{\circ} \mathrm{C}$ e a $70 \%$ da máxima capacidade de retenção de água (\% MCR) às profundidades de 0-5, 5-10 e 10-20 $\mathrm{cm}$

11 Conteúdo da fração amônio e enriquecimento em ${ }^{15} \mathrm{~N}$ depois da adição de ${ }^{15} \mathrm{NH}_{4}^{+}$nos manejos: lavoura convencional (LC), semeadura direta (SD) e pastagem $(\mathrm{P})$, nos meses de outubro a março

12 Propriedades do complexo de solos Paleudol petrocálcico - Argiudol típico, depois de 18 anos de agricultura sob plantio convencional na Estação Experimental Balcarce do INTA-Argentina.

13 Seqüência de cultivos prévios à instalação do experimento na Estação Experimental do INTA Balcarce-Argentina.

14 Seqüência de culturas após à instalação do experimento na Estação Experimental do INTA Balcarce-Argentina.

15 Taxas de mineralização bruta do solo Argiudol típico sob pastagem no Sudeste da província de Buenos Aires (Argentina) calculadas com diferentes intervalos de tempo entre a primeira e segunda extração $(n=9)$ 


\title{
Mineralização bruta de nitrogênio em um Molisol do sudeste da Província de Buenos Aires (Argentina)
}

\author{
Autor: CECILIA DEL CARMEN VIDELA \\ Orientador: Prof. Dr. PAULO CESAR OCHEUZE TRIVELIN
}

\section{RESUMO}

A intensificação da agricultura convencional que ocorreu nas últimas décadas na região Sudeste da Província de Buenos Aires (Argentina), provocou degradação das propriedades do solo e redução da fertilidade nitrogenada, apesar dos níveis relativamente elevados de matéria orgânica nesse solo. A inclusão de pastagens (P) nas rotações agrícolas e a adoção da semeadura direta (SD), como manejos alternativos à lavoura convencional (LC), visaram deter a degradação desse solo. A adoção de diferentes sistemas de manejo influem na dinâmica do nitrogênio no solo, modificando a sua disponibilidade às plantas. Com base nesta hipótese, o objetivo geral deste trabalho foi o de quantificar os processos de mineralização, nitrificação e consumo brutos do nitrogênio em um Molisol do SE da Província de Buenos Aires, manejado durante 17 anos com LC e transformado para $\mathrm{P}$ ou SD. Os processos brutos do ciclo do nitrogênio foram quantificados pela técnica da diluição do isótopo ${ }^{15} \mathrm{~N}$. Foram realizados os seguintes experimentos: (a) avaliação em laboratório de taxas de mineralização bruta (TMB), consumo bruto (TCB) e nitrificação bruta (TNB) em amostras deformadas e em condições de umidade e temperatura constantes; (b) avaliação dos efeitos do manejo na distribuição das frações granulométricas da matéria orgânica; (c) avaliação das relações entre os processos brutos do ciclo do nitrogênio e as frações granulométricas da matéria orgânica, (c) avaliação em laboratório dos efeitos da temperatura e da umidade do solo 
nas TMB e TCB e (d) determinações de TMB e TCB em campo durante o ciclo da cultura de milho nos manejos SD, LC e pastagem. A metodologia de diluição do isótopo ${ }^{15} \mathrm{~N}$ permitiu a determinação de taxas de mineralização e de consumo bruto em solo com diferentes sistemas de manejo, tanto em condições de laboratório, com amostras deformadas, quanto diretamente em campo, com amostras indeformadas. $\mathrm{Na}$ quantificação da taxa de nitrificação bruta, a marcação do solo com amônio- ${ }^{15} \mathrm{~N}$ não se mostrou adequado, levando a resultados muito variáveis, com evidencias de estimulação pelo substrato. Em todos os experimentos a TCB foi maior que a TMB e as quantidades totais consumidas superaram àquelas mineralizadas. Após seis anos da implantação dos manejos alternativos á LC (SD e P), os processos brutos de transformação do nitrogênio no solo apresentaram marcante estratificação, sendo maiores nas camadas superficiais do solo. As TMB da pastagem foram maiores às da LC, indicando melhora na condição biológica do solo, enquanto que SD somente manifestou uma tendência nesse sentido. Nos três manejos, grandes quantidades de $\mathrm{C}$ e $\mathrm{N}$ estiveram presentes nas frações $<50$ $\mu \mathrm{m}$, nas quais, a matéria orgânica tem alta proteção física e não foi modificada pelo manejo. A pastagem acumulou maior quantidade de $\mathrm{C}$ e de $\mathrm{N}$ nas frações leves $>50 \mu \mathrm{m}$ que LC. Não se encontrou um padrão simples relacionando a TMB e a TCB com as variáveis das frações granulométricas. Equações de regressão múltiplas para LC incluíram o $\mathrm{C}$ e $\mathrm{N}$ das frações mais finas, enquanto que para $\mathrm{P}$ apareceram as frações leves maiores que $50 \mu \mathrm{m}$, sugerindo recuperação da MO do solo. A temperatura e a umidade do solo modificaram as TMB e TCB, sendo que as maiores taxas ocorreram a $25^{\circ} \mathrm{C}$ e a $70 \% \mathrm{MCR}$. LC não apresentou resposta nem a temperatura nem a umidade de solo. Em determinações feitas em campo, após de 9 anos de instalados os manejos, as variações das TMB e TCB foram associadas, principalmente, às variações na umidade do solo. As TMB e TCB na pastagem foram geralmente maiores que as de LC e SD. SD apresentou maiores TMB e TCB que LC no final do ciclo do milho. As quantidades mineralizadas e consumidas acumuladas por SD foram significativamente maiores às correspondentes de LC, embora a cultura de milho não foi beneficiada por essas diferenças devido a disponibilidade de $\mathrm{N}$ no solo não coincidir com os estádios de máxima demanda pelas plantas. 


\title{
Gross nitrogen mineralization in a Mollisol of the southeast of Buenos Aires Province (Argentina)
}

\author{
Author: CECILIA DEL CARMEN VIDELA \\ Adviser: Prof. Dr. PAULO CESAR OCHEUZE TRIVELIN
}

\section{Summary}

The intensification of conventional agriculture in Southeast of Buenos Aires Province (Argentina), caused (conducted to) soil degradation and reduction of nitrogen fertility, despite the relatively high levels of organic matter on this soil. No tillage systems (SD) and inclusion of pastures $(\mathrm{P})$ in agricultural rotations are alternative soil managements to reduce the effects of conventional tillage (LC). Management systems affect the soil nitrogen dynamics modifying its availability to the plants. The objective of this work was to quantify the gross nitrogen mineralization, nitrification and consumption processes in a Molisol, which was previously under LC for 17 years. In 1994 it was transformed to P, SD or continued on LC. The gross nitrogen cycle processes were quantified using the isotope ${ }^{15} \mathrm{~N}$ dilution technique. The following experiments were carried out: (a) laboratory evaluation of gross mineralization (TMB), consumption (TCB) and nitrification rates (TNB) in disturbed soil samples with constant soil moisture and temperature conditions; (b) evaluation of the effect of management systems in the size distribution of soil organic matter; (c) evaluation of the relationships between the gross nitrogen processes and in the size fractions of organic matter, (c) laboratory evaluation of the effect of temperature and soil moisture on TMB and TCB, and (d) determination of TMB and TCB on field conditions during the growing season of maize under SD and LC and in a pasture during the same period. The isotope ${ }^{15} \mathrm{~N}$ 
dilution technique allowed the determination of gross mineralization rates for different management practices both in laboratory conditions with disturbed samples, and on field conditions with intact soil samples. For measurements of gross nitrification rates, soil label with ${ }^{15} \mathrm{~N}$-ammonium was not adequate, producing highly variable results and evidences of substrate stimulation. In all the experiments, the TCB was greater than $\mathrm{TMB}$ and the consumed total amounts were higher than the mineralized ones. After six years since management's installation, both the TMB and TCB gross nitrogen processes in soil were strongly depending of the soil depth, being the highest in the top $0-5 \mathrm{~cm}$ layer. The pasture TMBs were higher than LC ones, suggesting improvement in the soil biological condition, while SD only presented a trend in this way. For the three management systems, high levels of $\mathrm{C}$ and $\mathrm{N}$ contents were determined in $<50 \mu \mathrm{m}$ fractions, in which, the organic matter has a high level of physical protection and it was not modified by the management. The largest relative increase in $\mathrm{C}$ and $\mathrm{N}$ contents occurred in light $>50 \mu \mathrm{m}$ fractions of pasture. A simple pattern relating the TMB and TCB with the organic matter size fractions was not found. Linear multiple regression analysis for $\mathrm{LC}$ included $\mathrm{C}$ and $\mathrm{N}$ content on the $<50 \mu \mathrm{m}$ fractions, however for $\mathrm{P}$ models, the $\mathrm{C}$ and $\mathrm{N}$ contents on light $>50 \mu \mathrm{m}$ are frequently included variables, suggesting recovery of soil OM. The TMB and TCB were affected by soil moisture and temperature, appearing as optimal conditions to gross mineralization temperature of $25^{\circ} \mathrm{C}$ and soil moisture of $70 \%$ of field capacity. For field determinations, after 9 years of management installation, the variations of TMB and TCB were mainly associates to the soil moisture variations. Pasture TMB and TCB values were higher than LC and SD.TMB and TCB values of SD management system were higher than LC only on the February and March soil samplings. For all the management systems TCB was higher than TMB, being the total consumed amounts, higher than the mineralized ones. Total mineralized $\mathrm{N}$ was higher on SD than LC; however, the corn crop was not benefited since $\mathrm{N}$ availability did not meet the period of highest $\mathrm{N}$ demand. 


\section{INTRODUÇÃO}

A região do Sudeste da Província de Buenos Aires (Argentina) ocupa doze milhões de hectares e apresenta características de solo e clima que geram um mosaico de situações produtivas particulares, permitindo diferenciá-la do restante da região pampeana. A produtividade desta zona é relevante, pois representa $6 \%$ da área agrícola nacional e produz cerca de $18 \%$ do PBI agropecuário argentino. Esta área caracteriza-se pela presença de solos com níveis elevados de matéria orgânica, apresentando entre 25 e $45 \mathrm{~g} \mathrm{~kg}^{-1}$ C-orgânico. Nas últimas três décadas, a intensificação da agricultura com utilização de sistemas de lavouras do tipo convencional (LC) (arações e gradações) e a eliminação de pastagens que habitualmente eram incorporadas nas rotações (Darwich, 1991), resultaram na degradação das propriedades físicas, químicas e bioquímicas desses solos (Echeverría \& Ferrari, 1993, Studdert et al., 1997). Essa degradação é comprovada por problemas com erosão de solo e de deficiência de nutrientes, este último processo evidenciado, principalmente, na resposta à fertilização nitrogenada nas culturas de trigo (Berardo, 1994; González Montaner et al., 1997) e milho (Andrade et al., 2002). A expansão da cultura da soja nos últimos ciclos agrícolas também aprofundou os problemas derivados da intensificação agrícola.

Como alternativas de manejo, visando reverter o processo de degradação dos solos, destacam-se as lavouras conservacionistas como a semeadura direta (SD), sistema esse de manejo utilizado nos Estados Unidos desde 1945 e denominado "no-till" ou "notillage”. Esse sistema caracteriza-se, segundo Bradford \& Peterson (2000) e Oliveira et al. (2002), por ser um manejo em que o plantio ou a semeadura de uma cultura é realizada em solo não revolvido,protegido por resíduos vegetais de culturas anteriores. A 
cobertura do solo com resíduos vegetais deve ocupar pelo menos 30\% da superfície do solo (Studdert \& Echeverría, 2000). No final da década dos anos 70 deu-se início a utilização da SD na Argentina. Em 2002, cerca de 12 milhões de hectares já eram cultivados com SD (30\% da superfície agrícola nacional) (Peiretti, 2002); razão pela qual existe, na atualidade, grande interesse em estudos sobre a dinâmica de nutrientes nesse sistema, uma vez que ocorre redução da erosão do solo e aumento da conservação da matéria orgânica.

A adoção do manejo de semeadura direta afeta as propriedades físicas, químicas e biológicas do solo, e altera a posição e a distribuição dos resíduos vegetais no perfil, afetando às características e a distribuição dos nichos biológicos e os processos da transformação do $\mathrm{N}$ e de sua eficiência do uso pelas culturas.

A decomposição da matéria orgânica do solo (MOS) e as correspondentes mineralização e imobilização do $\mathrm{N}$, são processos chave no ciclo do $\mathrm{N}$ no sistema soloplanta. Esses processos envolvem uma grande complexidade devido à mistura heterogênea de componentes: desde resíduos de plantas e palha incorporados recentemente, até material húmico altamente resistente (Jenkinson, 1988). A biomassa microbiana, responsável pela decomposição de resíduos, é constituída também por uma mistura de microrganismos, que são afetados pelas condições ambientais. Em solos submetidos a lavoura convencional (LC), Studdert et al. (1997) encontraram que o conteúdo de matéria orgânica diminuiu $4,4 \mathrm{~g} \mathrm{~kg}^{-1}$ em 6 a 7 anos, e logo estabilizou-se em um nível de equilíbrio entre 26 e $29 \mathrm{~g} \mathrm{~kg}^{-1}$, baseado na seqüência das culturas à que estiveram sujeitos (Studdert \& Echeverría, 2000).

Nos últimos anos, estudos que utilizam a técnica da diluição isotópica do ${ }^{15} \mathrm{~N}$ demonstraram que a mineralização e a imobilização brutas, que determinam a disponibilidade de N, são importantes e parcialmente independentes entre si (Schimel, 1986; Davidson et al., 1991). A estimação dos fluxos brutos de N no solo permite compreenderem melhor os processos que governam o ciclo de $\mathrm{N}$ e, conseqüentemente, a disponibilidade de $\mathrm{N}$ para as plantas, além de facilitar a predição da mineralização líquida. Dos antecedentes apresentados, ressalta-se que no Sudeste da província de 
Buenos Aires ocorre a situação particular de solos com níveis elevados de matéria orgânica, mas com deficiências importantes de nitrogênio nos cultivos agrícolas da região. As modificações que ocorrem no solo, como conseqüência da utilização da semeadura direta, como o acúmulo de resíduos orgânicos na superfície, afetarão o processo de mineralização bruta e produzirão diferentes disponibilidades de $\mathrm{N}$ para as culturas. Com base nesta hipótese, o presente trabalho tem como objetivo geral a quantificação das taxas de mineralização bruta do nitrogênio em solos sob diferentes manejos: pastagem, plantio convencional e semeadura direta.

Os objetivos específicos são: (a) Ajustar e adaptar a metodologia da medição da mineralização bruta do nitrogênio, (b) Estimar as taxas de mineralização bruta de solos sob lavouras convencionais (PC), semeadura direta (SD) e pastagem (P), em condições de laboratório (amostra modificada) e em campo (solo não modificado), (c) Analisar o efeito de variáveis ambientais (temperatura e umidade do solo) no processo de mineralização bruta, (d) Analisar as relações entre as taxas de mineralização bruta e as frações lábeis da matéria orgânica.

Neste trabalho de tese de doutorado os resultados serão apresentados na forma de cinco trabalhos independentes e as conclusões gerais estarão destacadas ao final. 


\section{REVISÃO DE LITERATURA}

\subsection{Ciclo do nitrogênio no sistema solo-planta.}

Em representações simplificadas do ciclo do nitrogênio no sistema solo-planta como a apresentada na Figura 1, estão envolvidos seis processos simultâneos e interdependentes, e quatro frações ou "pools". Estes "pools" se definem como frações de nitrogênio identificáveis por análises químicas.
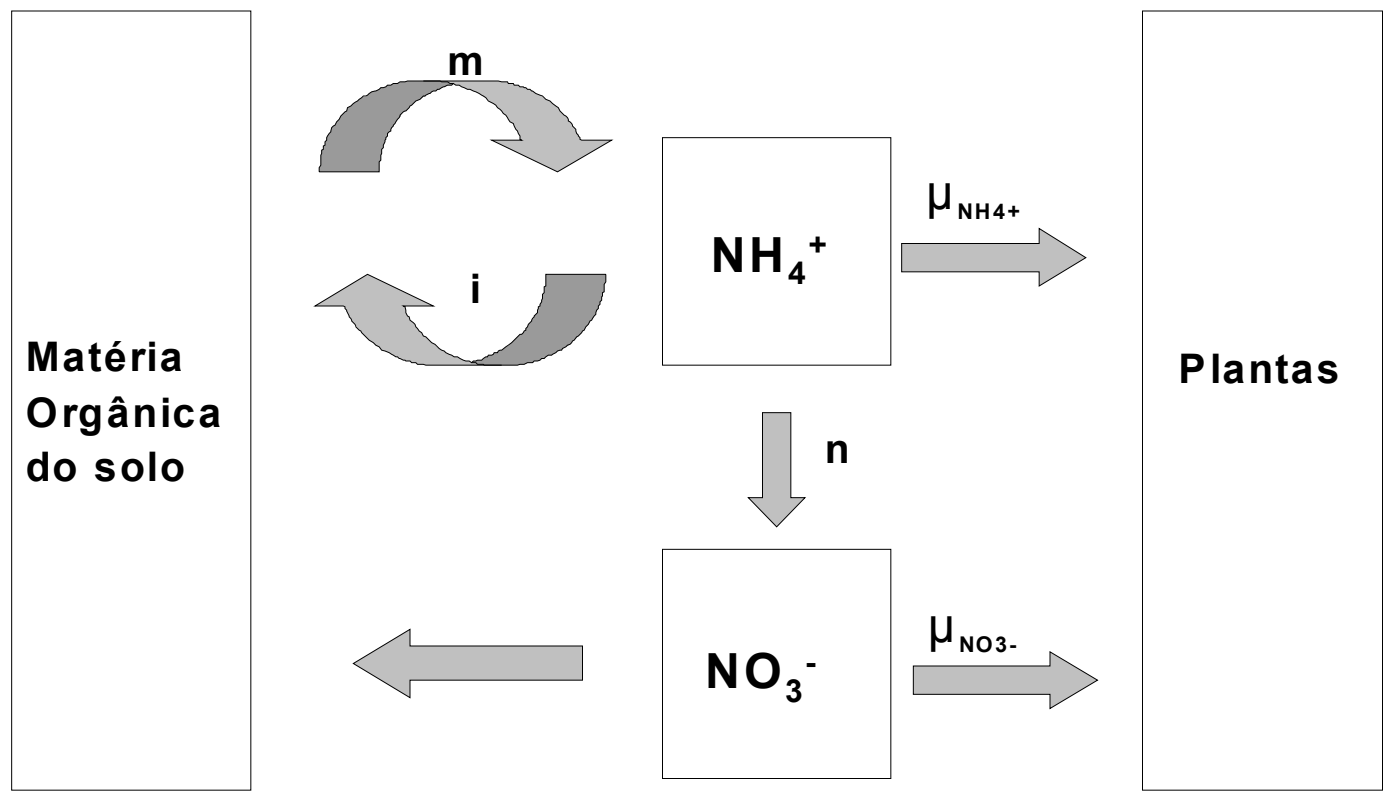

Figura 1. Ciclo simplificado do nitrogênio em sistema solo-planta (Barraclough, 1991). 
$\mathrm{O}$ ciclo interno do nitrogênio consiste de processos que convertem $\mathrm{N}$ de uma forma química em outra ou transferem $\mathrm{N}$ entre distintos "pools" do ecossistema. Este ciclo interno inclui a absorção de $\mathrm{N}$ pelas plantas, o retorno de $\mathrm{N}$ ao solo na forma de resíduos vegetais da parte aérea e raízes, a mineralização de $\mathrm{N}$ (conversão de $\mathrm{N}$ orgânico a inorgânico), a imobilização microbiana de $\mathrm{N}$ (consumo de $\mathrm{N}$ inorgânico pelos microrganismos) e a nitrificação (produção de nitrito - nitritação - a partir do amônio e de nitrato -nitratação - a partir do nitrito). Os movimentos de nitrogênio nesse sistema são mediados pela atividade de comunidades de microrganismos, que são afetados pelas condições ambientais, principalmente pela temperatura e a umidade do solo, assim como pelo $\mathrm{pH}$ e a reserva de C-orgânico no solo.

As medições simples de alterações nos tamanhos dos "pools" não oferecem explicação acerca dos fluxos de entrada e saída desde um "pool" para outro, já que, por exemplo, a fração amônio sofre no solo processos que a consomem (imobilização, nitrificação, fixação nas argilas, volatilização) e que a produzem (mineralização). Do ponto de vista da produção agrícola, os efeitos líquidos da atividade heterotrófica da microbiota do solo na ciclagem de $\mathrm{N}$ foram amplamente estudados (mineralização e imobilização líquidas do N), ainda que em termos de biologia de solo, bioquímica e ecologia, os estudos dos processos líquidos não reflitam o que realmente está acontecendo no sistema. Por exemplo, uma baixa taxa de mineralização líquida pode ser produto de uma baixa atividade biológica total no ecossistema, ou pode ser o resultado de uma alta atividade de processos que trabalham em sentidos opostos, isto é, mineralização e imobilização bruta muito ativas (Figura 2).

Situação 1

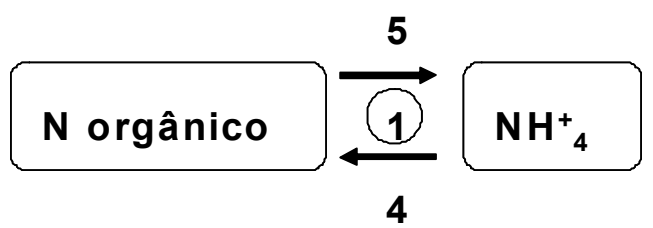

Situação 2

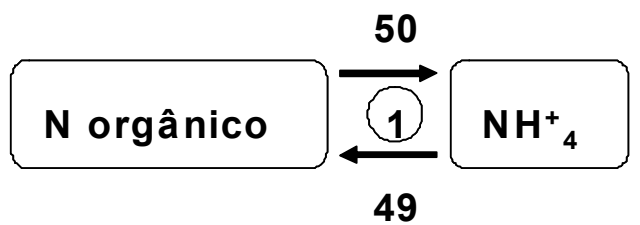

Figura 2. Esquemas do processo de mineralização líquida em duas situações contrastantes. (Adaptado de Myrold, 2004) 
Existem ainda muitas incógnitas dentro do ciclo interno no nitrogênio, muitas etapas ou passagens de um "pool" para outro que não estão devidamente esclarecidos, conduzindo os modelos preditivos a falhas em condições ambientais ou sistemas produtivos diferentes daqueles para os quais foram ajustados.

\subsection{Mineralização bruta do nitrogênio}

As determinações de mineralização líquida foram usadas historicamente como indicadoras da disponibilidade in situ de N no solo (Hatch et al., 1990; Stenger et al., 1995). Não obstante, estes valores de mineralização são o resultado líquido de combinações de taxas brutas dos processos que compõem o ciclo do nitrogênio, particularmente amonificação, imobilização e nitrificação. Nos últimos anos, estudos

usando o isótopo estável do nitrogênio ${ }^{15} \mathrm{~N}$, demonstraram que a mineralização e a imobilização bruta, que determinam à disponibilidade de $\mathrm{N}$, são importantes $\mathrm{e}$ parcialmente independentes entre si (Schimel, 1986; Davidson et al., 1991). A estimativa dos fluxos brutos de $\mathrm{N}$ no solo permite compreender melhor os processos que governam o ciclo do $\mathrm{N}$ e, conseqüentemente, a disponibilidade do nutriente para as plantas (Barraclough \& Puri, 1995; Recous et al., 1999; Sparling et al., 1995).

A mineralização bruta é definida como o processo de conversão direta de Norgânico em $\mathrm{NH}_{4}{ }^{+} / \mathrm{NH}_{3}$ (amonificação) e só pode ser estimada utilizando-se a diluição da abundância de ${ }^{15} \mathrm{~N}$ no "pool" de $\mathrm{NH}_{4}^{+}$marcado inicialmente com ${ }^{15} \mathrm{~N}$, pelo ${ }^{14} \mathrm{NH}^{+}{ }_{4}$ proveniente da mineralização da matéria orgânica. Com esta técnica é medida só a mineralização bruta (que introduz ${ }^{14} \mathrm{~N}$ desde a matéria orgânica), já que os processos que consomem amônio extrairão ${ }^{14} \mathrm{~N}$ e ${ }^{15} \mathrm{~N}$ em proporção constante, num dado intervalo de tempo.

Isto é verdade já que com os valores habitualmente usados de incorporação de amônio enriquecido em ${ }^{15} \mathrm{~N}$ ao solo (como exemplo: $10 \%$ de átomos em excesso ou mais), resultará desprezível o fracionamento isotópico que certamente ocorre em todos 
os processos do ciclo do $\mathrm{N}$ (Yoneyama, 1996).

Estes conceitos e o desenvolvimento matemático deles foram publicados por Kirkham \& Bartholomew (1954), mas tiveram pouca utilização de imediato, devido aos altos custos das determinações de ${ }^{15} \mathrm{~N}$ e às condições restritivas das equações. A partir da metade da década dos anos oitentas, as equações foram simplificadas e superadas algumas restrições, tornando o método mais acessível. Por outra parte, o desenvolvimento da espectrometria de massa automatizada por combustão diminuiu o custo analítico favorecendo a maior utilização da metodologia. Barraclough et al., (1985) e Nishio et al., (1985) publicaram independentemente simplificações das equações propostas por Kirham \& Bartholomew (1954), que permitiram a determinação experimental das taxas de mineralização bruta pela equação (1)

$$
\mathbf{A}^{*}=\mathbf{A}^{*} /\left(1+\left(\theta \mathbf{t} / \mathbf{A}_{0}\right)^{m / \theta}\right.
$$

Significando: $\mathrm{A}_{\mathrm{t}}^{*}$ - abundância de ${ }^{15} \mathrm{~N}$ em excesso no "pool" de amônio no tempo t; $\mathrm{A}_{\mathrm{o}}{ }_{\mathrm{o}}$ abundância de ${ }^{15} \mathrm{~N}$ em excesso no "pool" de amônio no início $(\mathrm{t}=0) ; \mathrm{t}$ - tempo em dias; A - tamanho do "pool" de amônio; $\theta=\left(\mathrm{A}_{t}-\mathrm{A}_{0}\right) / \mathrm{t} ; \mathrm{m}$ - taxa de mineralização bruta

A equação (1), utilizada na determinação da taxa de mineralização bruta (TMB), é valida se forem satisfeitas as seguintes condições (Barraclough, 1991):

1.- Os processos que consomem amônio, como absorção pelas plantas e nitrificação, não discriminam entre $\mathrm{o}{ }^{14} \mathrm{~N}$ e ${ }^{15} \mathrm{~N}$.

2.- $\mathrm{O} \mathrm{N}$ do marcador deve ser misturado uniformemente com o $\mathrm{N}$ nativo do solo, de forma que o $\mathrm{N}$ marcado e não marcado sejam utilizados em proporção às quantidades relativas presentes.

3.- Durante todo o período experimental, as taxas dos processos devem ser descritas por cinética de ordem zero.

4.- $\mathrm{O} N$ mineralizado deve ter abundância natural de ${ }^{15} \mathrm{~N}(0,3663 \%)$. Esta condição significa que não deve ocorrer remineralização durante o período experimental.

A primeira condição é satisfeita com os valores de enriquecimento 
habitualmente utilizados (maiores a $10 \%$ em átomos de ${ }^{15} \mathrm{~N}$ ), que fazem desprezíveis as diferenças originadas pelo fracionamento isotópico. A distribuição homogênea do marcador deve ser atendida cuidadosamente, já que grandes diferenças em tamanho e enriquecimento do "pool" amônio podem ocasionar erros nas determinações de TMB (Monhagan, 1995). É recomendável a utilização de um injetor múltiplo para distribuir o marcador de maneira o mais homogenea possível e realizar as injeções dispensando a solução, na medida em que o injetor e extraído do solo. No caso de solos com alto conteúdo de areia, onde a difusão da solução marcadora é lenta e a adição de grandes volumes poderá alterar em muito o nível de umidade do solo, é aconselhável a utilização de injetores de gás ${ }^{15} \mathrm{NH}_{3}$ (Murphy et al, 1997).

A condição de que as taxas do processo devem ser descritas por cinética de ordem zero durante o período experimental não é muito restritiva, já que nas condições habituais de trabalho (entre 2 e 7 dias) a maioria dos processos são adequadamente representados por esta cinética (Barraclough, 1995). A condição mais restritiva refere-se a não ocorrência de remineralização de $\mathrm{N}$ imobilizado durante as determinações. Quando se começa a trabalhar com um solo novo é recomendável que sejam testadas essas condições, realizando experimentos de diluição de "pool” em vários intervalos de tempo. A diminuição das taxas de mineralização bruta no tempo significa que está

aconteendo a remineralização, já que está ingressando no pool ${ }^{15} \mathrm{~N}$-amônio, sendo aconselhável trabalhar somente no período que as TMB sejam constantes.

Segundo Barraclough (1995), para solos temperados a $15^{\circ} \mathrm{C}$ ou mais, sete dias seria um intervalo máximo razoável e, para solos tropicais, com temperaturas até $23^{\circ} \mathrm{C}, 3$ a 5 dias seriam adequados.

\subsection{Técnica da diluição do isótopo de ${ }^{15} \mathrm{~N}$}

Esta técnica tem sido usada para quantificar as taxas de transformações brutas de $\mathrm{N}$ em solos sob diferentes condições ambientais e de manejo, ajudando na elucidação 
de algumas etapas do ciclo do nitrogênio que permanecem como "caixas pretas". $\mathrm{Na}$ seqüência, serão mencionadas algumas das aplicações mais relevantes da técnica.

Para conhecer o aporte de resíduos de plantas no processo de mineralização do nitrogênio Hood \& Wood (1996) estudaram a mineralização bruta desde folhas e raízes de Alnus glutinosa, encontrando que $\mathrm{N}$ de raízes representaram menos que $3 \%$ da mineralização total. Watkins \& Barraclough (1996) trabalharam com resíduos de trigo e colza e acharam que $24 \%$ do $\mathrm{N}$ da colza foi mineralizado em 12 dias, entanto que só 12 $\%$ do trigo foi mineralizado nesse período.

Pilbeam \& Warren (1995) utilizaram a técnica da diluição do ${ }^{15} \mathrm{~N}$ para compreender por que a cultura de milho crescendo em solos tropicais com baixos teores de $\mathrm{N}$ da região de Kenya não respondia à fertilização com $\mathrm{N}$. Eles comprovaram que existe para estes solos uma relação muito estreita entre a mineralização bruta e o conteúdo de umidade do solo, e correspondência entre a distribuição anual das chuvas e o crescimento das culturas.

Barraclough (1997) estudou a mineralização de aminoácidos (leucina e glicina). Há poucos anos, considerava-se que a única via possível para a liberação de $\mathrm{N}$ durante a decomposição de substratos complexos, dava-se pelo ataque de enzimas exocelulares com produção de amônio e que os microrganismos só podiam absorver dessa fração mineral. Por outra parte, existia a possibilidade que essas enzimas exocelulares degradassem o substrato complexo até aminoácidos simples e que os microrganismos absorvessem dessas moléculas, ocorrendo a deaminação no interior da célula, com liberação do excesso de amônio. Esse trabalho confirmou que efetivamente os microrganismos podem utilizar alternativamente amônio ou aminoácidos, o que não estava estabelecido até então e em que circunstâncias se utilizavam uma ou outra via, se elas coexistem e de que depende a ocorrência de cada uma.

No trabalho de Landi, et al., (1999), foi utilizado um inibidor da glutaminosintetase para bloquear a imobilização do $\mathrm{N}$ e determinar as taxas brutas de mineralização a partir das taxas líquidas, mas o inibidor não foi completamente efetivo, sendo mineralizado e os microrganismos do solo passaram a imobilizar $\mathrm{NO}_{3}^{-}$. O'Dowd 
et al. (1999) avaliaram a mineralização de solos com D e L-leucina, demonstrando que o solo teria o dobro de microrganismos que assimilam L que D-leucina. Estes últimos seriam mais lentos para reagir e explicariam o período lag que ocorre no crescimento ou na resposta fisiológica, quando se agrega um resíduo.

Stark \& Hart (1997) estudaram a nitrificação bruta em ecossistemas não perturbados de coníferas. Nesses sistemas, a nitrificação não é considerada um processo importante do ciclo do $\mathrm{N}$, devido a que $\mathrm{NO}_{3}^{-}$não se acumula e as determinações das taxas de nitrificação líquida apresentaram valores muito baixos. Eles comprovaram que a nitrificação é um processo ativo, mais que o consumo de nitrato pelos microrganismos é também muito ativo, pelo que o nitrato não se acumula nestes sistemas, sendo o seu tempo de residência muito curto.

São poucos os trabalhos voltados a analisar o efeito do manejo do solo sob as taxas de mineralização bruta. Gava (2003) estudou as taxas de mineralização e consumo de amônio em campo numa cultura de milho sob plantio convencional (PC) e semeadura direta (SD). Não foi encontrado efeito significativo do manejo nas variáveis estudadas: Possivelmente o período de implantação da SD tenha sido demasiado curto para manifestar-se o efeito do novo manejo. Também, a grande variabilidade entre as repetições pode ter ocultado possíveis diferenças. Nos dois anos estudados é destacável uma queda nos processos brutos ao final do ciclo do milho, em resposta às baixas temperaturas e umidade do solo. As taxas de consumo de amônio foram sempre maiores que as de mineralização, provavelmente um pequeno estímulo dos processos que consomem $\mathrm{NH}_{4}{ }^{+}$quando se injetou a solução de ${ }^{15} \mathrm{~N}$-amônio, e também devido ao ambiente de alta demanda de $\mathrm{N}$ nesse agroecossistema.

Poucos trabalhos têm sido publicados, relacionando as taxas de mineralização bruta com as diferentes frações da matéria orgânica. Monaghan \& Barraclough (1995), utilizando a técnica de marcação cruzada ou espelho, analisaram a contribuição da matéria macrorgânica do solo nas taxas de mineralização bruta e foi informado que ela contribui com média de $12 \%$ ou 4,5\% na mineralização total, dependendo do tipo de solo que a originou. Esta matéria macrorgânica pode atuar como fonte ou como dreno do 
nitrogênio mineralizado do resto do solo, principalmente nas primeiras etapas desde a incorporação.

Puri \& Ashman (1998) quantificaram o $\mathrm{N}$ da biomassa microbiana (NBM) e as taxas de mineralização bruta (TMB) em um solo de bosque em campo e não encontraram correlação entre elas. A TMB apresentou valores variáveis através do ano, enquanto a biomassa microbiana (BM) não teve mudanças. Tentaram medir o aporte da $\mathrm{BM}$ à mineralização ( $\alpha=$ proporção do $\mathrm{N}$ mineralizado proveniente da $\mathrm{BM}$ ), mais falharam em marcar uniformemente a biomassa microbiana.

No trabalho publicado por Compton \& Boone (2002), foram quantificadas as taxas de mineralização e nitrificação bruta em amostras de solo de bosque com diferentes historias de manejo prévio (pastagem, agricultura ou bosque). Depois da extração do $\mathrm{N}$ mineral para calcular TMB e a taxa de nitrificação (TNB), o solo foi fracionado densimétricamente em fração leve e pesada. A fração leve continha maior quantidade de $\mathrm{N}$ que a fração pesada, atuando a primeira como um dreno do $\mathrm{N}$ agregado. Infelizmente, não foram analisadas as relações entre as TMB e C, N o tamanho (massa) das frações separadas.

Cookson \& Murphy (2004) analisaram as TMB e TNB em solos com ou sem a fração lábil dissolvida da matéria orgânica (MOD). A eliminação da MOD por lavagem produz uma diminuição das TMB, TNB, do $\mathrm{N}$ potencialmente mineralizável e do $\mathrm{N}$ da biomassa microbiana, enquanto que a respiração não foi afetada, o que significa que a remoção da MOD não afetou o ciclo microbiano do C. Embora MOD trata-se de uma pequena fração da MO do solo, ela apresenta importante contribuição no fornecimento de $\mathrm{N}$ nos solos agrícolas.

Certamente é preciso continuar trabalhando em pesquisas que busquem a compreensão das relações entre o manejo das lavouras em sistemas agrícolas e os processos brutos do ciclo do nitrogênio. Também é importante estudar os sítios ou frações de onde provem a matéria orgânica que se mineraliza e tem influência no crescimento das culturas, não só do ponto de vista produtivo, como também da sustentabilidade dos sistemas. 


\subsection{Manejo do solo}

Entre as alternativas de manejo para diminuir a degradação do solo pode-se destacar a semeadura direta (SD), considerada como lavoura conservacionista, que vem se desenvolvendo nas últimas décadas, sistema este que não se faz o revolvimento do solo como na agricultura convencional por meio de aração e gradação, e mantém os resíduos de culturas recobrindo pelo menos 30\% da superfície do solo. Este sistema de manejo do solo foi motivo de interesse nos últimos anos, dado que elimina a lavra do solo, protegendo-o dos riscos da alteração de suas propriedades em manejos agrícolas muito agressivos, como ocorre em manejos agrícolas convencionais (Echeverría et al., 1994). Nos cultivos sob SD, todas as operações se realizam mantendo em superfície os resíduos de colheita do cultivo antecessor. Por conseguinte, aumenta-se a infiltração e reduzem-se as perdas de água por evaporação, protegendo-se o solo contra a erosão. Como conseqüência da ausência de revolvimento e do recobrimento da superfície do solo com resíduos culturais, as relações solo-planta-ambiente na SD são diferentes das que se geram sob lavouras convencionais (LC), motivo pelo qual surge a necessidade de ajustar o manejo das culturas (Allmaras et al., 1985).

A cobertura de resíduos produz mudanças no sistema solo, que afetarão o funcionamento do mesmo. Nas condições da região sudeste de Buenos Aires é de particular importância o efeito da cobertura de resíduos na temperatura do solo a qual é relevante na germinação, já que condiciona sua duração e uniformidade. Em solos sob $\mathrm{SD}$, determinaram-se menores flutuações de temperatura nas camadas superficiais (Cox et al., 1990; Domínguez et al., 2001), devido a que recebe menor incidência de energia solar e ao menor fluxo de calor em profundidade. Numerosos autores reportaram diferenças significativas de temperatura entre solos sob SD e LC. O maior conteúdo de água sob $\mathrm{SD}$, faz que se mantenham níveis de temperatura média e máxima mais baixos

e com menor amplitude térmica que com LC (Cox et al., 1990). Sob SD, a posição da cobertura de resíduos e a menor temperatura na superfície do solo, somadas ao maior conteúdo de umidade no perfil, originam um ambiente, onde os habituais processos 
biológicos do solo e a disponibilidade de N para os cultivos são afetados (Rice et al., 1986). Os solos sob SD apresentam geralmente menores níveis de $\mathrm{N}$ inorgânico do que aqueles que foram lavrados (Falotico et al., 1999). Isto é habitualmente atribuído a uma redução na mineralização e a aumentos nas perdas por desnitrificação, lixiviação do nitrato em profundidade e volatilização de amônia de fertilizantes e/ou por imobilização microbiana (Studdert \& Echeverría, 2000).

Em geral, a desnitrificação sob SD é maior devido a que se produz um aumento da síntese e na atividade enzimática desnitrificadora pelo maior conteúdo de água e a reduzida areação do solo (Rice y Smith, 1984). Esta condição particular do solo leva ao aumento da população de microrganismos desnitrificadores (Doran, 1980) e aumento na quantidade de micrositios anaeróbicos (Picone et al., 1997). Para solos de Balcarce, localizado a sudeste de Buenos Aires, Picone et al., (1997) encontraram que a taxa de desnitrificação média sob SD foi maior que sob LC. Os altos conteúdos de umidade e a disponibilidade de nitratos devido à fertilização nitrogenada e/ou mineralização poderiam incrementar as perdas de $\mathrm{N}$ por desnitrificação em solos sob SD, especialmente no início do desenvolvimento da cultura de trigo, quando a demanda por água e o consumo de nitratos por parte da planta são menores.

A redução na mineralização sob $\mathrm{SD}$ é habitualmente medida como mineralização líquida, ou seja, o resultado líquido dos processos de mineralização e imobilização bruta. As modificações que acontecem no solo como conseqüência da utilização da semeadura direta, produto do acúmulo de resíduos orgânicos na superfície, afetarão o processo de mineralização bruta e produzirão diferentes disponibilidades de $\mathrm{N}$ para as culturas.

\subsection{Fracionamentos da matéria orgânica do solo}

A matéria orgânica do solo (MOS) tem sido considerada, desde o início dos estudos sistemáticos do solo, um componente de fundamental importância para o 
desenvolvimento da agricultura. A MOS é chave nos processos de formação do solo: meteorização, formação do perfil, formação da estrutura, assim como também no desenvolvimento da fertilidade do solo, já que através da mineralização da MOS os nutrientes são disponibilizados às plantas. Nas últimas décadas, o papel da matéria orgânica do solo vem sendo enfatizando, também, como fonte de $\mathrm{CO}_{2}$ quando ela é oxidada ao converter florestas e pastagens naturais em áreas cultivadas e como seqüestradoras das crescentes quantidades de $\mathrm{CO}_{2}$ geradas pelas atividades humanas (Balesdent et al., 2000).

A matéria orgânica do solo consiste de uma mistura altamente heterogênea de resíduos vegetais e animais em distintos graus de decomposição, de substâncias sintetizadas química e biologicamente a partir dos seus corpos em decomposição, e materiais húmicos altamente resistentes (Jenkinson, 1988). A biomassa microbiana, responsável pela decomposição da $\mathrm{MO}$ é também uma mistura de microrganismos que são afetados pelas condições ambientais, principalmente temperatura e umidade do solo, assim como pelo $\mathrm{pH}$ e nível de energia.

A enorme complexidade da matéria orgânica e a sua importância na fertilidade do solo têm-se manifestado numa enorme quantidade de estudos objetivados em conhecer a natureza da $\mathrm{MO}$ e as relações dela com os processos produtivos em sistemas agrícolas. Devido a MOS ser uma mistura, desde há muito tempo vem-se fazendo tentativas de fracioná-la para poder explicar o seu comportamento. Os primeiros intentos de fracionamento datam de 1786, quando Achard tratou uma turfa com uma solução de alcalina, a que após acidificação, permitiu a obtenção dum precipitado amorfo e de cor escura. Deu-se início a partir de então a era dos fracionamentos químicos da MOS e os que predominaram na pesquisa durante muitos anos. Atualmente é aceito que as substancias húmicas dividem-se em três grupos, classificados em função a sua solubilidade em soluções ácidas e básicas: huminas, ácidos húmicos e ácidos fúlvicos. É importante saber que estas frações, ainda tendo nomes que indicam uma singularidade, não estão constituídas por simples compostos puros. Cada fração é uma mistura de substancias orgânicas com um amplo intervalo de pesos moleculares e cargas negativas, 
e ainda não é possível isolar simples compostos puros e identificar as suas estruturas (Haynes e Swift, 1990).

A informação que pode ser obtida quando se fraciona a MOS em ácidos fúlvicos, húmicos e huminas têm pouco poder explicativo em relação à compreensão do papel da MO nas propriedades e o funcionamento dos solos. Ainda conhecendo as quantidades de ácidos fúlvicos, húmicos e huminas e as suas características, não se têm informação sobre os teores de MO total do solo, nem sobre a função dessas MO na estabilidade dos agregados, nem sobre a disponibilidade de nitrogênio, carbono e fósforo para as plantas, etc. Os fatos de os ácidos fúlvicos, húmicos e huminas serem substancias orgânicas heterogêneas, mas que ainda não é possível identificar estruturas químicas diferenciais, já que elas são misturas e que as suas propriedades químicas e físicoquímicas podem variar com a sua origem e com os ambientes nos quais se originaram, impede que os fracionamentos químicos tenham condições para explicar o funcionamento e a dinâmica da MOS.

Existem duas causas pelas quais os fracionamentos químicos têm pouca significância em estudos agronômicos: a) tanto os ácidos húmicos quanto os fúlvicos tem taxas de "turnover" muito baixas (Anderson e Paul, 1984) e por isso, não estão envolvidos em processos em curto prazo que determinam a produtividade de uma cultura (dias ou meses) e, b) ainda não se conhece a importância dessas frações nos grandes processos do solo, tais como a agregação e a mineralização da MOS (Feller e Beare, 1997). Existe a possibilidade de as extrações ácidas e alcalinas usadas para separar ácidos húmicos e fúlvicos sejam muito desnaturantes, resultando em extrações de compostos similares a partir de "pools" muito diferentes da MOS.

Como resultado do baixo poder explicativo dos fracionamentos químicos da MOS, nas últimas duas décadas foi desenvolvido uma importante quantidade de pesquisa na área de caracterização da $\mathrm{MO}$ em solos agrícolas, envolvendo técnicas de fracionamento físico.

As associações da $\mathrm{MO}$ com os constituintes minerais do solo, principalmente argilas minerais, têm sido historicamente reconhecidas como muito importantes, já que 
elas regulam a mineralização e armazenagem de MO (Greenland, 1965a, 1965b). É reconhecida a relação entre dinâmica de MO com a textura e a estrutura do solo, fato pelo qual conseguir uma quantificação da MO ligada às frações granulométricas, permitiria melhorar o poder explicativo dos fracionamentos.

\subsubsection{Fracionamentos físicos}

Os fracionamentos físicos da matéria orgânica baseiam-se na função dos minerais do solo na estabilização e "turnover" da MO do solo (Christensen, 1992). Existem dois grupos principais de métodos para fracionamentos físicos da MO: (a) métodos densimétricos e (b) métodos gravimétricos.

Os métodos densimétricos assumem que a $\mathrm{MO}$ do solo pode ser dividida em duas frações que diferem em estrutura e funcionamento: a chamada "fração leve" (MO livre ou não complexada) que é considerada ser constituída por restos vegetais e animais em decomposição, mas ainda reconhecíveis, com relação $\mathrm{C}: \mathrm{N}$ relativamente alta, de rápido "turnover" e uma densidade específica consideravelmente menor que os minerais do solo. A "fração pesada" inclui MO que forma complexos com minerais, MO está formada, também, por produtos de decomposição, somente que mais processados (húmus verdadeiro), com uma relação $\mathrm{C}: \mathrm{N}$ estreita, taxa reduzida de "turnover" e densidade específica mais alta devido à sua intima associação com os minerais do solo (Monnier et al., 1962). Geralmente, estas frações são separadas adicionando o solo em líquidos com densidades específicas entre 1,6 e 2,2 $\mathrm{g} \mathrm{cm}^{-3}$, mas também tem sido usadas tamisagens e flotação em água para separá-las.

Em alguns trabalhos (Meijboom et al., 1995, Barrios et al., 1996) foram separadas 3 frações: Leve $\left(\delta=1,8-2 \mathrm{~g} \mathrm{~cm}^{-3}\right.$, matéria macro-orgânica pouco decomposta de origem vegetal e animal), Média $\left(\delta=2-2,4 \mathrm{~g} \mathrm{~cm}^{-3}\right.$, verdadeiros complexos organo minerais) e pesada ( $\delta>2,4 \mathrm{~g} \mathrm{~cm}^{-3}$, grãos minerais cobertos de $\left.\mathrm{MO}\right)$. Estas separações foram ampliadas para um grupo de densidade maior, ainda que a interpretação dos 
resultados obtidos seja menos claro que quando se aplica o conceito original de duas frações.

Certamente, a matéria orgânica é um continuum em propriedades e composição e antes de fazer um fracionamento, deveriam se conceituar teoricamente as frações que se pretende separar, em função do objetivo do experimento, para poder escolher a metodologia mais adequada.

Os métodos granulométricos baseiam-se no conceito que as frações de MOS associadas com partículas de diferente tamanho possuem diferentes funções no "turnover" da MOS.

Este enfoque permite a separação de três grandes tipos de frações orgânicas ou organo - minerais:

a) MO particulada de dimensões de areia $(>50 \mu \mathrm{m})$. As relações $\mathrm{C}: \mathrm{N}$ podem variar de 25 (partículas de 200-2000 $\mu \mathrm{m}$ ) até 15 (nas partículas de 200-50 $\mu \mathrm{m}$ ). Estas frações podem representar de $20-40 \%$ da MO total.

b) Fração complexo MO-silte, de tamanho entre 2 e $50 \mu \mathrm{m}$, constituídos por uma mistura de restos vegetais e fúngicos muito decompostos, associados com microagregados do tipo MO-silte-argila, muito estáveis e que resistiriam à dispersão, com relações C:N médias, de aproximadamente 15 . Representam entre 20 a $30 \%$ da MO total.

c) Frações organo - argilosas $<2 \mu \mathrm{m}$, constituídas por MO amorfa, também podem encontrar-se células bacterianas ou mesmo colônias em diferentes estágios de decomposição. A relação C:N geralmente é menor que 10.

O fracionamento granulométrico pode ser feito em amostras de solo completas ou em frações separadas previamente por densimetria.

O maior objetivo metodológico neste tipo de fracionamento é atingir a máxima dispersão do solo (separação de areia, silte e argilas) com mínima alteração da matéria orgânica associada. Entre as ferramentas que habitualmente são usadas para a dispersão, encontram-se o ultra-som e as agitações em água ou eventualmente dispersantes 
químicos como o hexametafosfato de sódio (HMP) ou a resina sódica. Estes procedimentos solubilizam menos que $5 \%$ do C orgânico do solo.

No caso da dispersão com ultra-som, não é recomendável aplicar o tratamento na amostra completa do solo, existindo resultados de trabalhos em que houve liberação dos componentes microbiais da $\mathrm{MO}$, que foram redistribuídos para tamanhos menores e para a fração solúvel (Christensen, 1992). Também foi demonstrado que podem acontecer quebras de restos vegetais e transferências, desde frações de maior tamanho para as frações finas (Balesdent et al., 1991).

Atingida a dispersão, realiza-se o fracionamento com o auxílio de peneiras de diferente tamanho: 200, 50, e $20 \mu \mathrm{m}$, e por centrifugação ou sedimentação são separadas as frações $20-2 \mu \mathrm{m}$ e menor de $2 \mu \mathrm{m}$.

O esquema de fracionamento organo-mineral de solos segundo Moraes Sá (2001), é apresentado na Figura 3.
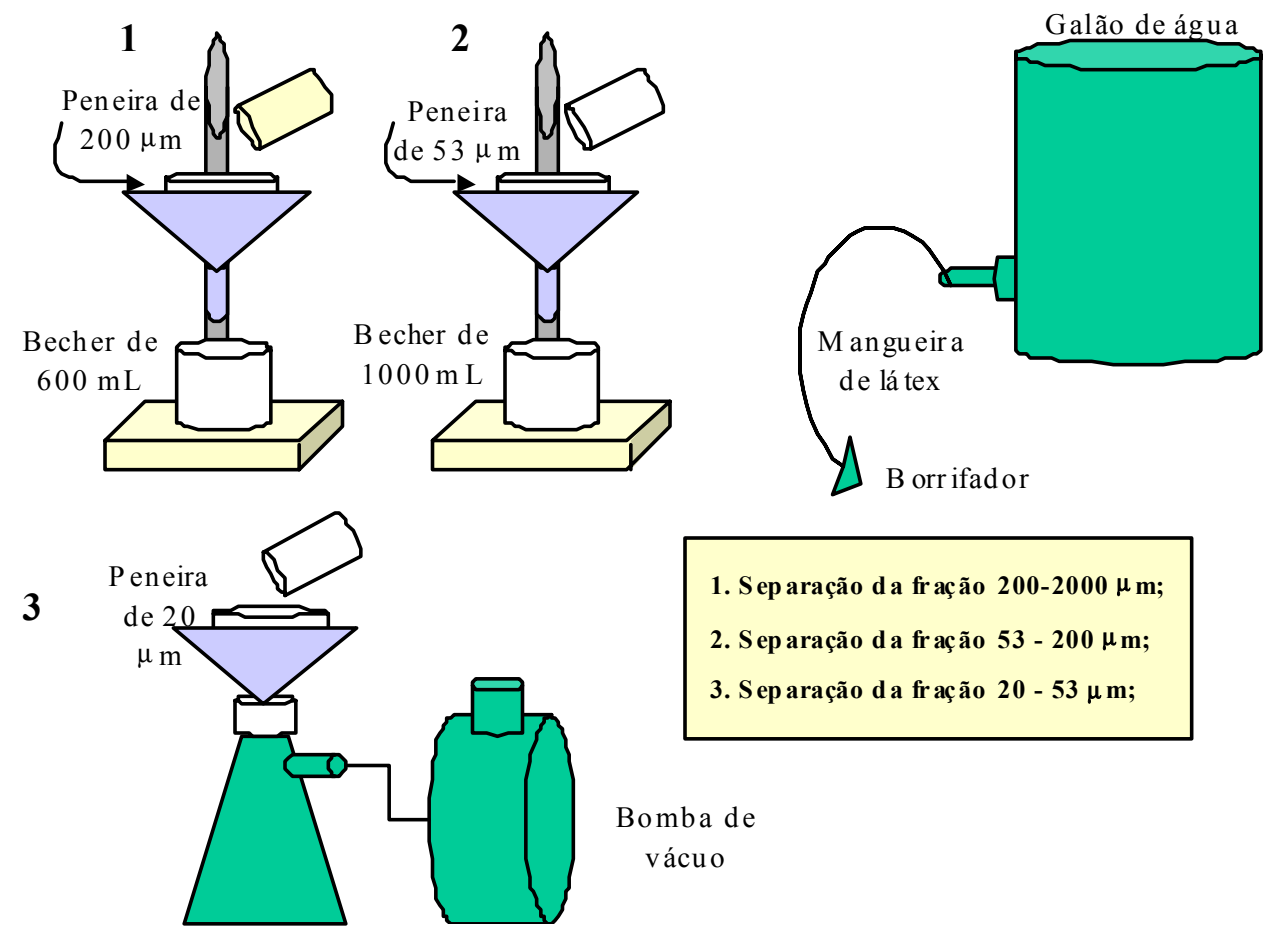

$$
\begin{aligned}
& \text { 1. S ep aração d a fr ação } 200-2000 \mu \mathrm{m} \text {; } \\
& \text { 2. S ep aração d a fr ação } 53-200 \mu \mathrm{m} \text {; }
\end{aligned}
$$

3. S ep aração d a fração $20-53 \mu \mathrm{m}$;

Bomba de vácuo

Figura 3. Fracionamento granulométrico (organo-mineral) proposto por Sá (2001). 
Após o fracionamento, normalmente realiza-se uma caracterização física e bioquímica das frações granulométricas, quantificando-se o conteúdo de $\mathrm{C}$ orgânico total, nitrogênio total, carboidratos hidrolisáveis, relação galactose + manose a arabinose+xilose $(\mathrm{GM} / \mathrm{AX})$, com o objetivo de conhecer as propriedades e a origem da MO nas diferentes frações.

\subsubsection{Dinâmica da matéria orgânica do solo associada às frações} granulométricas

A dinâmica da matéria orgânica do solo tem sido estudada com diversos enfoques, destacando-se pela sua aplicabilidade os seguintes:

a) Experimentos de incubações em laboratório ou campo avaliando o $\mathrm{C}$ e o $\mathrm{N}$ potencialmente mineralizável, onde se observa que geralmente o nitrogênio potencialmente mineralizável (NPM) aumenta da fração de tamanho areia para a de argila, existindo uma relação inversa entre tamanho de partículas e mineralização do $\mathrm{N}$ (Sollins et al., 1984).

A contribuição relativa de cada fração na quantidade total de $\mathrm{C}$ ou $\mathrm{N}$ mineralizado é dependente da textura do solo, em solos arenosos, a fração de MO de tamanho areia é a principal fonte de $\mathrm{C}$ e $\mathrm{N}$ mineralizável. Em solos argilosos, a maioria do $\mathrm{N}$ mineralizado provém da fração de tamanho argila.

b) Experimentos que avaliam a abundância natural de ${ }^{13} \mathrm{C}$ no tempo. Podem-se aplicar quando se conhece a história da vegetação (tipo de plantas, segundo seu metabolismo, C3 ou C4) podendo-se identificar mudanças no $\delta^{13} \mathrm{C}$ em resposta à acumulação de $\mathrm{C}$ em diferentes frações derivadas de vegetação "nova" (introduzida pelas culturas) ou velha (vegetação original). Em vários estudos que empregaram este enfoque em solos temperados e tropicais, encontrou-se uma tendência que o tempo de residência médio é maior nas frações de menor tamanho (Balesdent, 1991, Cerri, et al., 1985). 
c) Experimentos que descrevem os efeitos das praticas de manejo na variação da matéria orgânica associada às frações granulométricas no tempo. Estes estudos têm analisado o efeito da mudança no uso da terra, por exemplo, implantação de pastagens ou cultivos agrícolas depois do desmatamento de florestas naturais. Em geral, é sugerido que em uma escala de médio a longo prazo (mais de cinco anos), os efeitos do manejo do solo na acumulação de MO é diferente em função da textura do solo. Em solos de textura arenosa, uma proporção elevada da dinâmica da MO se deve às mudanças associadas com a fração areia, mas em solos de textura fina, a maior parte da variação está associada com a fração argila.

Um quarto enfoque que ajudaria a melhorar a compreensão dos mecanismos de acumulação e dinâmica da matéria orgânica do solo é analisar as relações entre as frações granulométricas da MO e os fluxos brutos de nitrogênio no solo, estudados com o emprego da técnica de diluição do isótopo ${ }^{15} \mathrm{~N}$ (Barraclough, 1995). 


\section{MINERALIZAÇÃO BRUTA DE NITROGÊNIO NO SUDESTE DE BUENOS AIRES (ARGENTINA): EFEITO DO MANEJO E DA PROFUNDIDADE DE AMOSTRAGEM}

\section{Resumo}

Existe grande interesse no entendimento da dinâmica do nitrogênio $(\mathrm{N})$ em solos com transformação de manejo convencional para semeadura direta (SD) ou pastagem, uma vez que cerca de 50\% da superfície agrícola da Argentina já adota a SD. Realizou-se um experimento de laboratório para determinar o efeito do manejo e da profundidade de amostragem nas taxas de mineralização (TMB) e de consumo bruto de N. O solo utilizado (complexo Argiudol tipico - Paleudol petrocalcico) foi manejado durante 17 anos com lavoura convencional e em 1994 foi convertido a três manejos diferentes: semeadura direta $(\mathrm{PD})$, pastagem $(\mathrm{P})$, ou continuou sob lavoura convencional (LC). Consideraram-se duas profundidades de solo: 0-10 cm e 10-20 cm. A TMB foi estimada com a técnica de diluição do isotópo ${ }^{15} \mathrm{~N}$ em quatro oportunidades durante um período de incubação de 35 dias, adiçionando $10 \mu \mathrm{g} \mathrm{g}^{-1}$ de ${ }^{15} \mathrm{~N}-\left(\mathrm{NH}_{4}\right)_{2} \mathrm{SO}_{4}$ (abundância de $10 \%$ de átomos de ${ }^{15} \mathrm{~N}$ em excesso). A TMB apresentou valores entre 0,62 e 4,77 mg $\mathrm{kg}^{-1} \mathrm{dia}^{-1}$. Em geral, a pastagem apresentou maiores TMB nos $10 \mathrm{~cm}$ superficiais e nos primeiros dias de medição, enquanto que a LC apresentou as maiores TMB a 21dias de iniciada a incubação de $10-20 \mathrm{~cm}$ de profundidade. A SD teve comportamentos semelhantes à pastagem, mas com taxas menores. $\mathrm{O}$ consumo de amônio foi um 
processo importante nos três manejos e profundidades, sendo maiores as quantidades totais consumidas às mineralizadas nos três manejos. A diferença entre $\mathrm{N}$ mineralizado $\mathrm{e}$ $\mathrm{N}$ consumido foi menor para $\mathrm{P}$, sugerindo maior disponibilidade de $\mathrm{N}$ para as plantas.

\section{Summary}

There is a considerable interest in the understanding of nitrogen dynamics on soils converted from conventional to no tillage or pastures, since $50 \%$ of the agricultural soils in Argentina is under no tillage practices. A laboratory experiment was carried out with the aim of determining the effect of different soil management systems and soil depths on gross nitrogen mineralization (TMB) and consumption rates. The studied soil was a Typic Argiudoll - Petrocalcic Paleudoll complex which had been under conventional tillage for $17 \mathrm{yr}$ until 1994 when it was converted to three different soil management systems: no tillage (SD treatment), pasture ( $\mathrm{P}$ treatment) or continued under conventional tillage (LC treatment). Two sampling depths $0-10$ and 10-20 cm were analyzed. TMB was estimated through ${ }^{15} \mathrm{~N}$ dilution technique, adding ${ }^{15} \mathrm{~N}$ labeled $\left(\mathrm{NH}_{4}\right)_{2} \mathrm{SO}_{4}\left(10 \%{ }^{15} \mathrm{~N}\right.$ at. exc.) four times during an incubation period of 35 days. TMB values ranged between 0.62 and $4.77 \mathrm{mg} \mathrm{N} \mathrm{kg}^{-1} \mathrm{day}^{-1}$. $\mathrm{P}$ treatment presented higher TMB in the $10 \mathrm{~cm}$ superficial and during the first days of measurements, whereas LC mineralized at higher rates 21 days from incubation start at $10-20 \mathrm{~cm}$ soil depth. SD treatment had a similar behavior to $\mathrm{P}$ treatment, but at lower rates. The ammonium consumption was an important process in the three management systems and analyzed depths, being the total consumed amounts, higher than the mineralized ones in the three management systems. The difference between total mineralized and consumed nitrogen was lower to P treatment than SD and LC treatments was, suggesting higher plants $\mathrm{N}$ availability. 


\subsection{Introdução}

A decomposição da matéria orgânica do solo e as correspondentes mineralização e imobilização são processos chaves na ciclagem do nitrogênio $(\mathrm{N})$ no sistema solo-planta. Estes processos são altamente complexos, pois a matéria orgânica a ser decomposta é uma mistura muito heterogênea, constituída por restos vegetais e animais recentemente incorporados e, também, por materiais húmicos muito resistentes (Jenkinson, 1988). A biomassa microbiana, responsável pela decomposição da matéria orgânica no solo (Sparling \& Ross, 1993), é composta por uma mistura de microrganismos e sofre mudanças em resposta às variações na temperatura e umidade do solo, mas também no pH e no estado de energia do solo.

Os solos agrícolas do sudeste (SE) da província de Buenos Aires contêm elevados níveis de Carbono orgânico (C), entre 25 e $45 \mathrm{~g} \mathrm{~kg}^{-1}$ de $\mathrm{C}$ orgânico. Nas últimas duas décadas o manejo habitual destes solos foi o plantio convencional e não se incluíram pastagens nas rotações agrícolas, o que resultou em degradação nas suas propriedades físicas, químicas e bioquímicas (Darwich, 1991), principalmente evidenciada por deficiências de nutrientes, em particular de nitrogênio, nas culturas de trigo (Berardo, 1994; Echeverría \& Videla, 1998) e milho (Andrade et al., 2002). A redução do conteúdo de matéria orgânica no SE de Buenos Aires foi de $4,4 \mathrm{~g} \mathrm{~kg}^{-1} \mathrm{em} 6$ a 7 anos de plantio convencional, alcançando níveis de equilíbrio entre 26 e $29 \mathrm{~g} \mathrm{~kg}^{-1}$ (Studdert et al., 1997).

A semeadura direta, por reduzir os distúrbios produzidos no solo, está sendo amplamente adotada na Argentina, sendo de 12 milhões de hectares a superfície cultivada com este sistema em 2002 (Peiretti, 2002), pelo qual é de grande interesse o conhecimento da dinâmica dos processos envolvidos na conservação da matéria orgânica. Geralmente, a semeadura direta incrementa a quantidade de $\mathrm{N}$ no solo, e também o $\mathrm{C}$ e $\mathrm{N}$ da biomassa microbiana, produzindo uma estratificação dessas frações no solo (Doran, 1987; Gupta et al., 1994; Alvarez et al., 1995). A alternativa tradicional para melhorar esses solos tem sido a inclusão de 3 a 4 anos de pastagens após um ciclo 
agrícola de 6 a 7 anos, conduzindo a incrementos nos níveis de $\mathrm{C}$ orgânico para valores perto dos originais (Studdert et al., 1997). A adoção desse manejo possibilita já nos primeiros ciclos incremento no $\mathrm{N}$ disponível, como resposta na contribuição de frações lábeis dos resíduos vegetais.

A mineralização líquida tem sido usada como indicador da disponibilidade de $\mathrm{N}$ in situ (Hatch et al., 1990; Stenger et al., 1995), mas na realidade, a mineralização líquida é o resultado de combinações de taxas brutas dos processos que integram o ciclo do N, particularmente, amonificação, imobilização e nitrificação. O modelo de mineralização líquida proposto por Echeverría et al. (1994), estima a produção de N num período de tempo a partir de $\mathrm{N}_{0}$ (potencial de mineralização) e a constante de mineralização $\mathrm{k}$, integrando os efeitos da temperatura e a umidade do solo. Por meio desse modelo é possível avaliar a capacidade relativa do solo para prover nutrientes às plantas, mas ele não tem boa capacidade para prever a mineralização quando ao solo é adicionado material vegetal de diferentes qualidades ou formas físicas, adição essa que depende do tipo de manejo do solo (Studdert \& Echeverría, 2000). Nos últimos anos, foram desenvolvidos trabalhos utilizando ${ }^{15} \mathrm{~N}$ que demonstraram que os processos de mineralização e imobilização bruta, os que determinam a disponibilidade de N, são parcialmente independentes entre si. (Davidson, 1991). A estimativa dos fluxos brutos de $\mathrm{N}$ no solo permite uma melhor compreensão dos processos que governam o ciclo de $\mathrm{N}$ e, também, a disponibilidade de nutriente para as plantas. A técnica de diluição do isótopo ${ }^{15} \mathrm{~N}$ para quantificar a mineralização bruta (Kirkham \& Bartholomew, 1954), tem como base a diluição da abundância de ${ }^{15} \mathrm{~N}$ na fração de $\mathrm{NH}^{+}$, inicialmente marcada com ${ }^{15} \mathrm{NH}^{+}$, pelo amônio com abundância natural que provém da mineralização da matéria orgânica. Essa técnica é a única ferramenta disponível para estimar a taxa de mineralização bruta, independente dos processos que consomem $\mathrm{NH}_{4}^{+}$, e vem sendo muito usada nos últimos anos (Barraclough \& Puri, 1995; Recous et al., 1999; Fabrizzi et al., 2003).

O objetivo deste experimento, desenvolvido em laboratório, foi determinar a influência dos sistemas de manejo: pastagem, plantio convencional e semeadura direta, e 
de duas profundidades de amostragens do solo, nas taxas de mineralização bruta de nitrogênio.

\subsection{Material e Métodos}

As amostras de solo para realizar este experimento foram colhidas no campo Experimental do Instituto Nacional de Tecnología Agropecuaria (INTA) Balcarce no experimento cuja descrição consta no Anexo A. Em dezembro de 2000 colheram-se amostras compostas de solo nas parcelas LC, SD e P, nas profundidades de 0-10 e 10-20 $\mathrm{cm}$, que foram secas ao ar, peneiradas (peneiras de $2 \mathrm{~mm}$ de malha) e armazenadas até a realização do experimento em laboratório. Os conteúdos de $\mathrm{C}$ orgânico destas amostras foram de 26,2, 26,8 e 28,2 $\mathrm{g} \mathrm{kg}^{-1}$ de C, respectivamente, para LC, SD e P.

O experimento foi realizado em laboratório, a uma temperatura de $25 \pm 2^{\circ} \mathrm{C}$, com as amostras de solo umedecidas até $60 \%$ de capacidade máxima de retenção de água e pré-incubadas durante 5 semanas. A pré-incubação foi realizada para permitir a recuperação da atividade biológica do solo após o período em que permaneceu seco e armazenado (dezembro de 2000 até abril de 2001), mas também evitando o flush de amônio que acontece após a reativação dos microrganismos. As parcelas experimentais na determinação das taxas de mineralização bruta constaram de $80 \mathrm{~g}$ de solo (base solo seco em estufa a $105^{\circ} \mathrm{C}$ ) acondicionados em copos plásticos e cobertos com lâminas de Parafilm ${ }^{\circledR}$ para evitar a dessecação. Nos tempos de 0, 7,21 e 35 dias, contados a partir do final da etapa de pre-incubação, adicionou-se em parcelas individuais uma alíquota de 3,5 mL de uma solução de sulfato de amônio com um excesso do isótopo ${ }^{15} \mathrm{~N}$ de $10 \%$, a uma dose $10 \mathrm{mg} \mathrm{g}^{-1}$ de $\mathrm{N}$ aplicado ao solo, usando um dispositivo com sete seringas e agulhas hipodérmicas (Figura 4). Em cada manejo, profundidade de solo e tempo de incubação, foram preparadas 6 parcelas onde adicionou-se ${ }^{15} \mathrm{NH}_{4}{ }^{+}$; em três delas a extração do $\mathrm{N}$ mineral foi realizado no tempo de $24 \mathrm{~h}\left(\mathrm{t}_{\mathrm{o}}\right)$ e nas outras três após $72 \mathrm{~h}\left(\mathrm{t}_{\mathrm{f}}\right)$ da adição de ${ }^{15} \mathrm{NH}^{+}$. A seleção deste tempo entre as extrações foi realizada por meio de 
um experimento que consta no Anexo B (Videla et al., 2002). Para a quantificação do N mineral foi separada cerca de $60 \mathrm{~g}$ de solo, após homogeneização do solo em cada parcela. A extração foi realizada com $200 \mathrm{~mL}$ de solução de $\mathrm{KCl} 2 \mathrm{M}$, sob agitação por 1h. A solução contendo as frações minerais de $\mathrm{N}$ foi filtrada antes de seguir para as etapas de determinações. Na massa restante de $20 \mathrm{~g}$ de solo de cada parcela, determinouse o conteúdo de umidade por gravimetria. $\mathrm{O} \mathrm{N}$ mineral (amônio: $\mathrm{N}^{-\mathrm{NH}^{+}}{ }_{4}$ e nítrico: $\mathrm{N}$ -

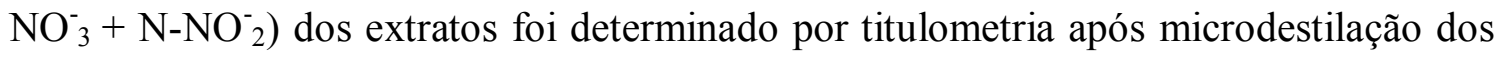
extratos por arraste de vapor na presença de $\mathrm{MgO}$ e liga de Devarda (Bremner, 1965). Cinqüenta $\mathrm{mL}$ de extrato contendo as frações minerais, amônio e nitrato, foram concentrados por microdifussão para a determinação de ${ }^{15} \mathrm{~N}$. A microdifussão foi realizada segundo o método de Brookes et al. (1989), sob agitação durante 3 dias, adicionando-se $\mathrm{MgO}$ ao extrato (microdifussão da fração amônio) e por mais três dias com adição de Liga de Devarda (microdifussão da fração nítrica), em ambiente escuro. $\mathrm{O}$ amônio de cada fração foi retido em pequenos discos de papel de microfibra ("Whatman GF/D") contendo $10 \mathrm{~mL}$ de solução 2,5M $\mathrm{KHSO}_{4}$ e selados em fita de polytetrafluoroetileno (PTFE) (Sorensen \& Jensen, 1991). Depois da microdifussão, removida a fita de PTFE, os filtros foram secos em um dessecador por $24 \mathrm{~h}$ e colocados em cápsulas de estanho para serem levados para a determinação de ${ }^{15} \mathrm{~N}$ em espectrômetro de massas Europa Sc. ANCA-SL.

Foram calculadas as taxas de mineralização bruta (TMB), as de consumo bruto de amônio (TCB) que inclui a assimilação microbiana, volatilização de amônia, a lixiviação, fixação pelas argilas e nitrificação (Hart et al., 1994) e as de nitrificação (TNB).

Os cálculos da taxa de mineralização e de consumo foram realizados usando as equações apresentadas por Hart et al. (1994).

$$
\begin{gathered}
m=\theta\left(\log A^{*}{ }_{0} / A_{*}\right) / \log \left(1+\theta t / A_{0}\right) \\
c=m-\left(A_{t}-A_{0}\right) / t
\end{gathered}
$$


onde: $\mathrm{m}$ - taxa de mineralização; $\mathrm{A}_{\mathrm{t}}{ }$ - abundância de ${ }^{15} \mathrm{~N}$ (\% de átomos em excesso) no tempo t; $\mathrm{A}^{*}{ }_{\mathrm{o}}$ - abundância de ${ }^{15} \mathrm{~N}$ (\% de átomos em excesso) no tempo $0 ; \mathrm{t}$ - tempo; $\mathrm{A}$ tamanho da fração amônio, $\theta=\left(\mathrm{A}_{\mathrm{t}}-\mathrm{A}_{0}\right) / \mathrm{t}$; c - taxa de consumo de amônio.

Para o cálculo da taxa de nitrificação, utilizou-se a expressão proposta por Barraclough (1991) em que se calcula previamente a abundância média de ${ }^{15} \mathrm{~N}$ da fração de amônio e, posteriormente, com o valor de enriquecimento médio obtido é calculada a taxa de nitrificação bruta.

$$
\begin{aligned}
& {\left[A^{*}\right]_{t 1-t 2}=1 / t \cdot A_{0}^{*} \cdot A_{0}(m / \theta)} \\
& N^{*}=\left[A^{*}\right]+\left(N_{0}^{*}-\left[A^{*}\right]\right) /\left(1+\theta t / N_{0}\right)^{n / q}
\end{aligned}
$$

onde: $\mathrm{n}$ - taxa de nitrificação; [A*] a abundância de ${ }^{15} \mathrm{~N}$ ( \% de átomos em excesso) média na fração de amônio; $\mathrm{N}_{0}^{*}$ - abundância de ${ }^{15} \mathrm{~N}$ ( \% de átomos em excesso) média na fração nítrica no tempo $\mathrm{t}=0 ; \mathrm{q}=\left(\mathrm{N}_{\mathrm{t}}-\mathrm{N}_{\mathrm{o}}\right) / \mathrm{t}$, mudança no tamanho da fração de nitrato.

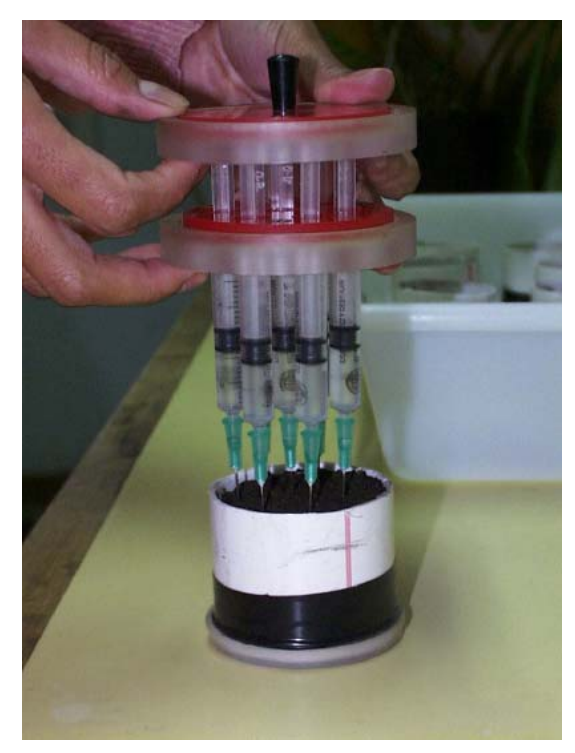

Figura 4. Dispositivo utilizado para a adição de ${ }^{15} \mathrm{NH}^{+}{ }_{4}$ no solo das parcelas experimentais, contendo sete seringas e agulhas hipodérmicas. 
$\mathrm{Na}$ seqüência, os efeitos estudados serão denominados como: manejo P, LC e $\mathrm{SD}$, tempo de adição de ${ }^{15} \mathrm{NH}_{4}{ }^{+}$após $0,7,21$ e 35 dias do início das determinações dos fluxos brutos de $\mathrm{N}$ e profundidade de colheita das amostras de solo de 0-10 e 10-20 cm.

As adições com ${ }^{15} \mathrm{NH}_{4}{ }^{+}$ao solo sendo realizadas em parcelas separadas, caracterizaram a independência entre determinações da primeira e segunda extração, respectivamente, para os tempos $t_{o}$ e $t_{f}$. Esse procedimento permitiu realizar combinações das três parcelas, resultando em nove repetições para cada intervalo de tempo, para os manejos P, SD e LC. As taxas (TMB) calculadas foram submetidas a análise de variância como parcelas divididas, sendo a parcela principal o manejo e a subparcela o tempo da adição, separadamente para cada profundidade, por não ser este fator independente. Quando foram encontrados efeitos significativos do tempo de adição de ${ }^{15} \mathrm{NH}_{4}^{+}$, realizaram-se análises separadas para esse fator e comparações de médias pelo teste de Tukey ao nível de probabilidade de 5\%.

\subsection{Resultados e Discussão}

\section{Nitrogênio mineral e enriquecimento isotópico}

$\mathrm{O}$ conteúdo de $\mathrm{N}$-amônio foi menor que $10 \mathrm{mg} \mathrm{g}^{-1}$ de $\mathrm{N}$, em todos os manejos e profundidades de amostragem (Figuras 5 e 6), diminuindo entre a primeira e a segunda extração que é um indicativo de consumo de amônio. Somente foi verificado mineralização líquida positiva no tempo de adição de 21 dias, na profundidade de 0-10 cm (Figura 5). Estes baixos níveis de amônio estariam indicando que os processos que consomem amônio nesse solo, ocorreram ativamente. Um dos principais processos que consomem amônio é a nitrificação, já que se o amônio fosse imobilizado pela biomassa microbiana, a concentração de $\mathrm{N}$ nítrico na extração com $\mathrm{KCl}$ seria baixa, o que não ocorreu; a volatilização de amônia deve ser praticamente nula pelo $\mathrm{pH}$ levemente ácido e o elevado poder de tamponamento do solo (Videla, 1994) e a fixação nas argilas é um processo desprezível nesses solos. Picone (1978) quantificou uma fixação de 0,01\% do 
$\mathrm{N}-\mathrm{NH}_{4}^{+}$agregado em solos Argiudoles típicos de Balcarce, concluindo que o processo de fixação é de pouca importância tanto do amônio de fertilizações como aquele originado da amonificação da matéria orgânica, fato pelo qual, o amônio estaria quase em sua totalidade disponível para microrganismos e plantas. Como confirmação da hipótese de ativa nitrificação, os conteúdos de nitrato tiveram quantidades iniciais altas (acumuladas durante o período de pré-incubação), mas com uma tendência a aumentar a quantidade líquida de N-nítrico depois da adição de ${ }^{15} \mathrm{~N}$ (Figuras 5 e 6), talvez como um efeito de estimulação pelo substrato.
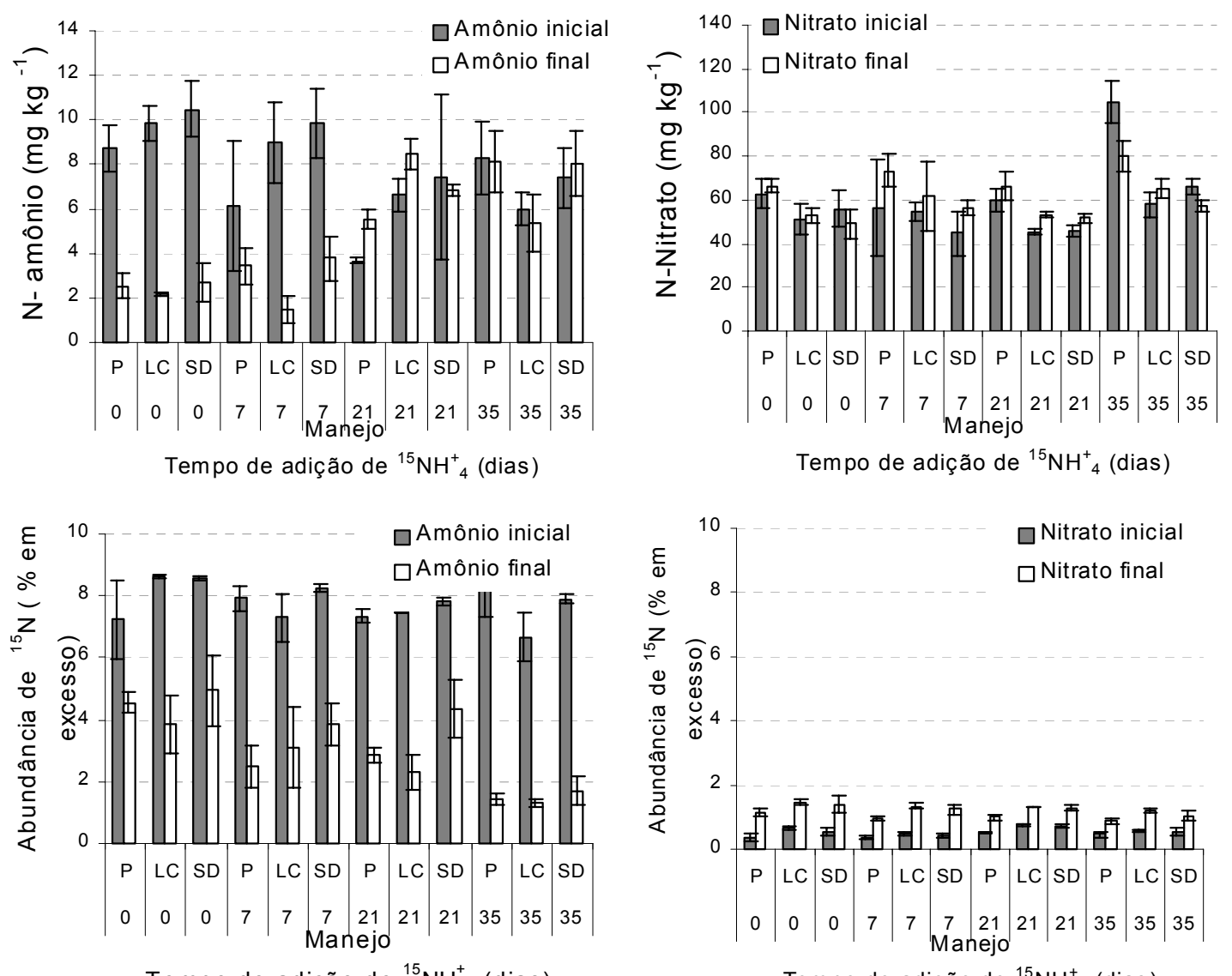

Figura 5. Conteúdo do $\mathrm{N}$ inorgânico (amônio e nítrico) e abundância em excesso de ${ }^{15} \mathrm{~N}$ na profundidade de $0-10 \mathrm{~cm}$ em solos do Sudeste de Buenos Aires sob pastagem (P), lavoura convencional (LC) e semeadura direta (SD). As barras verticais indicam os desvios padrões das médias para $\mathrm{n}=27$. 
Em pesquisa usando a metodologia de incubação aeróbia para medir a mineralização liquida no mesmo solo do presente trabalho, Navarro et al. (1980) concluíram que o processo de nitrificação foi limitado pela taxa de produção de amônio a partir da matéria orgânica. Os resultados apresentados nas Figuras 5 e 6 demonstraram que a produção de amônio não é uma etapa que limite a nitrificação, uma vez que as quantidades líquidas de amônio são baixas, a produção de nitrato foi muito ativa, permitindo a acumulação de quantidades importantes desse íon. A fração de ${ }^{15} \mathrm{~N}$ adicionado que foi recuperado no $\mathrm{N}$ inorgânico (Hart et al., 1994) na primeira extração (24 h após a adição de ${ }^{15} \mathrm{NH}^{+}{ }_{4}$ ) foi de 99, 88, 73 e 85\% para as adições de ${ }^{15} \mathrm{NH}_{4}{ }^{+}$ realizadas, respectivamente, aos 0, 7, 21 e 35 dias após o período de pré-incubação do solo. Os desvios padrões das medidas dessas frações foram sempre menores que 4, indicando baixa variabilidade entre sítios de amostragem (blocos).

Essas recuperações foram altas se comparadas com as obtidas para períodos de 0,5 e $2 \mathrm{~h}$ ao tempo 0 por Andersen \& Jensen (2003) e Wang et al. (2001), da ordem de 82 e 67 a 94\%, respectivamente. Esses resultados representam uma segurança em relação ao tempo 0 escolhido $(24 \mathrm{~h})$, já que deixam claro que os processos abióticos de fixação de amônio e a imobilização não invalidam as TMB calculadas e, ademais, provem de tempo suficiente para favorecer a distribuição homogênea do marcador na amostra, por difusão.

$\mathrm{O}$ enriquecimento em ${ }^{15} \mathrm{~N}$ da fração amônio na extração inicial (24 h) foi de 7$8 \%$ em átomos de ${ }^{15} \mathrm{~N}$ em excesso, sem diferenças entre manejos, profundidade e tempo de adição. Estes enriquecimentos diminuíram até valores entre 2 a $4 \%$ de átomos em excesso na segunda extração $(72 \mathrm{~h}$ ), conforme o manejo e profundidade de solo, que levou a diferentes diluições isotópicas em função da velocidade de ingresso de ${ }^{14} \mathrm{~N}$ originado da matéria orgânica. Na fração nítrica, os valores iniciais flutuaram entre $0,4 \mathrm{a}$ $0,5 \%$ de átomos em excesso e os finais entre 1 e 1,2, na medida em que parte do marcador foi assimilado pelas bactérias nitrificadoras, teoricamente, na mesma proporção que o amônio foi mineralizado. 

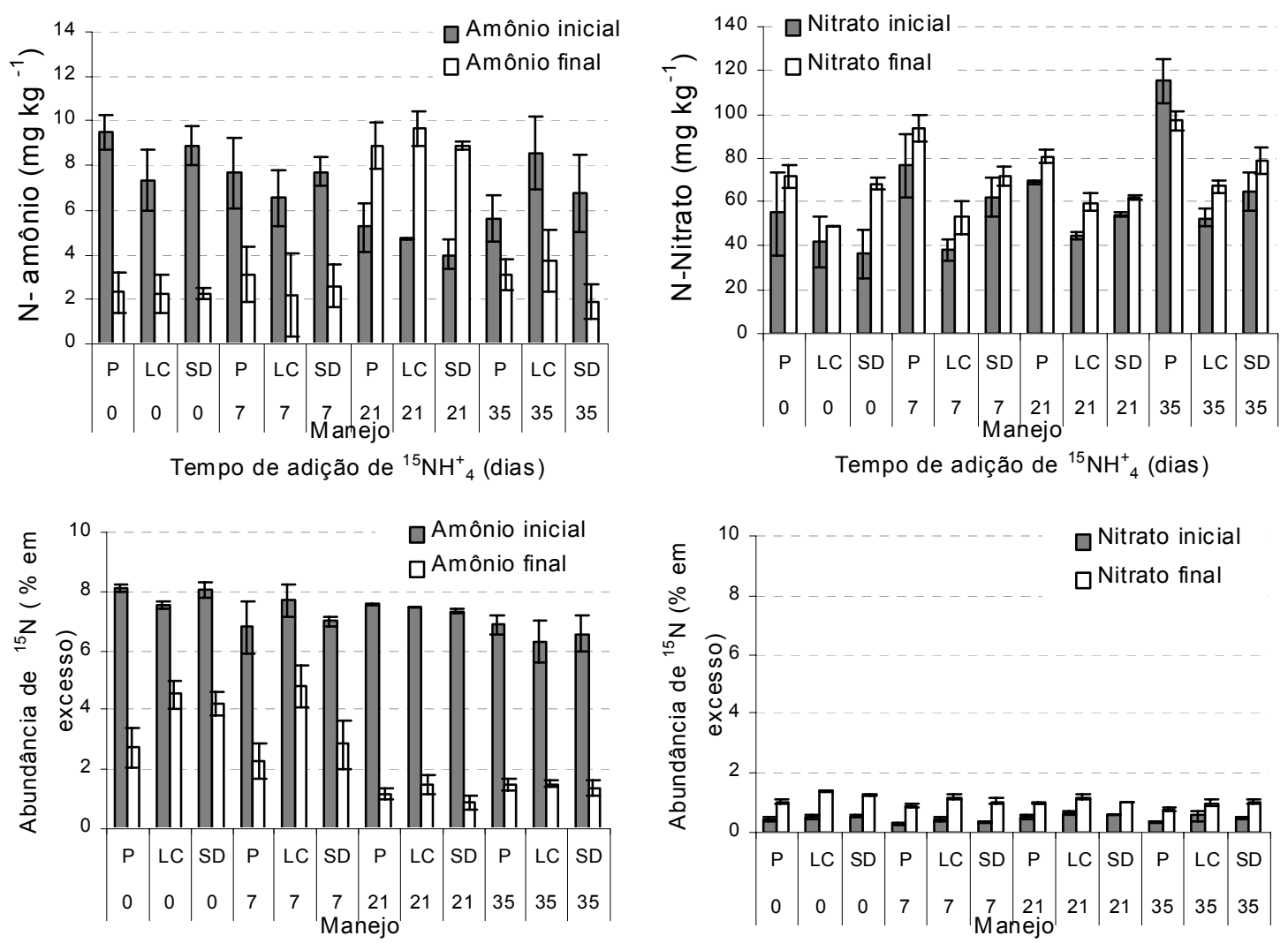

Tempo de adição de ${ }^{15} \mathrm{NH}^{+}{ }_{4}$ (dias)

Tempo de adição de ${ }^{15} \mathrm{NH}_{4}^{+}$(dias)

Figura 6. Conteúdo de $\mathrm{N}$ inorgânico (amônio e nítrico) e abundância em excesso de ${ }^{15} \mathrm{~N}$ na profundidade de 10-20 $\mathrm{cm}$ em solos do Sudeste de Buenos Aires sob pastagem (P), lavoura convencional (LC) e semeadura direta (SD). As barras verticais indicam os desvios padrões das médias para $\mathrm{n}=27$.

\section{Mineralização bruta}

Apesar de os níveis de $\mathrm{N}$-amônio no solo permaneceram baixos em todos os manejos e profundidades nos 35 dias de medições, a mudança no enriquecimento da fração de amônio conduz à quantificação de mineralização bruta. $\mathrm{O}$ excesso isotópico do ${ }^{15} \mathrm{~N}$-amônio diminuiu durante as incubações como resultado da diluição da fração marcada, pela mineralização do $\mathrm{N}$ nativo do solo, com abundância natural. A diminuição desse enriquecimento do amônio foi diferente para as situações estudadas, conduzindo a diferentes taxas de mineralização bruta. 

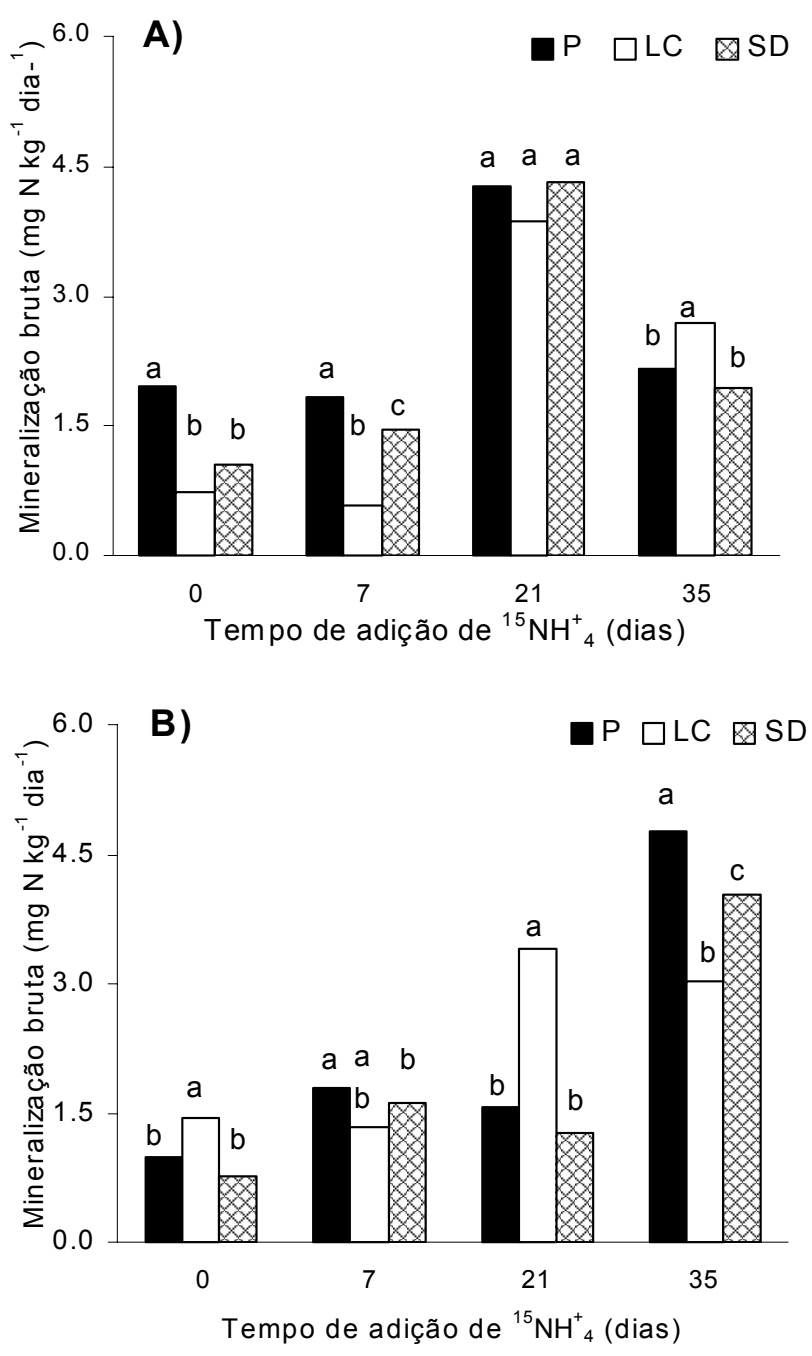

Figura 7. Taxas de mineralização bruta em solos com pastagem (P), lavoura convencional (LC) e semeadura direta (SD), de 0-10 cm (A) e de 10-20 cm (B). As letras sobre as barras indicam diferenças significativas $(p<0,05)$ entre manejos para cada tempo de adição.

As TMB apresentaram valores conservativos, em média entre 0,62 e 4,77 mg $\mathrm{kg}^{-1} \mathrm{dia}^{-1}$ de $\mathrm{N}$, sendo 0,053 e $6,97 \mathrm{mg} \mathrm{kg}^{-1} \mathrm{dia}^{-1}$ de $\mathrm{N}$ os valores extremos. Esses resultados são da mesma ordem que os obtidos por outros autores (Davidson et al., 1991; Pilbeam et al., 1993; Unkovich et al., 1998; Luxhøi et al., 2003). Mesmo que as comparações sejam dificultosas devido às diferenças de solos e condições ambientais, é 
importante destacar que as TMB, geralmente, não assumem valores maiores a 10 mg kg${ }^{1}$ dia $^{-1}$ de $\mathrm{N}$ e, apesar desta situação, elas são sempre maiores que as taxas de mineralização líquida.

Como tendência geral dos resultados de TMB, pode-se ressaltar que de $0-10 \mathrm{~cm}$ (Figura 7A), todos os tratamentos apresentaram valores máximos quando o ${ }^{15} \mathrm{NH}_{4}^{+}$foi adicionado aos 21 dias. Os tratamentos $\mathrm{P}$ e SD tiveram comportamentos similares, sendo as suas TMB maiores que as em LC, nos três primeiros tempos. Na profundidade de 10$20 \mathrm{~cm}$ (Figura 7B), P e SD tiveram novamente comportamentos similares entre si com uma queda das TMB aos 21 dias e uma importante recuperação aos 35 dias, mas a LC teve igual comportamento que nos $10 \mathrm{~cm}$ superficiais, não apresentando a tendência de se recuperar como ocorreu com $\mathrm{P}$ e $\mathrm{SD}$, no ultimo tempo.

Devido à falta de independência entre profundidades, realizaram-se análises estatísticas separadas para cada profundidade, obtendo-se para ambas as profundidades, efeito significativo do tempo de adição, e da interação tempo de adição $\times$ manejo. $\mathrm{O}$ comportamento dos manejos não foi o mesmo no tempo nem comparando-se entre si, como reflexo do impacto diferencial do manejo no processo de mineralização. Na superfície $(0-10 \mathrm{~cm})$ as TMB mostraram um máximo aos 21 dias, e depois diminuíram com as taxas de $\mathrm{P}$ sendo maiores que em LC a 0 e 7 dias; no dia 21 os manejos comportaram-se igualmente e aos 35 dias LC foi significativamente superior a SD e P (Figura 7A). Na profundidade de $10-20 \mathrm{~cm}$, as TMB de $\mathrm{P}$ e $\mathrm{SD}$ tiveram aumento importante ao final do período (dia 35), enquanto que as TMB de LC aumentaram no início e se estabilizaram entre os dias 21 e 35 (Figura 7 B).

\section{Nitrificação e consumo de amônio}

No calculo das TNB, no tempo 21 dias, ocorreu uma situação particular na grandeza e no enriquecimento em ${ }^{15} \mathrm{~N}$ da fração de amônio que conduziu a erros matemáticos no cálculo do enriquecimento médio do amônio ([A*], na equação 4) e, como conseqüência, uma redução de $44 \%$ na quantidade de valores calculados de taxa de nitrificação. É possível que os valores que não conduziram a erros matemáticos neste tempo de adição, tenham também algum vício já que curiosamente eles assumiram 
valores maiores que a taxa de consumo de amônio, e é evidente que se a nitrificação é um dos processos que integram o consumo, ela poderia, no máximo ser igual que o consumo. É preciso lembrar o fato que no presente trabalho a taxa de nitrificação foi calculada indiretamente, enriquecendo a fração de amônio, que é o substrato da nitrificação.
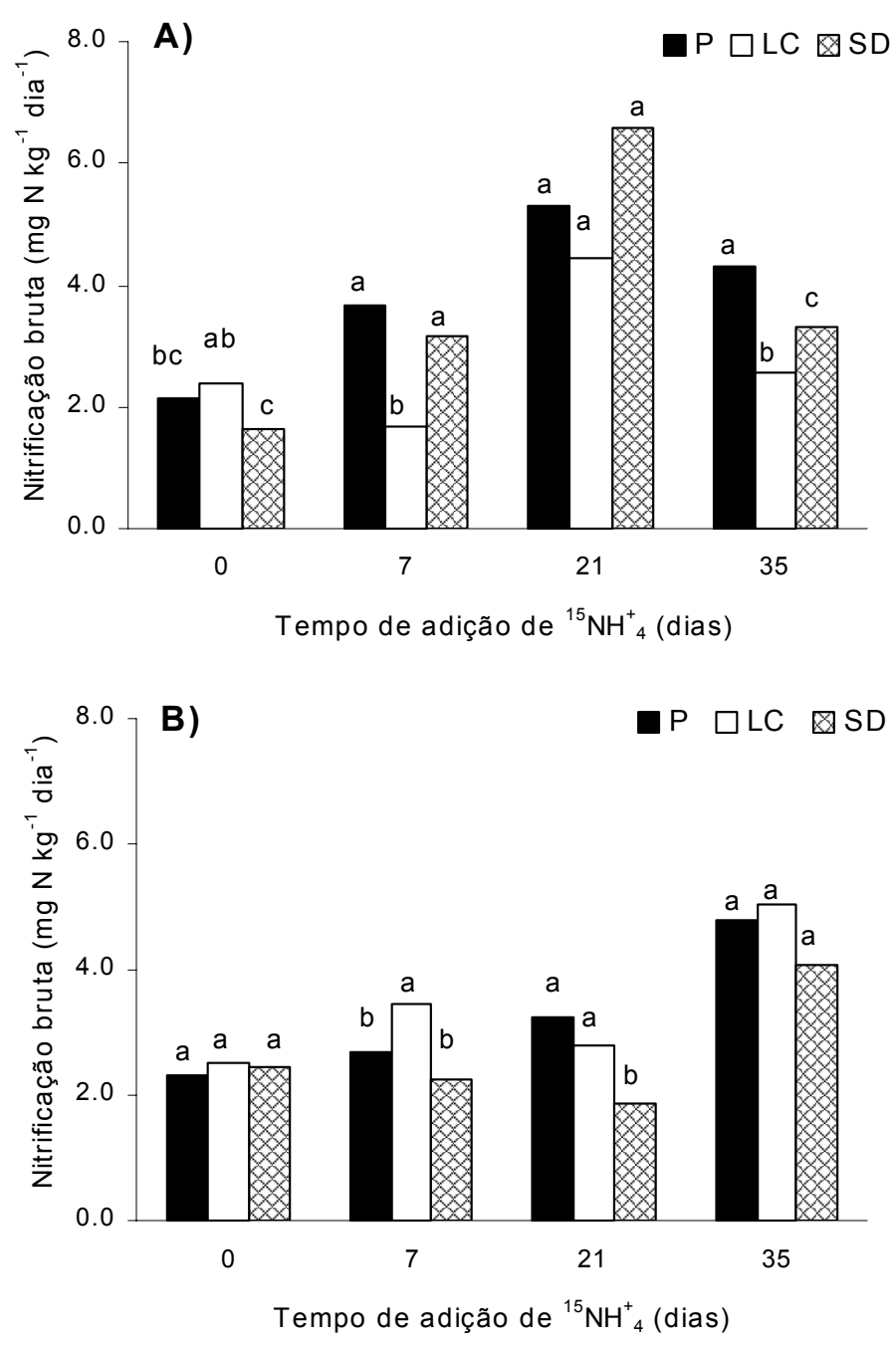

Figura 8. Taxas de nitrificação bruta em solos com pastagem (P), lavoura convencional (LC) e semeadura direta (SD), de 0-10 cm (A) e de 10-20 cm (B). As letras sobre as barras indicam diferenças significativas $(\mathrm{p}<0,05)$ entre manejos para cada adição de ${ }^{15} \mathrm{NH}_{4}^{+}$. 
O predomínio na bibliografia de trabalhos que calcularam a taxa de nitrificação diretamente injetando ${ }^{15} \mathrm{~N}^{-\mathrm{NO}_{3}}{ }_{3}$ (Watson \& Mills, 1998; Chen \& Stark, 2000; Coompton \& Boone, 2002) é um reflexo da possibilidade de estimulação por substrato da nitrificação. Luxhøi et al. (2003) concluíram que é possível que o ${ }^{15} \mathrm{~N}^{-\mathrm{NH}^{+}}{ }_{4}$ tenha estimulado a nitrificação, devido a concentração de ${ }^{15} \mathrm{NH}_{4}^{+}$ter incrementado as taxas de nitrificação em solo de baixo conteúdo inicial de amônio. No presente experimento esta situação só aconteceu na injeção 3, mais a fração de amônio foi menor que $10 \mathrm{mg} \mathrm{kg}^{-1}$ de solo durante os quatro tempos de adição de ${ }^{15} \mathrm{NH}_{4}^{+}$.

Além da situação descrita anteriormente, as taxas de nitrificação bruta apresentaram valores médios maiores e tendências similares que a MB (Figura 8). Na profundidade de 0-10 cm, as TNB no manejo LC foram maiores que as de SD no tempo de adição 1(dia 0) e de 10-20 cm no tempo de adição 2 (dia 7), LC superou as TNB de SD e de P. É mais freqüente encontrar na bibliografia trabalhos em que a TMB seja maior que a TNB (Davidson et al., 1991; Chen et al., 2000; Compton \& Boone, 2002), mais vários pesquisadores têm comunicado resultados em que as TMB foram menores que as TNB (Watson \& Mills, 1998; Recous et al., 1999; Luxhøi et. 2003). Resultados como esses estariam indicando a avidez das bactérias nitrificadoras pelo amônio produzido na mineralização (amonificação). No caso da pastagem, a presença continua de plantas impediria a acumulação de $\mathrm{N}$-nitrato, principalmente nos períodos de crescimento vegetal ativo, mas nos manejos agrícolas, a presença de plantas crescendo é estratégica para evitar possíveis perdas por desnitrificação e/ou lixiviação de nitrato, no caso de se apresentarem as outras condições para que essas perdas venham a ocorrer.

As taxas de consumo de amônio (Figura 9) apresentaram valores menos variáveis entre manejo, profundidade e tempo de adição, mas com valores médios maiores que TMB, indicando que existiriam várias situações em que é possível encontrar mineralização liquida negativa (imobilização), mesmo que ocorrendo mineralização bruta. Murphy et al. $(1998,1999)$ comunicaram valores de TCB maiores que TMB em solos australianos franco-arenosos, franco-argilo-arenosos e francos argilosos sob diferentes manejos agrícolas ou de pastagem, com diferentes padrões de mineralização e 
consumo. No presente experimento, a pastagem apresentou TCB maiores que LC nos três primeiros tempos de adição, nos $10 \mathrm{~cm}$ superficiais, enquanto que estas diferenças só foram significativas com SD no dia 0 e, no último tempo de adição esta tendência inverteu-se (Figura 9). De 10-20 cm, os três manejos se comportaram de forma similar até o segundo tempo de adição, $\mathrm{P}$ alcançou valores máximos aos 35 dias.
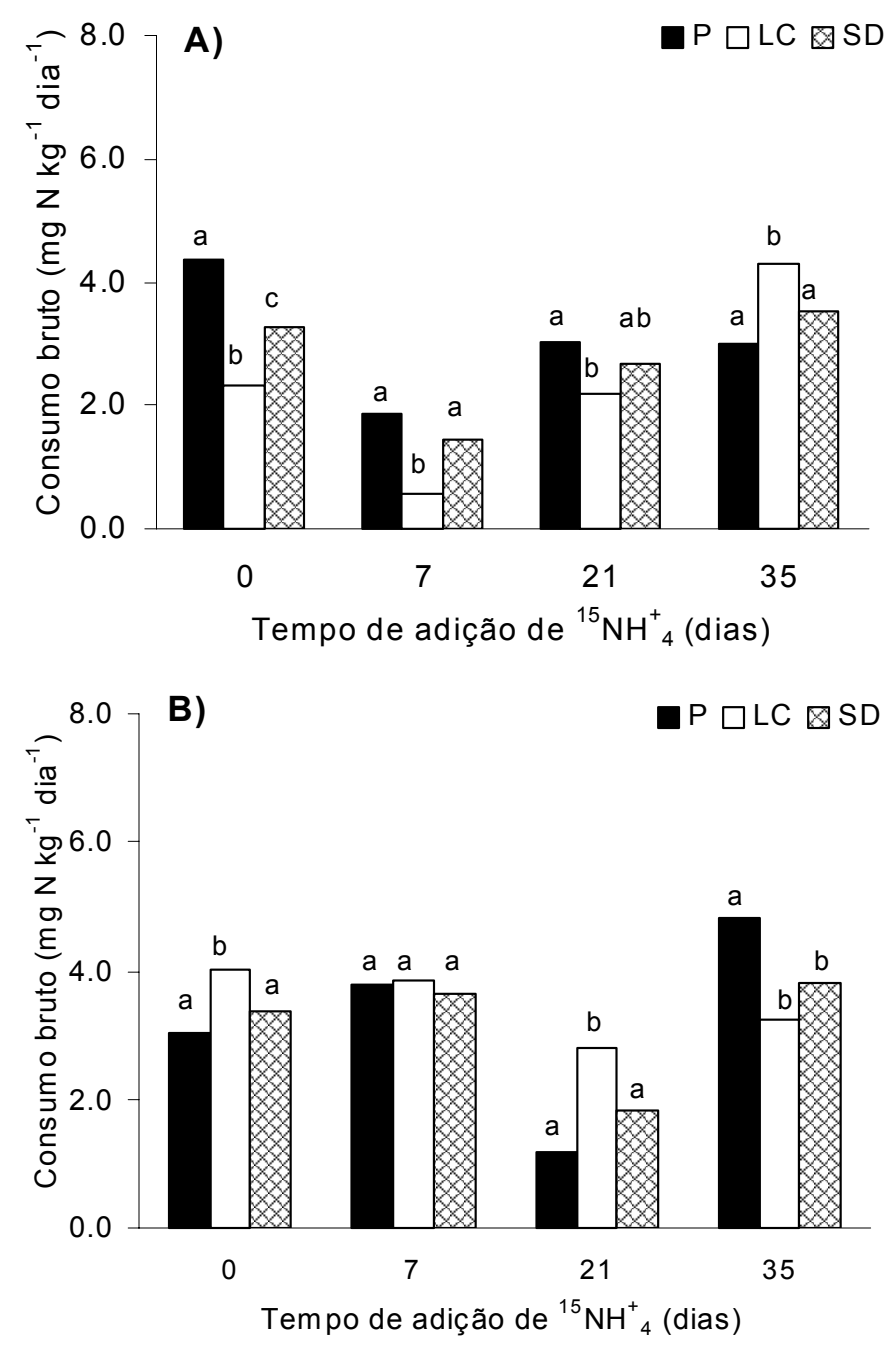

Figura 9. Taxas de consumo bruto de amônio em solos com pastagem (P), lavoura convencional (LC) e semeadura direta (SD), em amostras de solo colhidas nas profundidades de $0-10 \mathrm{~cm}$ (A) e de $10-20 \mathrm{~cm}$ (B). As letras sobre as barras indicam diferenças significativas $(\mathrm{p}<0,05)$ entre manejos para cada tempo de adição de ${ }^{15} \mathrm{NH}_{4}^{+}$. 

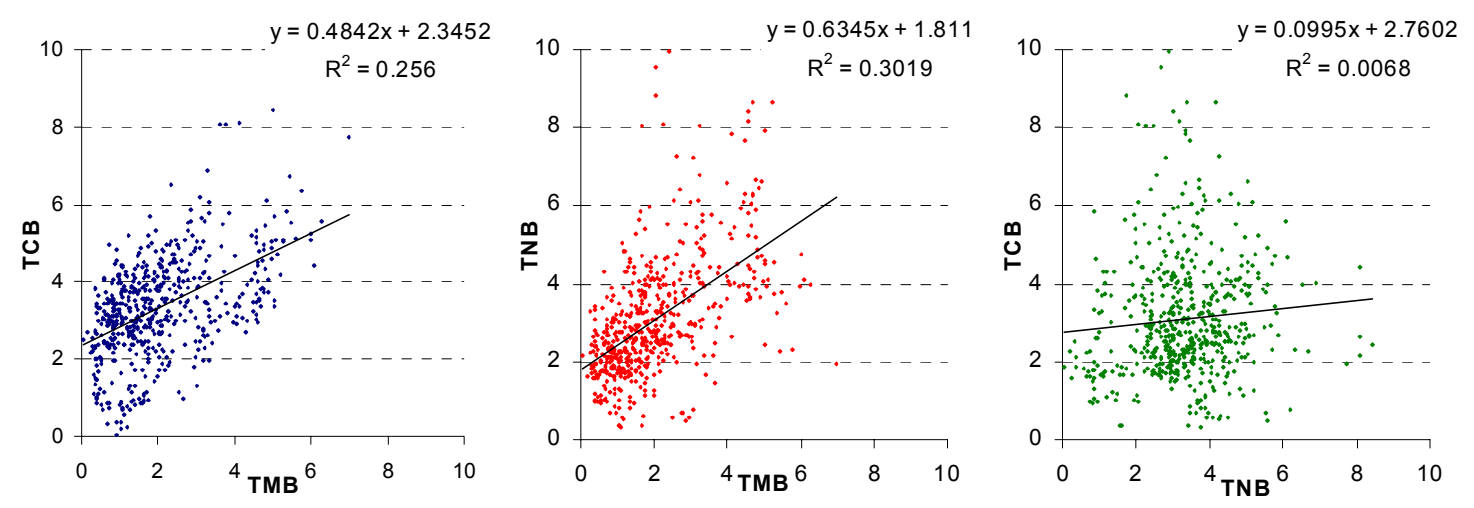

Figura 10. Relações entre taxas de mineralização bruta (TMB), consumo bruto (TCB) e nitrificação bruta (TNB) de todos os manejos, profundidades e tempos de adição de ${ }^{15} \mathrm{NH}_{4}^{+}$.

As taxas de produção (mineralização) e consumo de amônio estiveram significativamente correlacionadas $\left(\mathrm{r}^{2}=0,256, \mathrm{p}<0,0001\right)$, da mesma forma que as de nitrificação e mineralização $\left(r^{2}=0,302, p<0,0001\right)$, enquanto que as de nitrificação e consumo tiveram uma relação muito débil e não significativa $\left(\mathrm{r}^{2}=0,07, \mathrm{p}=0,05\right)$ (Figura 10). As TMB estiveram positivamente correlacionadas com as TNB, indicando que a nitrificação foi favorecida pelo incremento nas taxas de mineralização, como era esperado, já que o amônio produzido é usado como substrato para a nitrificação. A falta de relação entre TCB e TNB teria duas possíveis explicações: se o cálculo de TNB apresentasse erro metodológico produto de estimulação por substrato, como foi discutido anteriormente, ou, como conseqüência de grandes flutuações na imobilização do amônio, que é o outro processo que no sistema estudado explicaria o consumo de amônio. O que sabe ao certo é que os fluxos brutos apresentaram grandes valores em comparação com a grandeza inicial da fração amônio e com variações em resposta ao manejo. Estes resultados levam a inferir que a pastagem, em algumas oportunidades, ao ter acumulado um maior conteúdo de $\mathrm{C}$ orgânico desde a implantação do experimento $\left(\mathrm{P}=28,2, \mathrm{SD}=26,8\right.$ e LC=26,2 $\left.\mathrm{g} \mathrm{C} \mathrm{kg}^{-1}\right)$, está em condições de mineralizar o $\mathrm{N}$ orgânico do solo a taxas maiores que os manejos agrícolas. Dentre estes tratamentos, a SD tem 
manifestado um comportamento similar à pastagem em algumas situações, mais com menores taxas, enquanto que a LC, em outras circunstâncias, alcançou ou ainda melhorou o desempenho da pastagem e da SD.

Estes comportamentos estariam sugerindo a presença de frações de matéria orgânica de diferentes características (mais ou menos lábeis) nos diferentes manejos. Aparentemente, P e SD possuiriam, na profundidade de 10-20 cm, frações que começam a mineralizar mais lentamente, mas de grande tamanho, que conduzem a uma alta taxa de mineralização no quarto período de medição. Incrementos nas frações leve, media e pesada da matéria orgânica de pastagens em comparação com SD e LC já foram verificados em solos similares ao utilizado no presente experimento, embora as maiores diferenças acontecessem nas frações média e leve, o que explicaria a maior mineralização de C encontrada (Alvarez et al., 1998).

Com o objetivo de esclarecer os comportamentos às vezes opostos dos manejos, realizou-se um cálculo das quantidades acumuladas de $\mathrm{N}_{-} \mathrm{NH}_{4}^{+}$mineralizado e consumido durante o período experimental (Figura 11). Para este cálculo, se utilizaram os valores de densidade aparente $\left(\delta_{\mathrm{ap}}\right)$ medidos pelo método do anel volumêtrico para as duas profundidades analisadas: $1,10,1,19$ e $1,27 \mathrm{Mg} \mathrm{m}^{-3}$ para $\mathrm{P}$, SD e LC, respectivamente de $0-10 \mathrm{~cm} \mathrm{e} 1,12,1,16$ e $1,25 \mathrm{Mg} \mathrm{m}^{-3}$ de 10 a $20 \mathrm{~cm}$.

O calculo das quantidades acumuladas permite interpretar melhor que o processo de consumo foi sempre maior que a mineralização, indicando que ocorreu imobilização líquida nos três manejos estudados; que os tratamentos de manejo começaram a diferenciar-se a partir do tempo de adição 3 (21 dias) e, que finalmente LC apresentou maior consumo e mineralização acumulada. Por meio deste cálculo é possível compensar muitas das diferencias temporais. Se forem comparadas as quantidades totais mineralizadas e consumidas e as diferenças entre elas, que seriam uma medida da disponibilidade de $\mathrm{N}$ para as plantas, concluir-se-ia que a pastagem é a que apresenta menor diferença apesar de menor mineralização, mesmo assim deixaria uma maior quantidade de $\mathrm{N}$ disponível (Tabela 1). 


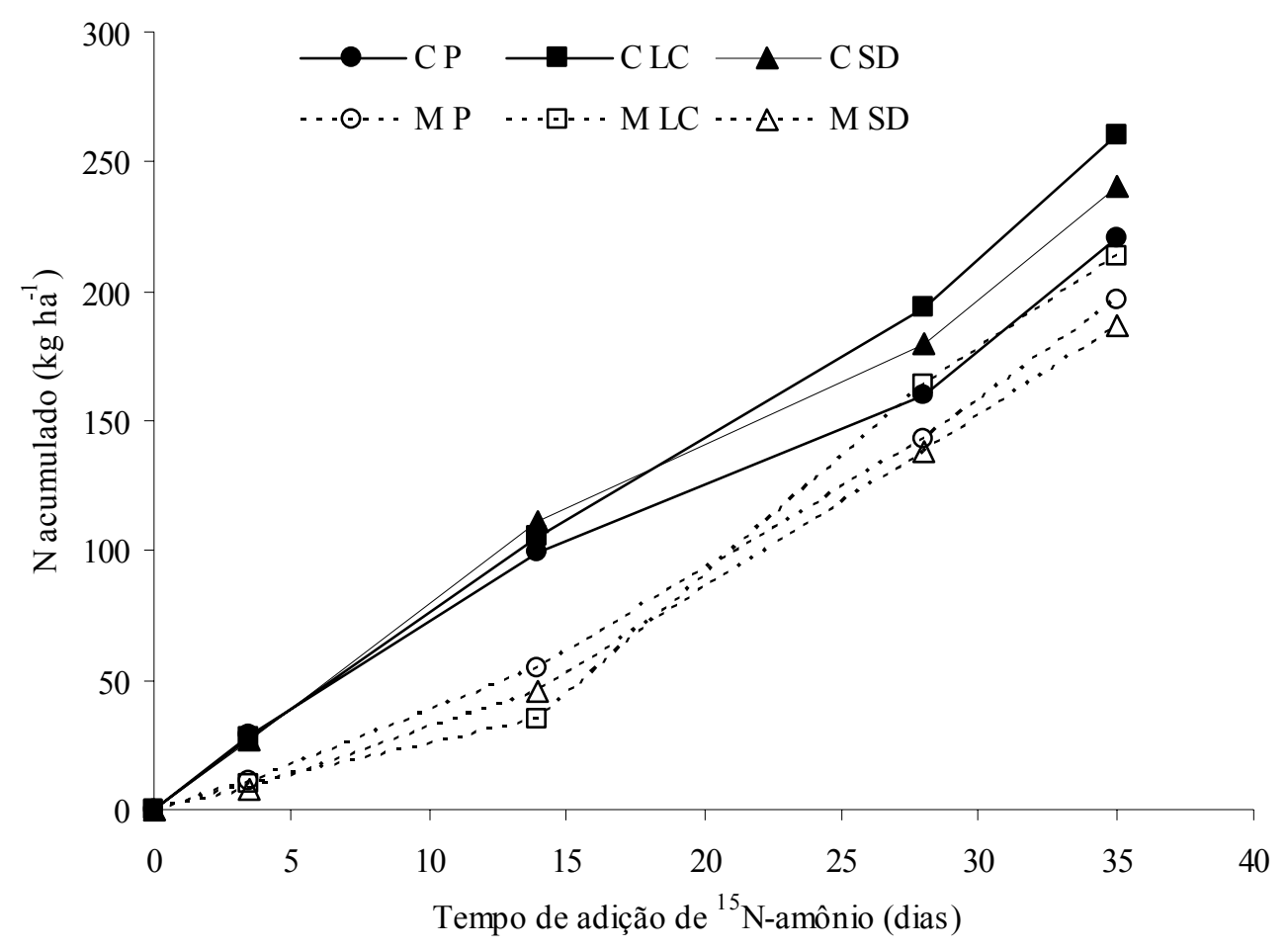

Figura 11. Acumulação de $\mathrm{N}$ mineralizado $(\mathrm{M})$ e consumido $(\mathrm{C})$ durante o período experimental para pastagem (P), lavoura convencional (LC) e semeadura direta (SD).

Tabela 1. Acumulação bruta de $\mathrm{N}$ mineralizado, consumido e diferenças entre consumo e mineralização para pastagem, semeadura direta e lavoura convencional durante 35 dias de incubação.

\begin{tabular}{|c|c|c|c|}
\hline & Consumo & Mineralização & Consumo - Mineralização \\
\hline & \multicolumn{3}{|c|}{$\mathrm{kg} \mathrm{N} \mathrm{ha}^{-1}$} \\
\hline Pastagem & $220,49 \mathrm{~b}$ & $196,67 \mathrm{ab}$ & 23,82 a \\
\hline Semeadura direta & 240,25 a & 187,03 a & $53,21 \mathrm{~b}$ \\
\hline Lavoura convencional & 260,55 a & $213,85 \quad b$ & $46,69 \mathrm{~b}$ \\
\hline
\end{tabular}




\subsection{Conclusões}

A metodologia de diluição do isótopo ${ }^{15} \mathrm{~N}$ permite a determinação das taxas de mineralização bruta em solo submetido a diferentes sistemas de manejo.

A pastagem apresenta maiores TMB nos $10 \mathrm{~cm}$ superficiais e nos primeiros dias de medição, enquanto que de 10-20 cm de profundidade, a LC começa mineralizar em taxas maiores após três semanas de incubação.

A SD teve um comportamento semelhante à pastagem, mas com taxas menores.

O consumo de amônio foi um processo importante nos três manejos e profundidades, superando as quantidades totais consumidas àquelas mineralizadas. 


\section{FRACIONAMENTO GRANULOMÊTRICO DA MATÉRIA ORGÂNICA DE UM MOLISOL DO SUDESTE DE BUENOS AIRES (ARGENTINA) SOB PASTAGEM, LAVOURA CONVENCIONAL E SEMEADURA DIRETA}

\section{Resumo}

Calibrou-se a metodologia de Feller (1979) para fracionar a matéria orgânica de um solo temperado do SE da província de Buenos Aires (Argentina). Analisou-se o efeito de sistemas de manejo do solo: lavoura convencional (LC), semeadura direta (SD) e pastagem (P) na distribuição por tamanho de partículas da matéria orgânica de um solo manejado com LC durante 17 anos, separando-se em 6 frações, a saber: 2000-200 $\mu \mathrm{m}$, leve (L) e pesada (P); de 200-50 $\mu \mathrm{m}$, leve e pesada; de 50-20 $\mu \mathrm{m}$ e $<20 \mu \mathrm{m}$; nas frações foi quantificada a massa da fração, $\mathrm{C}$ orgânico, $\mathrm{N}$ total e $\delta^{13} \mathrm{C}$. Em todos os manejos entre 82 e $95 \%$ do C e entre 87 e $97 \%$ do $N$ está nas frações $<50 \mu$ m, indicando alta proteção física da matéria orgânica e sugerindo baixas taxas de reciclagem nesses solos. Depois de 6 anos de instalados os manejos, P acumulou 112\% mais C e 116\% mais N nas frações leves $>50 \mu \mathrm{m}$ que LC. SD não apresentou diferencias significativas com respeito à $\mathrm{LC}$, embora tendeu a acumular maior quantidade de $\mathrm{C}$ e $\mathrm{N}$ que LC. Nas frações $<50 \mu \mathrm{m}$ não existiram diferenças em massa, $\mathrm{C}$ orgânico nem $\mathrm{N}$ total, concluindose que o manejo não causou modificações nessas frações. $\mathrm{O} \delta^{13} \mathrm{C}$ foi mais negativo nas frações de maior tamanho (recentemente incorporadas) como conseqüência da inclusão de espécies C3 nas rotações. Nas frações 200-50L e 50-20 $\mu \mathrm{m}, \delta^{13} \mathrm{C}$ de P teve valores mais negativos que LC e SD. 


\section{Summary}

Feller (1979) physical fractionation methodology was adjusted in order to fractionate the organic matter of a temperate soil from Southeast of Buenos Aires province (Argentina). The effect of soil management systems (conventional tillage $=\mathrm{LC}$, no tillage $=\mathrm{SD}$ and pasture $=\mathrm{P}$ ) on organic matter size fractions was analyzed. The soil was previously on conventional tillage for 17 years. Six size fractions were separated by sieving: 2000-200 $\mu \mathrm{m}$, light (L) and heavy (P), 200-50 $\mu \mathrm{m}$, light and heavy, 50-20 $\mu \mathrm{m}$ and $<20 \mu \mathrm{m}$. Mass of fraction, organic-C, total-N and $\delta^{13} \mathrm{C}$ were measured at $0-10$ and 10-20 cm soil depth for each size fraction. For all management systems was found that $82-95 \%$ of organic-C and $87-97 \%$ of total-N was located in $<50 \mu \mathrm{m}$ fractions, indicating the high physical protection of $\mathrm{OM}$ on these soils and suggesting low turnover rates. After 6 years from implantation from management installation, $\mathrm{P}$ treatment accumulated $112 \%$ more $\mathrm{C}$ and $116 \%$ more $\mathrm{N}$ than $\mathrm{LC}$ on $>50 \mu \mathrm{m}$ light fraction. SD did not present significant differences respect to LC for the analyzed variables. However, a remarkable tendency to accumulate more $\mathrm{C}$ and $\mathrm{N}$ was found. In $<50 \mu \mathrm{m}$ fraction there were not significant differences in mass, organic-C or total-N, suggesting that management system did not modify these fractions. The $\delta^{13} \mathrm{C}$ was more negative in the fractions $>50 \mu \mathrm{m}$ (most recently incorporated) as a result of $\mathrm{C} 3$ species inclusion in the

rotation cycles. In 200-50L and 50-20 fractions, $\delta^{13} \mathrm{C}$ of $\mathrm{P}$ treatment had more negative values than $\mathrm{LC}$ and SD.

\subsection{Introdução}

A enorme complexidade da matéria orgânica (MO) e a sua importância na fertilidade do solo promoveram uma grande quantidade de estudos orientados para o conhecimento de sua natureza e das relações com os processos produtivos nos sistemas agrícolas. Os fracionamentos da MO do solo, baseados em frações definidas fisicamente, estão sendo utilizados intensamente para interpretar a dinâmica da MO do solo, pois é 
comprovado que os fracionamentos químicos têm pouco poder explicativo em estudos agronômicos, já que tanto os ácidos húmicos como os fúlvicos possuem taxas de reciclagem muito baixas (Anderson \& Paul, 1984) e não estão envolvidos nos processos de curto prazo, que determinam a produtividade das culturas. Também é desconhecida a importância dessas frações químicas nos grandes processos do solo, tais como a agregação e a mineralização da MO (Feller \& Beare, 1997).

As associações da $\mathrm{MO}$ com os constituintes minerais do solo, principalmente argilas minerais, são muito importantes já que regulam a mineralização e a armazenagem de MO (Greenland, 1965a, 1965b). É reconhecida a relação entre a dinâmica da $\mathrm{MO}$ com a textura e a estrutura do solo, fato pelo qual, conseguir uma quantificação da MO ligada às frações granulométricas, permite melhorar o poder explicativo dos fracionamentos.

Nos últimos anos, o reconhecimento dos efeitos prejudiciais de lavouras nas propriedades físicas, químicas e biológicas do solo, tem levado à adoção crescente de práticas de manejo que reduzam esses impactos no solo. Na Argentina, a superfície em semeadura direta (SD) atingiu 12 milhões de hectares em 2002 (Peiretti, 2002); havendo grande interesse em estudos sobre dinâmica de nutrientes sob este sistema. A SD, em general, aumenta a quantidade de $\mathrm{N}$ ativo do solo e de $\mathrm{C}$ e $\mathrm{N}$ da biomassa microbiana, produzindo uma estratificação destas frações no perfil do solo (Doran, 1987; Follet \& Schimel, 1989; Alvarez et al., 1998). A inclusão de pastagens nas rotações agrícolas produz recuperação de solos degradados por lavouras; no SE de Buenos Aires verificouse que uma pastagem de 3 a 4 anos depois de um ciclo agrícola de 6 a 7 aumenta a MO até um nível próximo ao original (Studdert et al., 1997), sendo possível que nos primeiros anos de pastagem aconteça um aumento na disponibilidade de $\mathrm{N}$, devido à contribuição dos resíduos de plantas nas frações leves facilmente mineralizáveis.

Os objetivos do presente trabalho foram: a) ajustar a técnica para fracionar a matéria orgânica e b) analisar o efeito de sistemas de manejo do solo (lavoura convencional, semeadura direta e pastagem) na distribuição por tamanho de partículas da matéria orgânica de um solo submetido durante 17 anos a LC. Presume-se que o 
efeito das lavouras na distribuição da matéria orgânica deveria alterar somente a fração mais ativa, a de maior tamanho, já que a de menor tamanho estaria fisicamente protegida (Kristensen et al., 2000) e, portanto, não resultaria alterada pelo manejo do solo.

\subsection{Material e Métodos}

As amostras de solo utilizadas foram colhidas em campo cuja descrição consta no Anexo A. Em dezembro de 2000 extraíram-se amostras de solo compostas nas parcelas LC, SD e P, de 0-10 e 10-20 cm, secaram-se ao ar e peneiraram-se por $2 \mathrm{~mm}$. Os conteúdos de $\mathrm{C}$ orgânico destas amostras foram 26,2, 26,8 e 28,2 $\mathrm{g} \mathrm{kg}^{-1}$ de C, para LC, SD e P respectivamente.

\section{Ajuste metodológico}

O principal objetivo metodológico de um fracionamento físico é atingir a máxima dispersão do solo (separação de areia, limo e argila) com mínima alteração da MO associada. Como o método utilizado neste trabalho foi inicialmente desenvolvido para solos tropicais (Feller et al., 1979), em que a natureza dos agentes cimentantes é diferente de solos temperados (maior predomínio de cátions bivalentes, $\mathrm{Ca}$ e $\mathrm{Mg}$ e argilas de tipo 2:1), realizaram-se alguns testes para confirmar se o método era adequado para dispersar as partículas sem desnaturar a MO. O teste foi realizado com solo do tratamento pastagem $(\mathrm{P})$ de $0-10 \mathrm{~cm}$ de profundidade.

Para comprovar a qualidade do fracionamento devida ao agente dispersante, comparou-se a distribuição da fração mineral do solo com a $\mathrm{MO}$ destruída por aquecimento com água oxigenada $\left(\mathrm{H}_{2} \mathrm{O}_{2}\right)$ em relação ao solo sem destruição da $\mathrm{MO}$ com dispersão em água ( $30 \mathrm{~g}$ de solo em $100 \mathrm{~mL}$ de água desionizada) ou com dispersão com hexametafosfato de sódio (30 g de solo em $100 \mathrm{~mL}$ de HMP 0,5\%). Todos os testes foram realizados em triplicata, agitando a suspensão a $50 \mathrm{rpm}$ por $2 \mathrm{~h}$ com três pérolas de vidro de $10 \mathrm{~mm}$ de diâmetro. Antes da agitação, deixou-se a suspensão em refrigerador por $16 \mathrm{~h}$ para favorecer a posterior ruptura de agregados durante a agitação, 
como conseqüência da contração ocasionada pela baixa temperatura. Depois da agitação, a suspensão foi passada em peneira de malha 200 e $50 \mu \mathrm{m}$ e lavou-se com água desionizada o resíduo que permaneceu sobre a peneira. A fração $>200 \mu \mathrm{m}$ foi separada em leve (L) e pesada (P) por suspensão em água. O solo que passou pela malha de 50 $\mu \mathrm{m}$ foi submetido a ultra-som durante 4 a 8 minutos. $\mathrm{O}$ tempo de tratamento foi regulado para atingir uma dispersão adequada (verificada por observação ao microscópio óptico). Posteriormente, a suspensão foi tamisada a $20 \mu \mathrm{m}$, secada a $60^{\circ} \mathrm{C}$, em estufa com circulação de ar, até peso constante, pesada e moída. Em cada fração separada foi determinado o $\mathrm{C}$ total (como as amostras não continham $\mathrm{CaCO}_{3}$, considerou-se que o $\mathrm{C}$ orgânico é equivalente ao $\mathrm{C}$ total), $\mathrm{N}$ total e o $\delta^{13} \mathrm{C}$ em um espectrômetro de massas Europa Scientific Ltda. (Krewe, UK) acoplado a um analisador de C e N (Barrie \& Prosser, 1996).

$\mathrm{O} \delta^{13} \mathrm{C}$ é uma expressão da abundância natural de ${ }^{13} \mathrm{C}$ de uma amostra em relação a um padrão internacional (PDB), expresso em unidades per mil (\%), que é calculado por meio da seguinte equação:

$$
\delta^{13} \mathbf{C}=\left[\left(\mathbf{R}_{\text {amostra }}-\mathbf{R}_{\text {padrão }}\right) / \mathbf{R}_{\text {padrão }}\right] \cdot \mathbf{1 0 0 0}
$$

onde: $\mathrm{R}_{\text {amostra }}$ e $\mathrm{R}_{\text {padrão }}$ é a razão do isótopo pesado $\left({ }^{13} \mathrm{C}\right)$ ao leve $\left({ }^{12} \mathrm{C}\right)$ medido na amostra e no padrão (Boutton, 1996).

Existe uma discriminação isotópica das plantas pelo ${ }^{13} \mathrm{CO}_{2} \mathrm{e}{ }^{12} \mathrm{CO}_{2}$ durante a fotossíntese, devido às propriedades bioquímicas das enzimas que fixam $\mathrm{C}$ e ao processo de difusão das espécies de $\mathrm{CO}_{2}$ pela abertura estomática e espaço intercelular nas folhas. Esta discriminação é variável entre as plantas terrestres, classificadas em três tipos de ciclos fotossintéticos (C3, C4 ou CAM). Essa diferença é muito maior do que as pequenas variações que ocorrem durante a decomposição da $\mathrm{MO}$ no solo, fazendo com que o $\mathrm{C}$ orgânico do solo retenha a marcação da vegetação de origem. Esse efeito permite conhecer e datar mudanças na vegetação (Balesdent \& Mariotti, 1996).

Estudou-se a correlação da distribuição da fração mineral do solo com a $\mathrm{MO}$ destruída com $\mathrm{H}_{2} \mathrm{O}_{2}$ em relação aos tratamentos de dispersão $\mathrm{HMP}$ e $\mathrm{H}_{2} \mathrm{O}$ e para cada 
fração foram realizadas análises da variância e testes de Tukey ao nível de probabilidade de 0,05 .

\section{Fracionamento das amostras}

As amostras das parcelas sob P, LC e SD, nas profundidades de 0-10 e 10-20 cm, foram fracionadas segundo os resultados do ajuste metodológico anteriormente descrito. Pesaram-se $30 \mathrm{~g}$ de solo seco ao ar préviamente peneirado por $2 \mathrm{~mm}$, deixaram-se $16 \mathrm{~h}$ em refrigerador com $100 \mathrm{~mL}$ HMP $0,5 \%$. Agitaram-se por $2 \mathrm{~h}$ em mesa agitadora (50 rpm) e posteriormente peneiraram-se por 200 e $50 \mu \mathrm{m}$. As frações retidas em cada peneira foram lavadas e posteriormente secas a $60^{\circ} \mathrm{C}$ em estufa com circulação de ar. A fração menor de $50 \mu \mathrm{m}$ foi submetida ao ultra-som e posteriormente peneirada por 20 $\mu \mathrm{m}$. Depois de secas, as frações foram pesadas e moídas para a determinação de $\mathrm{C}$ e $\mathrm{N}$ total com um analisador de $\mathrm{C}$ e N, ANCA-SL, acoplado a um espectrômetro de massas Europa Scientific Ltda. (Krewe, UK).

As frações de solo foram expressas em $\mathrm{Mg} \mathrm{ha}^{-1}$, utilizando-se as densidades aparentes obtidas pelo método do anel volumétrico, de 1,10,1,19, 1,27 $\mathrm{Mg} \mathrm{m}^{-3}$, para as amostras de 0-10 $\mathrm{cm}$ de profundidade, e de 1,12,1,16,1,25 $\mathrm{Mg} \mathrm{m}^{-3}$ nas de 10-20 cm, respectivamente, para P, SD e LC. Separaram-se as seguintes frações: >200L - fração retida na peneira de $200 \mu \mathrm{m}$ e separada por suspensão em água, constituída, fundamentalmente, por restos de raízes e plantas; >200P - fração retida na peneira de $200 \mu \mathrm{m}$ e que sedimentou na suspensão em água, constituída fundamentalmente por partículas de areia; 200-50L - fração retida na peneira de $50 \mu \mathrm{m}$ e separada por suspensão em água, constituída fundamentalmente por material orgânico não reconhecível ao microscópio óptico; 200-50P - fração retida na peneira de $50 \mu \mathrm{m}$ e que sedimenta rapidamente ao suspender-se em água, de natureza organo-mineral; 50-20 fração retida na peneira de $20 \mu \mathrm{m}$ depois de submetida ao ultra-som a 240 watts de potência, também de natureza organo-mineral; $<20$ - fração que passou pela peneira de $20 \mu \mathrm{m}$ e que inclui partículas minerais de tamanho limo e argila, microagregados organominerais muito estáveis e matéria orgânica amorfa, humificada e fortemente unida às partículas minerais. 
As comparações da massa, conteúdo de $\mathrm{C}$ e de $\mathrm{N}$ entre manejos (P, LC e SD), foram realizadas com análises da variância separadas para cada fração e profundidade, quando for necessário realizaram-se testes de Tukey para 0,05 nível de probabilidade.

\subsection{Resultados e Discussão}

\section{Ajuste metodológico}

A destruição de $\mathrm{MO}$ com $\mathrm{H}_{2} \mathrm{O}_{2}$ para obter as frações minerais em cada granulometria não foi completamente efetiva, uma vez que se observou na fração $<20$ $\mu \mathrm{m}$ pequenas quantidades de $\mathrm{C}$ e de $\mathrm{N}$ (Figura 12). A matéria orgânica que está formando microagregados com colóides inorgânicos está muito protegida e, por isto, foi menos oxidada por $\mathrm{H}_{2} \mathrm{O}_{2}$, mas ainda não se conhece o significado biológico desta susceptibilidade à oxidação com $\mathrm{H}_{2} \mathrm{O}_{2}$ (Van Veen \& Kuikman, 1990). Considera-se que esta matéria orgânica é altamente resistente ao ataque por microrganismos e, portanto, seu aporte de nutrientes por mineralização será pouco expressivo. Assim mesmo, como não é esperado que essas frações sejam alteradas pelo manejo do solo, utilizaram-se, igualmente, os dados dessa distribuição granulométrica para verificar a eficiência de recuperação dos métodos examinados de fracionamento.

As recuperações acumuladas de massa de solo, $\mathrm{N}$ e $\mathrm{C}$ foram satisfatórias em general, mas a dispersão em água produziu maiores recuperações (Tabela 2). O tratamento com HMP teve maior variabilidade do que o tratamento com água, principalmente nos valores de $\mathrm{C}$ e $\mathrm{N}$ total, o que poderia relacionar-se às baixas concentrações de $\mathrm{N}$ e $\mathrm{C}$ em algumas frações separadas ou, ainda no caso do $\mathrm{N}$, à possibilidade de perda de $\mathrm{N}$ por volatilização de $\mathrm{NH}_{3}$, devido ao aumento de $\mathrm{pH}$ causado pelo HMP.

Com $\mathrm{H}_{2} \mathrm{O}$ como dispersante não se atingiram níveis adequados de dispersão, em todas as frações, exceto na de 50-20 $\mu \mathrm{m}$; observaram-se diferenças significativas nas frações minerais relativamente ao solo com a matéria orgânica destruída (Figura 13), 
obtendo-se baixa correlação entre os resultados $(\mathrm{r}=0,34, \mathrm{p}=0,188)$. Com $\mathrm{H}_{2} \mathrm{O}$ como dispersante, comparando-se com o solo com a MO destruída com $\mathrm{H}_{2} \mathrm{O}_{2}$, observou-se que não foi dispersa uma grande massa de solo das frações $>200,200-50$ e 50-20 $\mu \mathrm{m}$, enquanto a fração $<20 \mathrm{~mm}$ foi subestimada, já que parte dela ficou formando agregados de maior tamanho.

O HMP conseguiu dispersar adequadamente os agregados, o que é comprovado pela correlação de massas das frações minerais deste método e daquele com a $\mathrm{MO}$ destruída por $\mathrm{H}_{2} \mathrm{O}_{2}(\mathrm{r}=0,96, \mathrm{p}=0,08)$, o que se traduz em ausência de diferenças entre as frações minerais destes dois tratamentos (Figura 13).
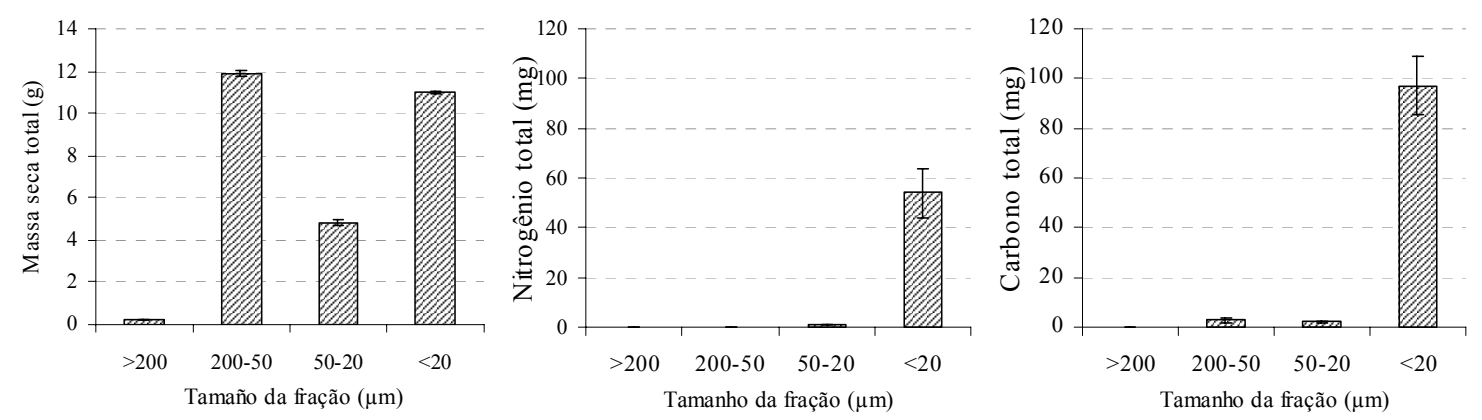

Figura 12. Distribuição da massa seca, nitrogênio e carbono total nas frações do solo de pastagem depois da destruição da matéria orgânica com $\mathrm{H}_{2} \mathrm{O}_{2}$.

Tabela 2. Recuperação da massa, carbono e nitrogênio total no solo de pastagem disperso com água $\left(\mathrm{H}_{2} \mathrm{O}\right)$ ou hexametafosfato de sódio (HMP). Valores entre parêntesis indicam desvios padrões da média para $n=3$.

\begin{tabular}{lccc}
\hline & Massa de solo & Carbono total & Nitrogênio total \\
\cline { 2 - 4 } & & $\%$ & \\
\hline Solo $+\mathrm{H}_{2} \mathrm{O}$ & $98,37(0,09)$ & $96,18(3,37)$ & $99,43(2,91)$ \\
Solo $+\mathrm{HMP}$ & $99,71(0,63)$ & $91,42(15,96)$ & $87,36(6,82)$ \\
Valores iniciais & $30 \mathrm{~g}$ & $788,8 \mathrm{mg}(62,5)$ & $71,3 \mathrm{mg}(2,48)$ \\
\hline
\end{tabular}


Na distribuição de $\mathrm{C}$ e $\mathrm{N}$ nas frações do solo disperso com HMP (Figura 14) observou-se uma quantidade importante de $\mathrm{C}$ e $\mathrm{N}$ nas frações de menor tamanho. $\mathrm{Na}$ fração $<20 \mu \mathrm{m}$ encontrou-se $72 \%$ do $\mathrm{N}$, enquanto que o $\mathrm{C}$ acumulou-se, também, na fração entre 200-50 $\mu \mathrm{m}$. A grande concentração de $\mathrm{N}$ justifica às baixas taxas de mineralização desses solos, já que a MO unida às frações limo e argila constitui complexos altamente humificados, difíceis de mineralizar (Edwards \& Bremner, 1967). $\mathrm{Na}$ fração $<20 \mu \mathrm{m}$ do solo disperso com HMP encontraram-se valores de $\delta^{13} \mathrm{C}$ próximos a $-20 \%$ e na fração mais grossa, valores de $-27 \%$ (Figura 14). O $\delta^{13} \mathrm{C}$ da fração $<20 \mu \mathrm{m}$ foi similar aos valores característicos destes solos na condição original, que foram desenvolvidos sob vegetação de pradaria mistura de espécies C3 e C4 (Andriulo, 1995). A diminuição de $\delta^{13} \mathrm{C}$ com o aumento do tamanho das frações é um reflexo da história agrícola do solo, com a inclusão de uma maior proporção de culturas de espécies de metabolismo C3 como trigo, girassol, soja, as que discriminam em contra o ${ }^{13} \mathrm{CO}_{2}$ (Boutton, 1996).

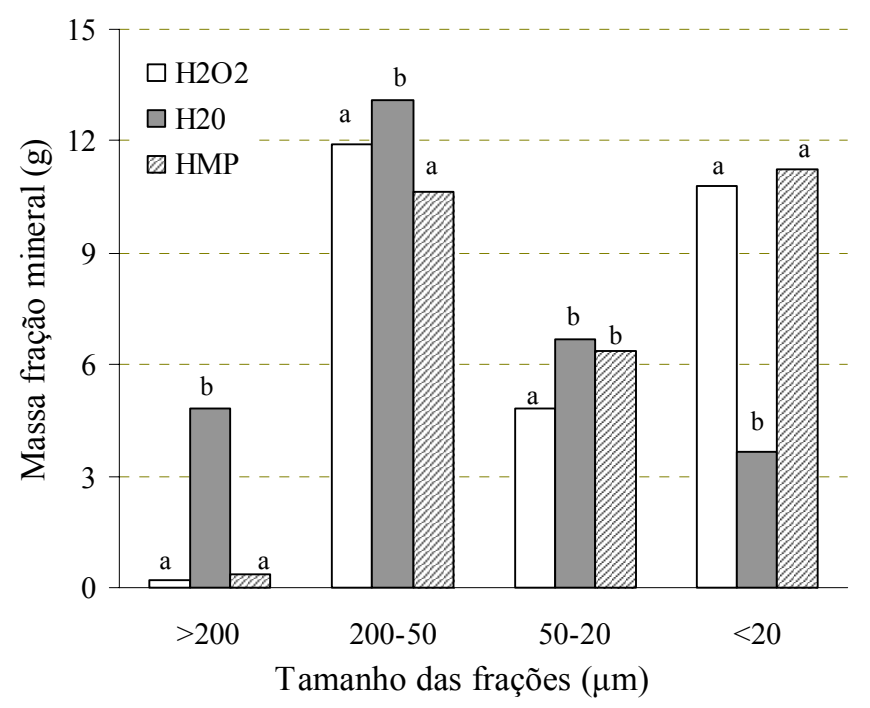

Figura 13. Distribuição da massa da fração mineral do solo de pastagem com a matéria orgânica destruída $\left(\mathrm{H}_{2} \mathrm{O}_{2}\right)$ e, sem destruição da $\mathrm{MO}$, com dispersão em água $\left(\mathrm{H}_{2} \mathrm{O}\right)$ e hexametafosfato de sódio (HMP). As letras indicam diferenças significativas entre tratamentos $(p<0,05)$, para cada tamanho de fração. 


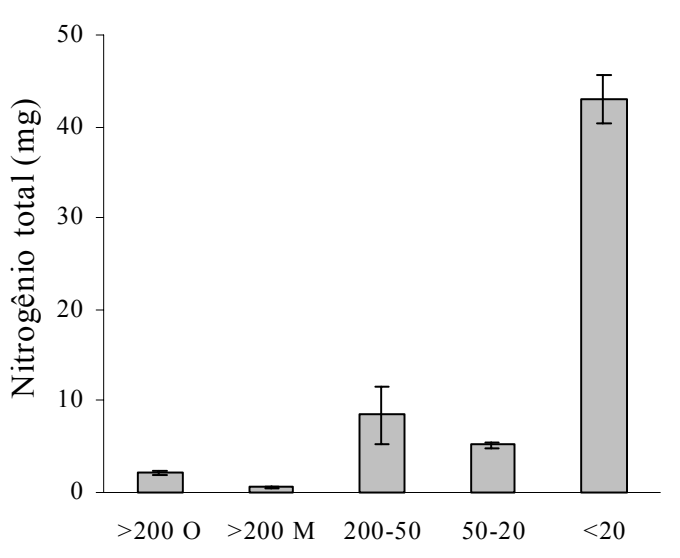

Tamanho das frações $(\mu \mathrm{m})$

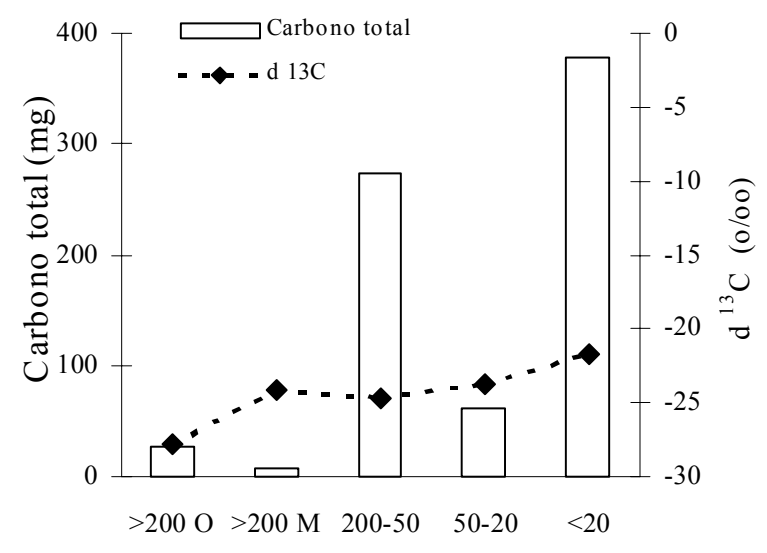

Tamanho das frações $(\mu \mathrm{m})$

Figura 14. Nitrogênio, carbono e $\delta{ }^{13} \mathrm{C}$ nas frações do solo de pastagem do SE da província de Buenos Aires (Argentina) disperso com HMP.

Tomando-se por base os resultados anteriores: níveis adequados de recuperação de massa, C e N (Gavinelli et al., 1995) e a boa correlação da distribuição das frações minerais com a $\mathrm{MO}$ do solo destruída com $\mathrm{H}_{2} \mathrm{O}_{2}$, considerou-se que a dispersão do solo com HMP é um método adequado para o fracionamento granulométrico de um solo temperado. Como efeito, os fracionamentos das amostras de solos foram realizados com esse agente dispersante.

\section{Fracionamento das amostras}

A distribuição da massa de solo apresentou grandes variações nas frações de maior conteúdo orgânico: >200L e 200-50L, tanto de 0-10 como de 10-20 cm, em resposta ao manejo do solo (Figura 15). A diferença em massa foi devida à acumulação de MO. Em seis anos desde o começo do experimento, em $\mathrm{P}$ verificou-se acumulação de MO, principalmente nas frações de maior tamanho, enquanto SD mostrou tendência similar, ainda que com valores menores e não significativos estatisticamente. O manejo $\mathrm{P}$ apresentou frações leves nos tamanhos $>200$ e 200-50 maiores que LC e SD na profundidade 0-10 cm, enquanto de 10-20 cm essas diferenças não foram significativas, e houve tendência a maior acumulação de MO em LC que em SD (Figura 15). As 
massas das frações $>200 \mathrm{P}$ e 200-50P, constituídas principalmente por minerais, não diferiram entre manejos como era de esperar, visto que o manejo não altera a composição mineralógica do solo, exceto quando acontece erosão.

Nas frações 50-20 e $<20 \mu \mathrm{m}, \mathrm{SD}$ apresentou diferenças significativas com respeito a P. Por se tratarem de frações organo-minerais, onde se encontraria principalmente matéria orgânica altamente humificada e resistente à degradação (Tisdall \& Oades, 1982), é difícil compreender o motivo dessas diferenças originadas no manejo do solo, em tão curto período de tempo. Na profundidade de $10-20 \mathrm{~cm}$, as diferenças foram menores entre tratamentos e somente na fração 200-50L é que houve diferença a favor de P (Figura 15). As frações pesadas (>200 e 200-50) não apresentaram diferenças em nenhuma das variáveis a esta profundidade.

De 0-10 cm, P apresentou maior conteúdo de C e N que SD e LC nas frações $>200 \mathrm{~L}$ e $200-50 \mathrm{~L}$, e de $\mathrm{N}$ na fração menor que $20 \mu \mathrm{m}$, não encontrando-se diferenças entre SD e LC (Tabela 3). Fabrizzi et al. (2003) encontraram diferenças significativas entre SD e LC nos conteúdos de C e N, nas frações de 212-2000 e 53-212 $\mu$ m, após 8 anos de instalada a SD em um solo muito degradado de Balcarce com história de 25 anos prévios de LC. Em solos similares, Eiza et al. (2004) encontraram que a SD acumulou maior quantidade de $\mathrm{C}$ na fração $>53 \mu \mathrm{m}$ quando o solo foi fertilizado com $\mathrm{N}$.

As frações >200P e 200-50P, constituídas principalmente por fração mineral, não apresentaram diferenças em C, N nem em $\delta^{13} \mathrm{C}$. Só na fração 200-50L o tratamento $\mathrm{P}$ apresentou $\delta^{13} \mathrm{C}$ mais negativo que SD e LC, seguramente como conseqüência da composição botânica da pastagem, com predomínio de Festuca arundinácea e Trifolium repens, de metabolismo $\mathrm{C} 3$ (Tabela 3). As relações $\mathrm{C}: \mathrm{N}$ foram diminuindo desde as frações de maior tamanho para as de menor, (excetuando as $>200 \mathrm{P}$ e 200-50P, que são predominantemente minerais), mas não se detectaram diferenças originadas pelos tratamentos de manejo em nenhuma fração. 

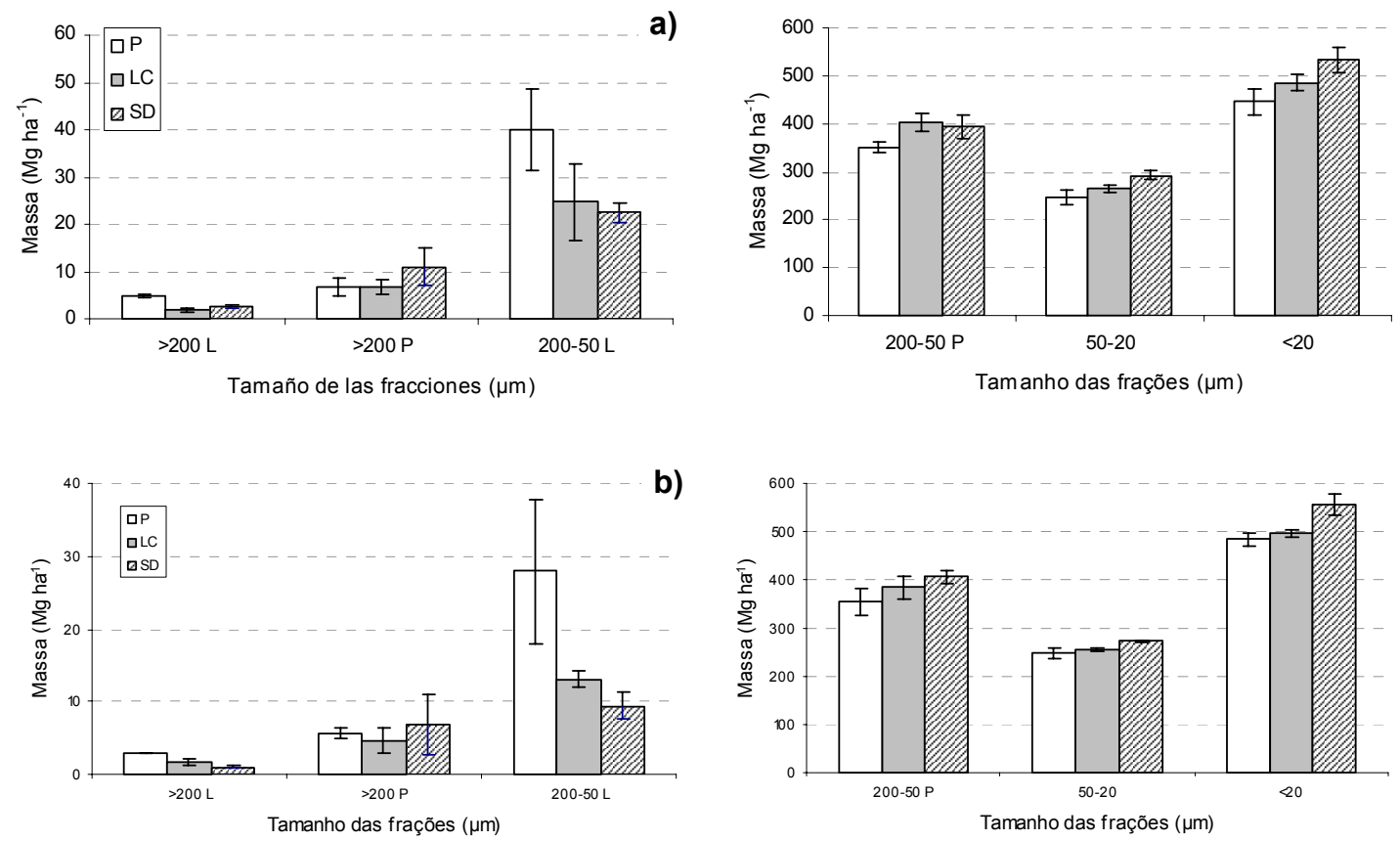

Figura 15. Distribuição da massa do solo depois do fracionamento nos tratamentos pastagem (P), lavoura convencional (LC) e semeadura direta (SD) às profundidades de (a) $0-10 \mathrm{~cm} \mathrm{e} \mathrm{(b)} 10-20 \mathrm{~cm}$.

As grandes quantidades de $\mathrm{N}$ e $\mathrm{C}$ encontradas nas frações $<50 \mu \mathrm{m}$, em todos os tratamentos de manejo, entre 82 e $95 \%$ do C e entre 87 e $97 \%$ do N, explicam a resposta à fertilização nitrogenada habitualmente encontrada nestes solos apesar dos altos conteúdos de $\mathrm{MO}$ e N. O aporte por mineralização das frações $<50 \mu \mathrm{m}$ é baixo devido a que possuem MO amorfa, altamente humificada e fortemente unida às argilas, com tempos de reciclagem muito lentos (entre 20 e 40\% cada 20 anos) (Feller, 1994).

As menores proporções de $\mathrm{C}$ e $\mathrm{N}$ na fração $<50 \mu \mathrm{m}$ encontradas na pastagem estão em concordância com as altas taxas de mineralização bruta do $\mathrm{N}$ nesse manejo (Figura 7). Incrementos no C orgânico de frações leve, média e pesada (fracionamento densimétrico) sob pastagem em comparação com o mesmo solo sob SD e LC, também foram verificados em solos similares aos do presente experimento, ainda que as maiores diferenças ocorreram nas frações média e leve, o que explicaria a maior mineralização de C encontrado (Alvarez et al., 1998). 
Depois de seis anos de implementação dos manejos, não se observaram diferenças estatisticamente significativas entre LC e SD, havendo uma tendência para que a $\mathrm{SD}$ acumule mais $\mathrm{C}$ e $\mathrm{N}$ nas frações leves. Essa tendência implicaria em maior disponibilidade de MO nas frações mais facilmente mineralizáveis, como se pode comprovar pelas diferenças na mineralização bruta entre SD e LC (Figura 7). É possível que as menores temperaturas habitualmente encontradas sob SD com respeito à LC, favoreçam o seqüestro de $\mathrm{C}$ por parte de $\mathrm{SD}$, ainda que nos primeiros anos de implementação do sistema sejam pequenas e não suficientes para serem detectadas pelas análises estatísticas.

Tabela 3. Carbono, nitrogênio, $\delta^{13} \mathrm{C}$ e relação $\mathrm{C}: \mathrm{N}$ nas frações granulométricas, à profundidade de 0-10 cm, nos tratamentos com pastagem (P), lavoura convencional (LC) e semeadura direta (SD). As letras minúsculas indicam diferenças significativas a nível $\mathrm{P} \prec 0,05$, segundo teste de Tukey ( $\mathrm{n}=3$ ).

\begin{tabular}{|c|c|c|c|c|c|c|c|c|c|}
\hline \multirow[t]{2}{*}{ Fração } & \multirow[t]{2}{*}{ Manejo } & C orgâr & aico & $\mathrm{N}$ tot & & \multirow{2}{*}{\multicolumn{2}{|c|}{$\begin{array}{c}\delta^{13} \mathrm{C} \\
\% 0\end{array}$}} & \multirow{2}{*}{\multicolumn{2}{|c|}{ C:N }} \\
\hline & & \multicolumn{4}{|c|}{$\mathrm{kg} \cdot \mathrm{ha}^{-1}$} & & & & \\
\hline \multirow[t]{3}{*}{$>200 \mathrm{~L}$} & $P$ & 1309 & $\mathrm{a}$ & 71 & $\mathrm{a}$ & $-26,71$ & $\mathrm{a}$ & 18.5 & \\
\hline & LC & 443 & $\mathrm{~b}$ & 28 & $\mathrm{~b}$ & $-27,40$ & $\mathrm{a}$ & 15,6 & $\mathrm{a}$ \\
\hline & SD & 591 & $\mathrm{~b}$ & 35 & $\mathrm{~b}$ & $-23,77$ & $\mathrm{a}$ & 16,9 & $\mathrm{a}$ \\
\hline \multirow[t]{3}{*}{$>200 \mathrm{P}$} & $\mathrm{P}$ & 23 & $a b$ & 0,51 & $\mathrm{a}$ & $-24,85$ & $\mathrm{a}$ & 27,8 & $\mathrm{a}$ \\
\hline & $\mathrm{LC}$ & 36 & $\mathrm{a}$ & 0,73 & $\mathrm{a}$ & $-21,13$ & $\mathrm{a}$ & 51,8 & $\mathrm{a}$ \\
\hline & SD & & b & 0,12 & $\mathrm{a}$ & $-24,66$ & $\mathrm{a}$ & 77,4 & $\mathrm{a}$ \\
\hline \multirow[t]{3}{*}{$200-50 \mathrm{~L}$} & $\mathrm{P}$ & 2613 & $\mathrm{a}$ & 225 & $\mathrm{a}$ & $-25,51$ & $\mathrm{a}$ & 11,6 & $\mathrm{a}$ \\
\hline & LC & 1399 & $\mathrm{~b}$ & 109 & $\mathrm{~b}$ & $-22,56$ & $\mathrm{~b}$ & 12,9 & $\mathrm{a}$ \\
\hline & SD & 1735 & $\mathrm{~b}$ & 128 & $\mathrm{~b}$ & $-21,98$ & $\mathrm{~b}$ & 13,5 & $\mathrm{a}$ \\
\hline \multirow[t]{3}{*}{$200-50 \mathrm{P}$} & $\mathrm{P}$ & 572 & $\mathrm{a}$ & 28 & $\mathrm{a}$ & $-21,11$ & $\mathrm{a}$ & 21,9 & \\
\hline & $\mathrm{LC}$ & 878 & $\mathrm{a}$ & 40 & $\mathrm{a}$ & $-20,84$ & $\mathrm{a}$ & 22,1 & \\
\hline & SD & 564 & $\mathrm{a}$ & 21 & $\mathrm{a}$ & $-21,06$ & $\mathrm{a}$ & 26,9 & $\mathrm{a}$ \\
\hline \multirow[t]{3}{*}{$50-20$} & $\mathrm{P}$ & 3205 & $\mathrm{a}$ & 248 & $\mathrm{a}$ & $-23,95$ & $\mathrm{a}$ & 12,9 & $\mathrm{a}$ \\
\hline & $\mathrm{LC}$ & 3173 & $\mathrm{a}$ & 270 & $\mathrm{a}$ & $-22,41$ & $\mathrm{~b}$ & 11,8 & $\mathrm{a}$ \\
\hline & SD & 2223 & $\mathrm{a}$ & 193 & $\mathrm{a}$ & $-22,39$ & $\mathrm{~b}$ & 11,5 & $\mathrm{a}$ \\
\hline \multirow[t]{3}{*}{$<20$} & $\mathrm{P}$ & 19963 & $\mathrm{a}$ & 2274 & $\mathrm{a}$ & $-22,04$ & $\mathrm{a}$ & 8,8 & $\mathrm{a}$ \\
\hline & LC & 22091 & $\mathrm{a}$ & 1974 & $\mathrm{a}$ & $-21,33$ & $\mathrm{a}$ & 11,2 & $\mathrm{a}$ \\
\hline & SD & 23584 & $\mathrm{a}$ & 2172 & $\mathrm{a}$ & $-21,15$ & $\mathrm{a}$ & 10,9 & $\mathrm{a}$ \\
\hline
\end{tabular}




\subsection{Conclusões}

O método de Feller et al., (1979) foi adequado para fracionar solos temperados.

Em todos os manejos, entre 85 e $93 \%$ do $\mathrm{C}$ e entre 79 e $93 \%$ do $\mathrm{N}$ está nas frações $<50 \mu \mathrm{m}$, indicando a alta proteção física da matéria orgânica desses solos, o que explica a sua baixa taxa de reciclagem.

A pastagem acumulou $112 \%$ mais $\mathrm{C}$ e $116 \%$ mais $\mathrm{N}$ nas frações leves $>50 \mu \mathrm{m}$ que LC.

$\mathrm{O}$ manejo $\mathrm{SD}$ não modificou os conteúdos de $\mathrm{C}$ e $\mathrm{N}$ do solo, nem a distribuição deles nas frações da matéria orgânica.

Os manejos não modificaram a composição em $\mathrm{C}$ e $\mathrm{N}$ nas frações $<50 \mu \mathrm{m}$. 


\section{RELAÇÕES ENTRE OS CONTEÚDOS DE C E N NAS FRAÇÕES DA MATÉRIA ORGÂNICA DO SOLO E OS PROCESSOS BRUTOS DO CICLO DO NITROGÊNIO}

\section{Resumo}

Investigou-se a influência dos conteúdos de $\mathrm{C}$ e $\mathrm{N}$ total, e a distribuição de $\mathrm{C}$ e $\mathrm{N}$ entre as frações granulométricas, nas taxas de mineralização (TMB) e consumo bruto (TCB) de nitrogênio. Avaliaram-se as correlações simples entre TMB e TCB quantificadas em quatro vezes durante um período de incubação de 35 dias, em relação aos conteúdos de $\mathrm{C}, \mathrm{N}$ e as relações $\mathrm{C}: \mathrm{N}$ do solo total e de frações granulométricas. Também foram realizadas análises de regressão linear múltipla. Relações simples entre $\mathrm{C}, \mathrm{N}$ e relação C:N das frações granulométricas da matéria orgânica explicaram, em média, menos que $60 \%$ da variabilidade das TMB e TCB. O conteúdo de C nas frações 2000-200L e 200-50L $\mu \mathrm{m}$ foram as variáveis que, com maior freqüência, se associaram às TMB e TCB. A inclusão de mais de uma variável em equações de regressão múltipla não melhorou muito o poder explicativo quando foram analisados todos os manejos juntos, mais sim quando eles foram considerados separadamente. Nas equações de regressão múltipla de $\mathrm{LC}$, freqüentemente aparecem $\mathrm{C}$ e $\mathrm{N}$ das frações de menor tamanho, indicando a degradação da matéria orgânica como conseqüência das lavouras, enquanto que para a pastagem são as frações leves e maiores de $50 \mu \mathrm{m}$, as que são incluídas com maior freqüência nos modelos. A SD apresentou uma situação intermédia entre as duas anteriores, mostrando tendência de melhora na condição do solo. Não foram ajustados modelos simples para explicar a variabilidade das TMB e TCB, o que 
sugere uma interação muito complexa do manejo e os processos brutos do nitrogênio no solo.

\section{Summary}

The relationship between $\mathrm{C}$ and $\mathrm{N}$ soil contents and gross nitrogen mineralization (TMB) and consumption rates (TCB) was investigated. In order to study the distribution of total $\mathrm{C}$ and $\mathrm{N}$ contents, soil samples from pasture (P), no tillage (SD) and conventional tillage (LC) were fractionated into six fractions: $2000-200 \mu \mathrm{m}$, light (L) and heavy (P), 200-50 $\mu \mathrm{m}$, light (L) and heavy (P), 50-20 $\mu \mathrm{m}$ and $<20 \mu \mathrm{m}$. TMB and TCB were estimated four times within a period of 35 days. The simple correlation between $\mathrm{C}, \mathrm{N}$ content and $\mathrm{C}: \mathrm{N}$ relation vs. gross nitrogen processes was analyzed. Stepwise multiple linear regression analysis was used as well. Simple relationships between $\mathrm{C}, \mathrm{N}$ and $\mathrm{C}: \mathrm{N}$ relation of the organic matter fractions explained on average less than $60 \%$ of the variability on TMB and TCB. The C content in the 2000-200L and 200-50L fractions were frequently associated to TMB and TCB. When all the management systems were analyzed together, the multiple regression models did not explain the TMB and TCB variability. When management systems were analyzed separately, the explained variability was always higher than $90 \%$. C and $\mathrm{N}$ contents on $<50 \mu \mathrm{m}$ fractions were frequently included on LC management models, while in the pasture models $\mathrm{C}$ content on $>50 \mu \mathrm{m}$ light fractions was the most frequently included. SD represented an intermediate situation between LC and P, demonstrating a tendency to improve the soil condition. A simple model relating gross processes to the variables analyzed was not found, suggesting a complex interaction between gross nitrogen processes and soil management system effects. 


\subsection{Introdução}

Quando uma área que esteve sob cultivo por um longo período de tempo é convertida em pastagem permanente, o conteúdo de matéria orgânica do solo aumenta devido aos aportes de material vegetal e às taxas mais lentas de decomposição (Haynes \& Beare, 1996). A aplicação de práticas de conservação como a semeadura direta em solos agrícolas, também pode aumentar o conteúdo de C orgânico (Beare et al., 1994) como conseqüência da redução ou eliminação das operações de revolvimento do solo, o que conduzirá à formação de agregados (Six et al., 2000) e, também, por modificar o ambiente total do solo, no que concerne à: densidade aparente, distribuição dos poros por tamanho, temperatura, regime de água e de aeração (Mielke et al., 1986). O incremento no conteúdo de matéria orgânica é um processo lento, difícil de detectar nas etapas iniciais de mudança no manejo do solo. Nos últimos anos, vêm-se procurando encontrar parâmetros de solo de simples estimativa que permitam fazer uma avaliação precoce das modificações na qualidade do solo, em resposta às praticas de manejo, tais como a semeadura direta ou a implantação de pastagens, depois de extensos ciclos agrícolas de práticas com lavouras convencionais.

$\mathrm{Na}$ busca desses parâmetros foram desenvolvidos vários trabalhos que quantificam frações de MO e tentam relacionar essas frações com indicadores da capacidade do solo para suprir às plantas com nitrogênio. Geralmente, é utilizado o nitrogênio potencialmente mineralizável (Feller \& Beare, 1997) ou a mineralização líquida para avaliar a capacidade do solo em prover nitrogênio às plantas. O conteúdo de nitrogênio na fração leve de 150-3000 $\mu \mathrm{m}$ correlacionou-se com a mineralização líquida do solo total para sete sistemas diferentes de manejo de rotações de culturas (Barrios et

al., 1996). O carbono na fração POM (matéria orgânica particulada, entre 2000 e 212 $\mu \mathrm{m})$ resultou ser um indicador sensível aos efeitos do manejo do solo em solos degradados do SE de Buenos Aires (Fabrizzi et al., 2003).

Existem poucos trabalhos que relacionam as frações de matéria orgânica com os processos brutos do ciclo do nitrogênio. Recentemente, Accoe et al (2004) 
relacionaram taxas de processos brutos com frações de $\mathrm{MO}$ em pastagens de diferentes idades, encontrando que a fração de matéria macro-orgânica de alta densidade poderia ser usada para predizer a acumulação de $\mathrm{MO}$, depois da conversão de áreas agrícolas em pastagens permanentes.

O presente trabalho teve como objetivo avaliar as relações dos conteúdos de $\mathrm{C}$ e $\mathrm{N}$ no solo total e nas frações granulométricas, com as taxas de mineralização e consumo bruto de nitrogênio.

\subsection{Material e Métodos}

Utilizaram-se os valores de $\mathrm{C}, \mathrm{N}$ e de relação $\mathrm{C}: \mathrm{N}$ obtidos no capítulo 4 e as taxas de mineralização e consumo bruto obtidas no capítulo 3 na avaliação da:

a) Correlação simples das taxas de mineralização bruta e de consumo bruto em quatro tempos de medição $(0,7,21$ e 35 dias após o início da incubação), expressos

como mg kg ${ }^{-1} \mathrm{dia}^{-1}$, e os conteúdos de carbono e nitrogênio (expressos como $\mathrm{g} \mathrm{kg}^{-1}$ de $\mathrm{C}$ ou de $\mathrm{N}$ ) e as relações $\mathrm{C}: \mathrm{N}$ do solo total e das frações granulométricas.

b) Regressão linear múltipla com o procedimento de seleção Stepwise do pacote SAS, para avaliar se alguma combinação das variáveis explicativas quantificadas poderia explicar uma maior proporção da variabilidade nas taxas de mineralização e consumo brutos.

O procedimento Stepwise inicia a seleção sem nenhuma variável no modelo e agrega, sistematicamente, efeitos significativamente associados com a variável de resposta. Depois que um efeito é adicionado no modelo, ele pode ser removido se no conjunto ele não satisfazer os requisitos de significância. O processo de seleção continua até que nenhum efeito no modelo satisfaça o nível de significância pré-estabelecido, ou até que um efeito que estava no modelo seja eliminado no passo seguinte. O nível de significância utilizado foi 0,15 para a entrada do efeito no modelo. 


\subsection{Resultados e Discussão}

Os conteúdos de C e N nas frações >200 L, 200-50 L, 200-50 P e 50-20 $\mu \mathrm{m}$ mostraram-se altamente correlacionados, com valores de coeficientes $\mathrm{r}$ entre $0,885 \mathrm{e}$ 0,975, e valores de probabilidade $<0,0001$, mas a correlação entre os conteúdos de $\mathrm{C}$ e $\mathrm{N}$ total não foi significativa. $\mathrm{O} C$ total correlacionou-se com o $\mathrm{C}$ em todas as frações separadas, exceto aquela $>200 \mathrm{P}$, como era lógico de se esperar já que essa fração é formada, fundamentalmente, por areia. $\mathrm{O} N$ total apresentou só uma correlação estreita $(\mathrm{r}=0,885, \mathrm{p}<0,0001)$ com o $\mathrm{N}$ da fração $<20 \mu \mathrm{m}$, indicando que é essa a fração que contém a maior parte do nitrogênio nos solos sob estudo; e correlações débeis com o N nas frações $>200 \mathrm{~L}(\mathrm{r}=0,428, \mathrm{p}=0,076)$ e 200-50L ( $\mathrm{r}=0,464, \mathrm{p}=0,053)$, que são também frações que apresentaram consideráveis conteúdos de nitrogênio (Tabela 3).

As taxas de mineralização bruta estiveram correlacionadas com as taxas de consumo nos quatro tempos de medições, com coeficientes entre 0,645 e 0,826 e valores de probabilidade sempre menores que 0,001 , resultado lógico se for considerado que o amônio produzido é o substrato para os processos de consumo de imobilização e nitrificação, principalmente.

A TMB e TCB calculada no dia 7 desde o início da incubação não apresentou correlação com nenhuma das variáveis estudadas motivo pelo qual ela não foi incluída na Tabela 4. Igualmente, as variáveis C, N e relação C:N da fração >200P e 200-50P não tiveram correlação com a TMB nem com a TCB em nenhum tempo, não sendo incluídas, pois, na referida tabela. Estes resultados eram previsíveis já que se tratam de frações, principalmente, de origem mineral que não deveriam ter efeito nos processos biológicos estudados; a fração $>200 \mu \mathrm{m}$ é constituída por areia grossa e a fração 200-50 $\mu \mathrm{m}$ por complexos organo-minerais com granulometria de areia fina e silte, considerados como muito estáveis e de pouca participação nos processos de curto prazo (Feller \& Beare, 1997). 
Os conteúdos de $\mathrm{C}$ e de $\mathrm{N}$ total só estiveram significativamente correlacionados com a TMB nos dias $21(\mathrm{r}=0,661)$ e $0(\mathrm{r}=0,601)$, respectivamente, enquanto que nunca estiveram correlacionados com as TCB, diferentemente dos resultados de Accoe et al. (2004) em que o C e $\mathrm{N}$ total explicaram sempre mais de $80 \%$ da variabilidade nas taxas de mineralização, nitrificação e imobilização. È possível que naquele trabalho, tenha se apresentado uma variação mais contínua nos conteúdos de $\mathrm{C}$ e $\mathrm{N}$, já que foram estudados solos agrícolas transformados em pastagens, com diferentes tempos.

A variável que sempre apresentou correlação significativa com TMB e TCB foi o conteúdo de $\mathrm{C}$ na fração >200 L (Tabela 4). Essa fração é constituída por restos de raízes e plantas, com taxas de reciclagem muito rápidas (Feller, 1994), conhecida como POM (matéria orgânica particulada). Essa fração é referida, freqüentemente, como uma fração lábil, apresenta rápida resposta às mudanças no manejo do solo, sendo utilizada em avaliações precoces de melhoria na qualidade do solo (Cambardella \& Elliot, 1992).

$\mathrm{O} \mathrm{N}$ nas duas frações leves de maior tamanho somente correlacionou-se com a TMB no dia 0 , não se correlacionando com a TCB. O conteúdo de C na fração 200-50 L apresentou com freqüência correlações significativas com as TMB, essas frações também são consideradas como POM por alguns pesquisadores e resultaram adequadas para expressar mudanças nos conteúdos de matéria orgânica antes que os efeitos sejam sentidos no $\mathrm{C}$ total. $\mathrm{O}$ conteúdo de $\mathrm{C}$ em frações de menor tamanho só se mostrou significativamente correlacionado com a TMB no dia $21 \quad(\mathrm{r}=0,591$ de 50-20 $\mu \mathrm{m}$ e $\mathrm{r}=0,519$ na fração $<20 \mu \mathrm{m})$. A relação C:N total só relacionou-se com a TMB no dia 21 . A relação C:N na fração >200 L correlacionou-se significativamente com TMB e TCB, exceto no dia 0 .

As únicas correlações com elevados coeficientes de Pearson foram àquelas calculadas entre a relação C:N da fração >200L e a TMB nos dias 21 e 35, sendo que o resto das correlações explicou em média $56 \%$ da variabilidade, indicando que talvez simples relações não estivessem em condições de explicar as diferenças em TMB e TCB. 
Tabela 4 Coeficientes de correlação de Pearson e significância das correlações entre as taxas de mineralização e consumo bruto, e os conteúdos de $\mathrm{C}, \mathrm{N}$ e relações $\mathrm{C}: \mathrm{N}$ do solo sem fracionar (total) e das frações de matéria orgânica.

\begin{tabular}{|c|c|c|c|c|c|c|}
\hline \multirow[b]{3}{*}{$\mathrm{C}_{\text {total }}$} & \multicolumn{3}{|c|}{ Taxa de mineralização bruta } & \multicolumn{3}{|c|}{ Taxa de consumo bruto } \\
\hline & dia 0 & dia 21 & dia 35 & dia 0 & dia 21 & dia 35 \\
\hline & 0,339 & $0,661 * * *$ & $-0,904$ & $-0,030$ & 0,408 & $-0,090$ \\
\hline $\mathrm{N}_{\text {total }}$ & $0,601 * * *$ & 0,066 & $-0,287$ & $0,505 *$ & 0,327 & $-0,287$ \\
\hline $\mathrm{C}_{\text {total }}: \mathrm{N}_{\text {total }}$ & $-0,142$ & $0,429 * *$ & 0,130 & $-0,399$ & 0,108 & 0,130 \\
\hline $\mathrm{C}_{>200 \mathrm{~L}}$ & $0,702 * * *$ & $0,626 * * *$ & $-0,519 *$ & $0,457 *$ & $0,534 * *$ & $-0,519 *$ \\
\hline $\mathrm{C}_{200-50 \mathrm{~L}}$ & $0,581 * *$ & $0,527 * *$ & 0,432 & $0,412 *$ & 0,404 & $-0,433$ \\
\hline $\mathrm{C}_{200-50 \mathrm{P}}$ & $-0,042$ & 0,256 & 0,321 & $-0,368$ & 0,074 & 0,321 \\
\hline $\mathrm{C}_{50-20}$ & 0,339 & $0,591 * *$ & $-0,053$ & $-0,067$ & 0,336 & $-0,053$ \\
\hline $\mathrm{C}_{<20}$ & 0,082 & $0,519 * *$ & 0,188 & $-0,319$ & 0,268 & 0,188 \\
\hline $\mathrm{N}_{>200 \mathrm{~L}}$ & $0,636 * * *$ & 0,413 & $-0,343$ & 0,395 & 0,286 & $-0,343$ \\
\hline $\mathrm{N}_{200-50 \mathrm{~L}}$ & $0,613 * * *$ & 0,422 & $-0,403$ & $0,485 * *$ & 0,345 & $-0,403$ \\
\hline $\mathrm{N}_{200-50 \mathrm{P}}$ & 0,035 & 0,131 & 0,266 & $-0,195$ & 0,135 & 0,266 \\
\hline $\mathrm{N}_{50-20}$ & 0,192 & $0,556 * *$ & 0,028 & $-0,207$ & 0,271 & 0,028 \\
\hline $\mathrm{N}_{<20}$ & 0,373 & $-0,202$ & $-0,194$ & 0,434 & 0,157 & $-0,194$ \\
\hline$C: N_{>200 \mathrm{~L}}$ & 0,449 & $0,827 * * *$ & $-0,929 * * *$ & 0,234 & $0,712 * * *$ & $-0,533 *$ \\
\hline $\mathrm{C}: \mathrm{N}_{200-50 \mathrm{~L}}$ & $-0,115$ & $0,464 * *$ & $-0,609 * *$ & $-0,297$ & 0,241 & $-0,116$ \\
\hline $\mathrm{C}: \mathrm{N}_{200-50 \mathrm{P}}$ & $-0,114$ & 0,307 & $-0,085$ & $-0,238$ & $-0,056$ & $-0,085$ \\
\hline $\mathrm{C}: \mathrm{N}_{50-20}$ & 0,322 & $-0,038$ & $-0,274$ & 0,449 & 0,266 & $-0,274$ \\
\hline $\mathrm{C}: \mathrm{N}_{<20}$ & $-0,251$ & 0,419 & 0,247 & $-0,484 *$ & 0,035 & 0,217 \\
\hline
\end{tabular}

*, **, ***: Coeficientes de correlação de Pearson significativos a p<0,05, 0,01 e 0,001 , respectivamente.

Ao se analisar as equações lineares múltiplas, incluindo todos os tratamentos de manejo e profundidades estudadas (Tabela 5), pode-se observar que a variável que aparece com maior freqüência é a relação C:N na fração $>200 \mathrm{~L}$, tanto para TMB como para TCB, nos dias 21 e 35. Este é um resultado que, devido ao fato dessa fração ter taxas de reciclagem rápidas, é freqüentemente citada na literatura, mesmo que nem sempre explicando as taxas de mineralização bruta, mas a mineralização líquida ou o nitrogênio potencialmente mineralizável. A relação íntima existente entre mineralização bruta e líquida, como fora demonstrado por Accoe et al. (2004) e Zaman \& Chang (2004), indica que, possivelmente, os mesmos fatores regulam os processos de produção e de consumo de $\mathrm{N}$. 
É notório que a fração 200-50P apareça várias vezes integrando os modelos, mesmo que ela não tenha apresentado coeficientes de Pearson significativos em nenhuma das variáveis (Tabela 4). Apesar de este tamanho de partículas tenha sido separada por flotação, em uma fração leve que inclui componentes orgânicas (200-50L), e uma fração pesada (>200-50P), é possível que tenham permanecido nesta última agregados de pequeno tamanho, resistentes ao efeito do HMP e do ultra-som, que efetivamente estão aportando $\mathrm{N}$ para a mineralização e, provavelmente, também C como fonte de energia para os microrganismos.

Tabela 5. Modelos de regressão linear múltipla para as taxas de mineralização (TMB) e de consumo bruto (TCB), influenciadas pelos conteúdos de $\mathrm{C}, \mathrm{N}$ e relações $\mathrm{C}: \mathrm{N}$, no solo total e nas frações granulométricas.

\begin{tabular}{|c|c|c|c|c|c|}
\hline & Parâmetro & Coeficiente & $\mathrm{R}^{2}$ parciais & $\mathrm{R}^{2}$ modelo & $\mathrm{P}$ \\
\hline \multirow[t]{4}{*}{ TMB 0} & Constante & $-0,91386$ & & 0,7247 & 0,0003 \\
\hline & $\mathrm{C}_{>200 \mathrm{~L}}$ & 0,03105 & 0,4924 & & \\
\hline & $\mathrm{N}_{<20}$ & 0,02952 & 0,1819 & & \\
\hline & $\mathrm{C}_{>200 \mathrm{P}}$ & $-0,0781$ & 0,0504 & & \\
\hline \multirow[t]{2}{*}{ TMB 7} & Constante & 2,16819 & & 0,1747 & 0,0844 \\
\hline & $\mathrm{N}_{200-50 \mathrm{P}}$ & $-1,02682$ & 0,1747 & & \\
\hline \multirow[t]{2}{*}{ TMB 21} & Constante & 0,26113 & & 0,6841 & $<0,0001$ \\
\hline & $\mathrm{C}: \mathrm{N}_{>200 \mathrm{~L}}$ & 0,22577 & 0,6841 & & \\
\hline \multirow[t]{4}{*}{ TMB 35} & Constante & 6,26495 & & 0,9159 & $<0,0001$ \\
\hline & $\mathrm{C}: \mathrm{N}_{>200 \mathrm{~L}}$ & $-0,21467$ & 0,8629 & & \\
\hline & $\mathrm{C}: \mathrm{N}_{200-50 \mathrm{P}}$ & $-0,0495$ & 0,0184 & & \\
\hline & $\mathrm{C}_{50-20}$ & 0,01155 & 0,0175 & & \\
\hline \multirow[t]{2}{*}{ TCB 0} & Constante & $-0,46393$ & & 0,2551 & 0,0325 \\
\hline & $\mathrm{N}_{\text {total }}$ & 0,05634 & 0,2551 & & \\
\hline \multirow[t]{3}{*}{ TCB 7} & Constante & $-6,97215$ & & 0,3689 & 0,1407 \\
\hline & $\mathrm{C}: \mathrm{N}_{50-20}$ & 0,49904 & 0,1305 & & \\
\hline & $\mathrm{C}: \mathrm{N}_{200-50 \mathrm{P}}$ & 0,16900 & 0,2384 & & \\
\hline \multirow[t]{3}{*}{ TCB 21} & Constante & $-2,88746$ & & 0,6686 & 0,0003 \\
\hline & $\mathrm{C}: \mathrm{N}_{>200 \mathrm{~L}}$ & 0,15318 & 0,5076 & & \\
\hline & $\mathrm{N}_{<20}$ & 0,05296 & 0,1610 & & \\
\hline \multirow[t]{4}{*}{ TCB 35} & Constante & 1,44892 & & 0,7078 & 0,0005 \\
\hline & $\mathrm{C}: \mathrm{N}_{>200 \mathrm{~L}}$ & $-0,15930$ & 0,2845 & & \\
\hline & $\mathrm{C}_{\text {total }}: \mathrm{N}_{\text {total }}$ & 0,36522 & 0,2911 & & \\
\hline & $\mathrm{C}: \mathrm{N}_{200-50 \mathrm{P}}$ & 1,19572 & 0,1322 & & \\
\hline
\end{tabular}


$\mathrm{Na}$ Tabela 5, também aparecem nos modelos, variáveis das frações menores de $50 \mu \mathrm{m}$, ainda que, com baixos coeficientes de regressão parcial. Estas frações têm tamanho silte e argila, e a matéria orgânica nelas tem natureza amorfa, altamente humificada e protegida em complexos organo-minerais, com taxas de reciclagem muito baixas, fatos pelos quais não era de esperar que elas aparecessem nos modelos.

Somente um dos modelos conseguiu explicar uma alta proporção na variabilidade da TMB, ou seja, o ajuste do dia 21, com 91,6 \% da variabilidade, explicada pela relação C:N nas frações >200L e 200-50L e pelo conteúdo de C na fração de 50-20 $\mu \mathrm{m}$. O resto dos ajustes explicou entre 17 e $71 \%$ da variabilidade, muito menos dos que foram comunicados por Accoe et al. (2004), em que os modelos explicaram sempre mais de $93 \%$ da variabilidade nas TMB e $88 \%$ nas taxas de imobilização bruta de solos sob pastagem perenes.

Com o intuito de conseguir equações com maior capacidade de predição, foram realizados, separadamente, para cada manejo estudado (P, SD e LC), outros processos de seleção de variáveis, com o mesmo método utilizado anteriormente (Tabela 6). Os novos ajustes apresentaram coeficientes de regressão elevados, explicando mais de $96 \%$ da variabilidade para os três manejos, exceto para a semeadura direta no dia 0 , em que o $\mathrm{R}^{2}$ foi de 0,5672. Mesmo que em alguns modelos tenham constado até quatro variáveis, observou-se em todos eles, que mesmo com duas variáveis foram conseguidos valores de capacidade de explicação maiores que $88 \%$. Esta melhora estaria indicando que são diferentes as variáveis que explicam a mineralização bruta, conforme o manejo a que foi submetido o solo.

$\mathrm{Na}$ lavoura convencional aparece com muita freqüência o conteúdo de nitrogênio nas frações de tamanho >200L e <20 $\mu \mathrm{m}$; a fração >200L foi fortemente afetada pelo manejo do solo e assume valores muito baixos comparativamente à pastagem e mesmo com a semeadura direta (Tabela 3). Apesar desta situação, essa fração é uma fonte importante e facilmente disponível de $\mathrm{N}$, uma vez que aparece nos modelos explicando uma parte importante da variabilidade nas TMB neste manejo. Já a fração $<20 \mu \mathrm{m}$, que não foi alterada pelo manejo do solo, aparece várias vezes nas 
equações, mais geralmente com coeficientes negativos o que indicaria que a sua presença diminui as taxas de mineralização. Nas situações em que essa fração assumiu coeficientes positivos, ela está sendo mineralizada pelos microrganismos o que confirma o proposto por Six et al. (2002) de que uma parte da matéria orgânica que está protegida por associação com partículas minerais de tamanho silte e argila $(<53 \mu \mathrm{m})$ é hidrolisável. A exposição destas frações, causada pela lavra do solo, favorece a disponibilidade para o ataque microbiano. Neste tamanho de partículas existe, também, uma outra fração bioquimicamente protegida que têm taxas de reciclagem muito lentas e é considerada não hidrolisável, sua composição química é tão complexa que ela permanece no solo por longos períodos, medidos por séculos. È esta segunda fração que explicaria como os solos do sudeste de Buenos Aires, apesar de submetidos a lavouras por muitos anos, permaneceram quantidades importantes de $\mathrm{MO}$, mas com muito pouco aporte à nutrição das culturas (Studdert et al., 1997). Deve-se ter em mente que apesar de o solo neste manejo estar mineralizando $\mathrm{N}$ de frações de menor tamanho, que representariam o estoque de nitrogênio do solo, mesmo assim as TMB foram baixas.

$\mathrm{Na}$ semeadura direta aparece com maior freqüência o conteúdo de $\mathrm{C}$ e de $\mathrm{N}$ nas frações >200L e 200-50L, o que estaria indicando que esse manejo tende a cumular maior quantidade de $\mathrm{C}$ e de $\mathrm{N}$ nessas frações (Tabela 3), o que leva a idéia que a TMB neste manejo é influenciada por essa presença. O fato de as frações $<20 \mu \mathrm{m}$ ingressarem menos freqüentemente nos modelos, estaria indicando que o solo tem outras fontes de $\mathrm{N}$ que os microrganismos disponibilizam. Cabe aclarar que apesar de as diferenças nas relações ajustadas, a semeadura direta não tem apresentado mudanças significativas na quantidade de $\mathrm{N}$ e $\mathrm{C}$ acumulado. Deve-se ter muita cautela quando se analisa o efeito da aplicação da semeadura direta em solos como os estudados, da ordem Mollisol, já que neles não sempre são verificados incrementos significativos nos estoques de $\mathrm{C}$ e $\mathrm{N}$ em curto prazo. Puget \& Lal (2004) não encontraram incrementos significativos nos estoques de $\mathrm{N}$ nesse tipo de solos, após 8 anos de conversão para a semeadura direta, apesar de que foi verificado nos $5 \mathrm{~cm}$ superficiais, incremento de $\mathrm{C}$ orgânico. Os mecanismos e vias de recuperação da MO, provavelmente, são mais complexos e 
dependentes de condições locais, de solo e do clima, sendo que as generalizações do efeito da semeadura direta nos estoques de $\mathrm{C}$ deverão ser usadas com muita prudência.

No solo sob pastagem, são as frações maiores de $50 \mu \mathrm{m}$ as que integraram os modelos, explicando a maior parte da variabilidade nas TMB, em concordância com os resultados de Accoe et al. (2004), Fabrizzi et al. (2003) e vários outros autores que relacionaram as frações particuladas com disponibilidade de nitrogênio.

Analisando-se as mudanças nos modelos através do tempo ( 0 a 35 dias), se observa que nem sempre foram as mesmas variáveis que explicaram a variabilidade das TMB. Este resultado indicaria que, em um solo que não está recebendo novos aportes orgânicos, a medida que o tempo transcorre, os microrganismos utilizam diferentes frações orgânicas.

Os modelos de regressão múltipla também melhoraram a capacidade de explicação da variação nas taxas de consumo bruto (Tabela 7), repetindo o comportamento dos modelos de TMB, onde uma ou duas variáveis explicaram mais de $88 \%$ na variabilidade e em conjunto mais de $89 \%$, exceto para a pastagem no dia 7 (49 $\%)$ e para SD no dia zero, em que nenhuma variável satisfez o nível pré-estabelecido de 0,15 de probabilidade.

De forma geral, não se evidenciou um padrão simples relacionando a TMB e a TCB com as variáveis das frações separadas. Observa-se que para $\mathrm{P}$ aparecem mais, freqüentemente, a variável C e N nas frações >200L e 200-50L, também chamadas de matéria orgânica particulada e com taxas de reciclagem maiores. A presença destas frações no solo após 6 anos de implantada a pastagem, indicaria uma melhora na quantidade e qualidade da matéria orgânica. No outro extremo, as TMB e TCB da LC aparecem freqüentemente relacionadas aos conteúdos de $\mathrm{C}$ e $\mathrm{N}$ nas frações de menor tamanho $(<50 \mu \mathrm{m})$ e taxas de reciclagem, o que seria conseqüência da baixa disponibilidade de frações lábeis. A semeadura direta apresenta uma situação intermédia entre as duas anteriores indicando que este manejo tende a melhorar a condição da MO de solo, mas ainda o período de tempo sob SD não é suficiente para essas diferenças serem significativas. 


\subsection{Conclusôes}

As relações simples entre $\mathrm{C}, \mathrm{N}$ e a relação $\mathrm{C}: \mathrm{N}$ das frações granulométricas da matéria orgânica explicaram em média menos de $60 \%$ da variabilidade das TMB e TCB. O conteúdo de C nas frações $>200 \mathrm{~L}$ e $200-50 \mu \mathrm{m}$ foram as variáveis que com maior freqüência se associaram às TMB e TCB.

A inclusão de mais de uma variável em equações de regressão múltipla não melhorou muito o poder explicativo, quando foram analisados todos os manejos juntos, mas sim quando eles foram considerados separadamente. $\mathrm{Na} \mathrm{LC}$, freqüentemente aparecem nas equações $\mathrm{C}$ e $\mathrm{N}$ das frações mais finas, enquanto que para pastagem são as frações leves maiores de $50 \mu \mathrm{m}$ es que ingressam com maior freqüência nos modelos. A SD apresenta uma situação intermédia entre as duas anteriores, revelando uma tendência de melhora na condição do solo. 


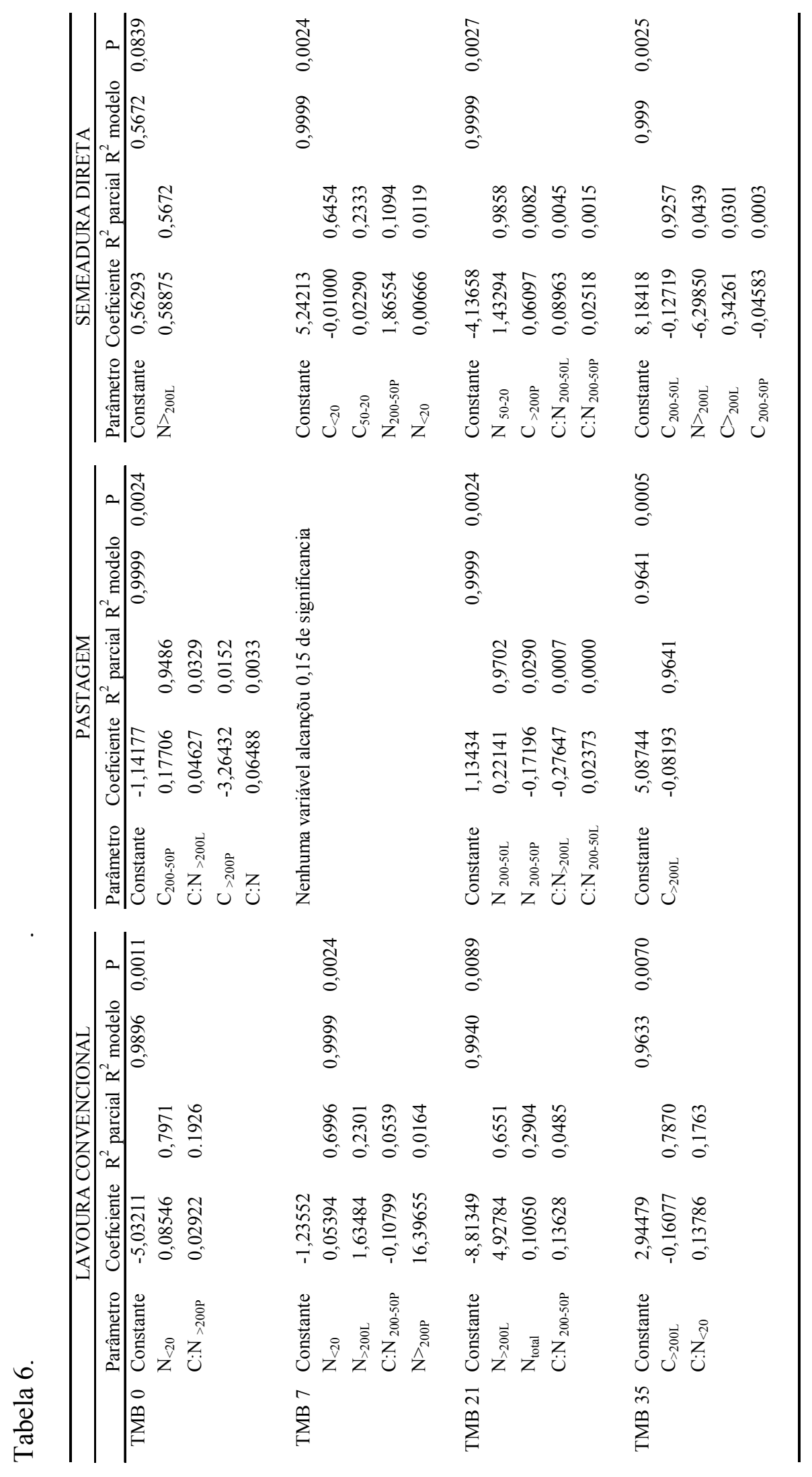




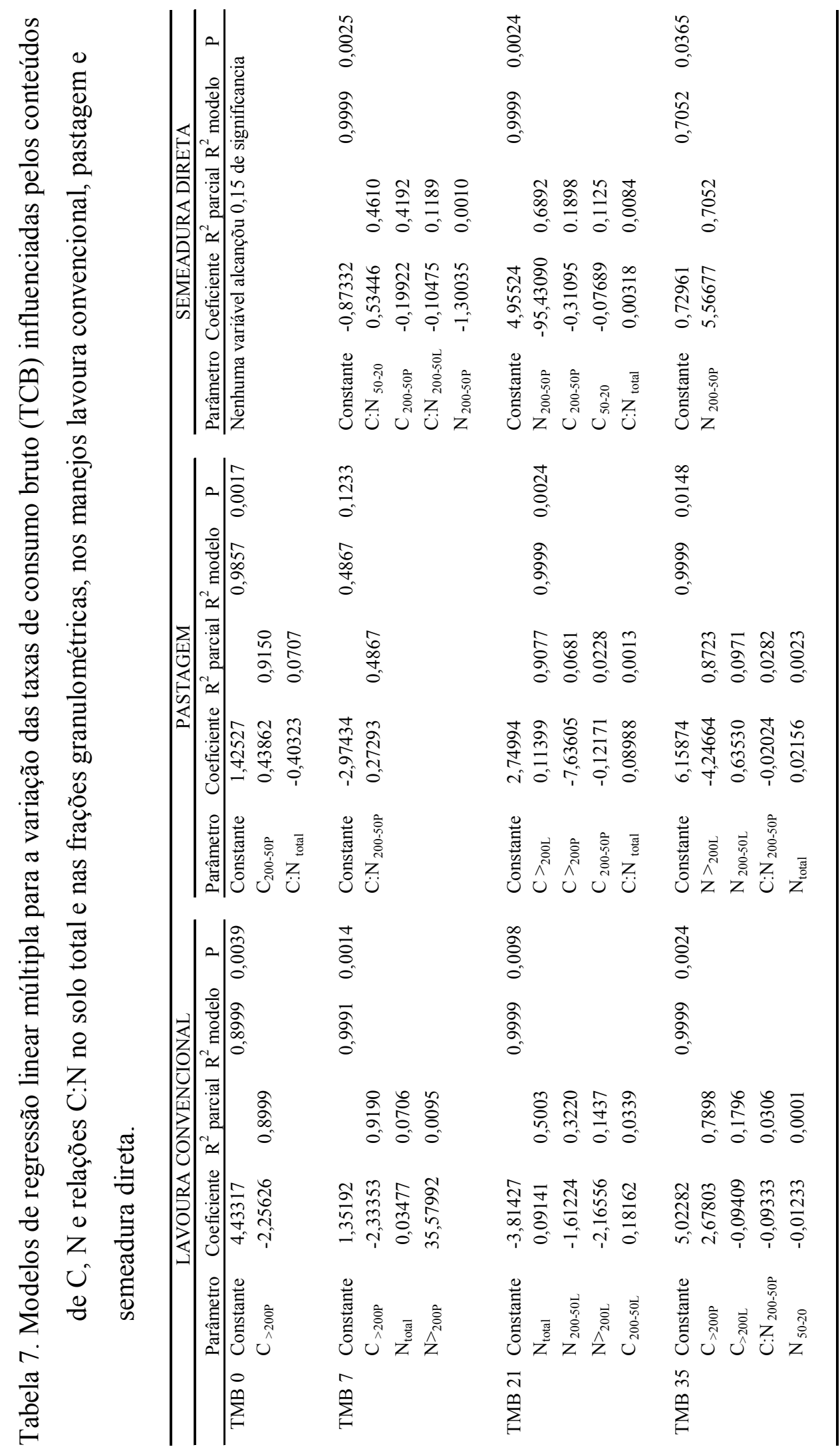


6 EFEITO DA TEMPERATURA E DA UMIDADE NAS TAXAS DE MINERALIZAÇÃO E DE CONSUMO BRUTO DE NITROGÊNIO DE UM MOLISOL DO SUDESTE DE BUENOS AIRES (ARGENTINA) SOB PASTAGEM, LAVOURA CONVENCIONAL E SEMEADURA DIRETA

\section{Resumo}

Estudou-se a influência da temperatura e da umidade do solo nas taxas de consumo (TCB) e de mineralização bruta (TMB) de um solo agrícola (Molisol) submetido por 9 anos a semeadura direta (SD), lavoura convencional (LC) e pastagem (P), depois de 17 anos de agricultura com lavoura convencional. Estudaram-se 3 profundidades de solo: 0-5, 5-10 e 10-20 cm em dois experimentos de laboratório: A) temperatura constante de $35^{\circ} \mathrm{C}$ e umidade variável a $25,55,65$ e $80 \%$ da máxima capacidade de retenção de água (\%MCR) e B) a umidade constante a $70 \% \mathrm{MCR}$ e temperaturas de $5,15,25$ e $35^{\circ} \mathrm{C}$. As TMB e TCB foram estimadas com a técnica de diluição do isótopo ${ }^{15} \mathrm{~N}$. Verificou-se efeito significativo de umidade e interação manejo $\times$ umidade no experimento $A$ e de temperatura e interação temperatura $\times$ manejo no experimento B. A umidade de $70 \% \mathrm{MCR}$ e temperatura de $25^{\circ} \mathrm{C}$ representaram as condições ótimas para os processos estudados. O manejo do solo foi o efeito que teve maior influência na TMB e TCB; P apresentou maiores taxas que SD e LC na maioria das combinações de temperatura e umidade, principalmente nos $5 \mathrm{~cm}$ superficiais $(1,06$ a 4,42 $\mathrm{mg} \mathrm{kg}^{-1} \mathrm{dia}^{-1}$ de $\left.\mathrm{N}\right)$ e diminuindo com a profundidade $\left(0,61\right.$ a $1,60 \mathrm{mg} \mathrm{kg}^{-1} \mathrm{dia}^{-1}$ aos 10-20 cm); LC apresentou sempre taxas baixas (0,54 a 1,74 mg N kg-1 $\left.\mathrm{dia}^{-1}\right)$ e com menores diferenças entre profundidades. SD também manifestou diferenças entre 
profundidades, mas menores que P. A TCB foi sempre maior que TMB o que conduz a mineralização líquida negativa.

\section{Summary}

Temperature and soil moisture are the major environmental factors affecting $\mathrm{N}$ mineralization in soils. The influence of soil water content and temperature on consumption (TCB) and gross mineralization rates (TMB) was evaluated on samples from an agricultural soil under no tillage (SD), conventional tillage (LC) and pasture (P) for 9 years. The soil had been under conventional tillage for 17 years before the management systems were implemented. Three soil depths were analyzed: 0-5, 5-10 and $10-20 \mathrm{~cm}$ in two laboratory experiments. A) At $35^{\circ} \mathrm{C}$ constant temperature and variable soil water content of $25,55,65$ and $80 \%$ of the field capacity (\%MCR). B) At 70 $\% \mathrm{MCR}$ constant soil water content and temperatures of 5, 15, 25 and $35^{\circ} \mathrm{C}$. Isotope ${ }^{15} \mathrm{~N}$ dilution technique was used to estimate TMB and TCB. Significant effect of water content and management $\times$ soil water interaction was verified in experiment $\mathrm{A}$. Temperature and temperature $\times$ management interaction were significant in experiment $\mathrm{B}$. Soil water content of $70 \% \mathrm{MCR}$ and $25^{\circ} \mathrm{C}$ temperature were optimal conditions for both gross processes. Soil management practices had more influence on TMB and TCB than water content and temperature. Pasture TMB was higher than SD and LC ones in most of the studied temperature and soil water conditions, mainly at $5 \mathrm{~cm}$ of depth (1.06 to $4.42 \mathrm{mg} \mathrm{N} \mathrm{kg}^{-1}$ soil day $\left.{ }^{-1}\right)$, decreasing according to soil depth (0.61 to $1.60 \mathrm{mg} \mathrm{N} \mathrm{kg}^{-1}$ soil day ${ }^{-1}$ to $\left.10-20 \mathrm{~cm}\right)$. LC TMB was always lower than P and SD rates $(0.54$ to 1.74 $\mathrm{mg} \mathrm{N} \mathrm{kg}{ }^{-1}$ soil day ${ }^{-1}$ ) and it had smaller differences between soil depths. SD also showed differences between soil depths, although lower than P. TCB was always higher than TMB suggesting negative net mineralization. 


\subsection{Introdução}

A conversão de $\mathrm{N}$ orgânico a $\mathrm{N}$ mineral no solo é realizada por microrganismos cuja atividade, por sua vez, é função das condições ambientais, principalmente a umidade e a temperatura. Por sua vez, as condições ambientais do solo podem ser modificadas por práticas de manejo, sendo que, uma adequada predição da disponibilidade de $\mathrm{N}$ no solo requer o entendimento dos efeitos que têm as condições ambientais e as práticas de manejo na atividade dos microrganismos encarregados da mineralização do nitrogênio.

A umidade do solo tem dois efeitos importantes sobre a mineralização do N; ela determina diretamente a disponibilidade de água para a atividade e sobrevivência dos microrganismos (Orchard \& Cook, 1983) e, indiretamente, controla a difusão de $\mathrm{O}_{2}$ no solo, determinando o volume de solo onde pode ocorrer atividade aeróbica (Skopp et al., 1990). Por sua vez, a temperatura modifica diretamente a mineralização do $\mathrm{N}$ por controlar os processos bioquímicos e, indiretamente, por afetar o consumo de $\mathrm{O}_{2}$ pelos microrganismos e, como conseqüência, o volume aeróbico do mesmo (Renault \& Sierra, 1994).

Em geral, é conhecido que tanto as taxas de amonificação como as de nitrificação líquida diminuem desde um valor ótimo, próximo à capacidade de campo ou máxima capacidade de retenção de água, na medida que os potenciais mátricos tornamse mais negativos quando o solo está secando. A taxa de redução nesses processos é maior para a nitrificação que para a amonificação. Resultados similares foram obtidos na medição de taxas de mineralização bruta em função da umidade em solos tropicais secos (Pilbeam et al., 1993; Pilbeam e Warren, 1995) e úmidos (Gava et al., 2002).

O efeito da temperatura nas taxas de mineralização líquida apresenta, em geral, um ajuste adequado à equação de Arrhenius, com um $\mathrm{Q}_{10}$ próximo a 2 (Stanford et al., 1973; Campbell et al., 1981). O processo de nitrificação, que é mediado por um limitado grupo de microrganismos, é a única transformação no solo que tem uma resposta à 
temperatura relacionada às zonas climáticas. Em áreas tropicais, o ótimo para a nitrificação está próximo a $35^{\circ} \mathrm{C}$, podendo ocorrer nitrificação até a $50^{\circ} \mathrm{C}$ (Myers, 1975), no oeste de USA, foi reportado um ótimo de $30^{\circ} \mathrm{C}$, enquanto que para solos do Canadá, o ótimo foi de $20^{\circ} \mathrm{C}$ (Malhi \& Mc Hill, 1982).

Embora os efeitos da temperatura e da umidade do solo nos processos do ciclo do $\mathrm{N}$ foram amplamente estudados, são muito poucos os trabalhos que relacionam as taxas de mineralização bruta com fatores ambientais e o manejo do solo. Zaman \& Chang (2004) trabalhando com solos silvo - pastoris da Nova Zelândia, reportaram que as TMB a $40^{\circ} \mathrm{C}$ foram significativamente maiores que a $25^{\circ} \mathrm{C}$ e a $5^{\circ} \mathrm{C}$, enquanto que as taxas de nitrificação bruta foram maiores a $25^{\circ} \mathrm{C}$ que a $40^{\circ} \mathrm{C}$ e $5^{\circ} \mathrm{C}$. O efeito da umidade foi significativo nas duas temperaturas superiores, mas não se encontraram diferenças para umidade a $5^{\circ} \mathrm{C}$.

A influência do manejo na capacidade do solo de reter água e nas variações da temperatura afetará os processos do ciclo do $\mathrm{N}$, particularmente a mineralização. Nesse contexto, é proposta deste trabalho estudar a influência da umidade do solo e da temperatura nas taxas de mineralização bruta de um solo agrícola do sudeste de Buenos Aires (Argentina), submetido a diferentes manejos.

\subsection{Material e Métodos}

Realizaram-se dois experimentos de laboratório: A) com a temperatura constante a $35^{\circ} \mathrm{C}$ e umidade variável $(25,55,65$ e $80 \%$ da máxima capacidade de retenção de água), e B) com a umidade constante a $70 \%$ da máxima capacidade de retenção de água e temperatura variável $\left(5,15,25\right.$ e $\left.35^{\circ} \mathrm{C}\right)$. As amostras foram colhidas como descrito no Anexo A.

Em março de 2003 colheram-se as amostras compostas de solo nas parcelas de LC, SD e P, nas profundidades 0-5, 5-10 e 10-20 cm, que foram secas ao ar, passadas por peneira de $2 \mathrm{~mm}$ e armazenadas até a realização dos experimentos. Nessas amostras 
foi determinado o conteúdo de C orgânico (Walkley \& Black, 1934), N total e o conteúdo de umidade à máxima capacidade de retenção de água $(\% \mathrm{CMR})$ com o método de membranas de pressão (Richards \& Fireman, 1943) a 0,033 MPa em amostras deformadas.

$\mathrm{O}$ experimento A foi realizado dentro de incubadora, na temperatura de $35^{\circ} \mathrm{C}$, com distribuição ao acaso e três repetições por tratamento (umidade do solo). As amostras de solo foram pré-incubadas a temperatura ambiente $\left(20^{\circ} \mathrm{C}\right)$ durante duas semanas a 25, 55, 65 e $80 \%$ da máxima capacidade de retenção de água, que corresponderam, respectivamente, aos níveis de umidade 0,$105 ; 0,174 ; 0,197$ e $0,236 \mathrm{~g}$ $\mathrm{g}^{-1}\left(\mathrm{~m} \mathrm{~m}^{-1}\right)$.

O experimento B foi realizado com distribuição ao acaso e três repetições por tratamento (temperatura) com as amostras pré-incubadas por duas semanas a $70 \%$ de $\mathrm{CMR}$, na temperatura ambiente $\left(20^{\circ} \mathrm{C}\right)$. Após o período de pré-incubação às amostras foram adicionadas como ${ }^{15} \mathrm{NH}_{4}^{+}$e postas à temperatura de estudo, em incubadora durante o tempo de determinação da TMB.

Para os dois experimentos, as taxas de mineralização bruta foram estimadas em $80 \mathrm{~g}$ de solo (base seca em estufa a $105^{\circ} \mathrm{C}$ ) acondicionados em copos plásticos, cobertos com lâminas de Parafilm ${ }^{\circledR}$ para evitar perdas de água por evaporação. Adicionou-se a solução de sulfato de amônio com uma abundância de $10 \%$ de átomos de ${ }^{15} \mathrm{~N}$ em excesso, a uma dose de $10 \mu \mathrm{g} \mathrm{g}^{-1} \mathrm{~N}$ de solo, usando um dispositivo com sete seringas e agulhas hipodérmicas, em um volume total de 3,5 mL. Depois de $24\left(\mathrm{t}_{\mathrm{o}}\right)$ e $72 \mathrm{~h}\left(\mathrm{t}_{\mathrm{f}}\right)$ desde a adição de amônio (ver Anexo B) (Videla et al., 2001) aproximadamente $60 \mathrm{~g}$ de solo foram extraídos com $200 \mathrm{~mL}$ de $\mathrm{KCl} 2 \mathrm{M}$, agitados durante $1 \mathrm{~h}$ e filtrados. Os extratos foram congelados até as determinações de $\mathrm{NH}^{+}{ }_{4} \mathrm{e}^{15} \mathrm{~N}$. O conteúdo de $\mathrm{NH}^{+}{ }_{4}$ dos extratos foi determinado por microdestilação por arraste de vapor em presença de $\mathrm{MgO}$. O conteúdo de ${ }^{15} \mathrm{~N}$ no amônio nos extratos foi determinado usando o método de microdifusão descrito por Sørensen \& Jensen (1991) em um espectrômetro de massas Europa Sc. ANCA-SL acoplado a um analisador de C e N. As taxas de mineralização 
bruta (TMB) e as de consumo bruto de amônio (TCB) foram calculadas com as equações 2 e 3 , respectivamente.

Os resultados foram submetidos à análise da variância e ao teste de diferença de médias (Tukey) a um nível de probabilidade de 5\%. Utilizou-se o procedimento GLM do pacote SAS, com uma análise fatorial para cada profundidade separadamente (0-5, 5$10,10-20 \mathrm{~cm})$ com os fatores manejo (P, SD, LC), as umidades $(25,55,65$ e $80 \%$ $\mathrm{MCR})$ e interação $\mathrm{M} \times \mathrm{U}$ para o experimento $\mathrm{A}$; e os fatores manejo $(\mathrm{P}, \mathrm{SD}, \mathrm{LC})$, temperatura $\left(5,15,25\right.$ e $\left.35^{\circ} \mathrm{C}\right)$ e interação $\mathrm{M} \times \mathrm{T}$ para o experimento $\mathrm{B}$.

\subsection{Resultados e Discussão}

Após 9 anos da implantação dos manejos, a pastagem e a SD conseguiram acumular maior quantidade de $\mathrm{C}$ e $\mathrm{N}$ que a LC (Tabela 8). As diferenças com a pastagem deram-se até $10 \mathrm{~cm}$ de profundidade no solo, enquanto que a SD acumulou maior quantidade de $\mathrm{C}$ e $\mathrm{N}$ na superfície $(0-5 \mathrm{~cm})$, devido à permanência de resíduos de culturas na superfície (Doran, 1987). Esse acúmulo de MO refletiu em aumento na capacidade máxima de retenção de água (Tabela 8), como conseqüência de uma redistribuição das classes de tamanho de poros, com diminuição da quantidade de microporos e aumento na quantidade de macroporos, principalmente nos primeiros $\mathrm{cm}$ do solo (Arshad et al., 1999). Os valores de MCR das camadas superficiais do solo para P e SD concordam com o valor obtido por Batallanez (1974) de $0,302 \mathrm{~g} \mathrm{~g}^{-1}$, para um solo do mesmo tipo deste trabalho com cobertura vegetal natural, podendo-se inferir que tanto na P como na SD estaria ocorrendo um processo de recuperação do solo. 
Tabela 8. Conteúdo de água na máxima capacidade de retenção (MCR), Carbono orgânico e Nitrogênio total do solo nos manejos com pastagem (P), semeadura direta (SD) e lavoura convencional (LC), nas profundidades de $0-5,5-10$ e $10-20 \mathrm{~cm}$.

\begin{tabular}{ccccc}
\hline Manejo & $\begin{array}{c}\text { Profundidade } \\
\mathrm{cm}\end{array}$ & $\begin{array}{c}\text { MCR } \\
\mathrm{g} \mathrm{g}^{-1}\end{array}$ & $\mathrm{C}$ orgânico & $\mathrm{N}$ total \\
\cline { 4 - 5 } & $0-5$ & 0,318 & 39,9 & $\mathrm{~g} \mathrm{~kg}^{-1}$ \\
P & $5-10$ & 0,282 & 31,6 & 3,0 \\
P & $10-20$ & 0,274 & 30,7 & 2,4 \\
P & $0-5$ & 0,295 & 31,5 & 2,3 \\
SD & $5-10$ & 0,252 & 27,5 & 2,4 \\
SD & $10-20$ & 0,272 & 26,8 & 2,2 \\
SD & $0-5$ & 0,279 & 27,2 & 2,1 \\
LC & $5-10$ & 0,271 & 27,1 & 2,1 \\
LC & $10-20$ & 0,279 & 28,3 & 2,3 \\
LC & & & & 2,2 \\
\hline
\end{tabular}

\section{Experimento A}

Apesar da impossibilidade de se fazer a análise estatística do efeito da profundidade de solo, devido à falta de independência entre as profundidades, pode-se observar pelos valores médios de todos os tratamentos com umidade e manejos (Figura 16) que houve um efeito importante de estratificação, tanto nas TMB como nas TCB, com maiores valores na superfície $(0-5 \mathrm{~cm})$ e pouca diferença entre as demais profundidades.

A TMB média foi de $1,60 \mathrm{mg} \mathrm{kg}^{-1} \mathrm{dia}^{-1}$ de $0-5 \mathrm{~cm}$ de profundidade, enquanto que os valores para 5-10 e 10-20 $\mathrm{cm}$ foram de 0,90 e $0,70 \mathrm{~m} \mathrm{~kg}^{-1} \mathrm{dia}^{-1}$ respectivamente. Valores médios e diferenças entre profundidades semelhantes foram quantificados em solos da Bélgica, após 6 ou 14 anos de implantação de pastagens, posterior a 20 anos de agricultura com lavouras convencionais (Accoe et., 2004). As TCB tiveram, em geral, valores maiores que as TMB, sendo a média para a profundidade superficial de 2,87 $\mathrm{mg}$ $\mathrm{kg}^{-1} \mathrm{dia}^{-1}$ e de 5-10 e 10-20, respectivamente, de 1,64 e 1,48 $\mathrm{mg} \mathrm{kg}^{-1} \mathrm{dia}^{-1}$. 


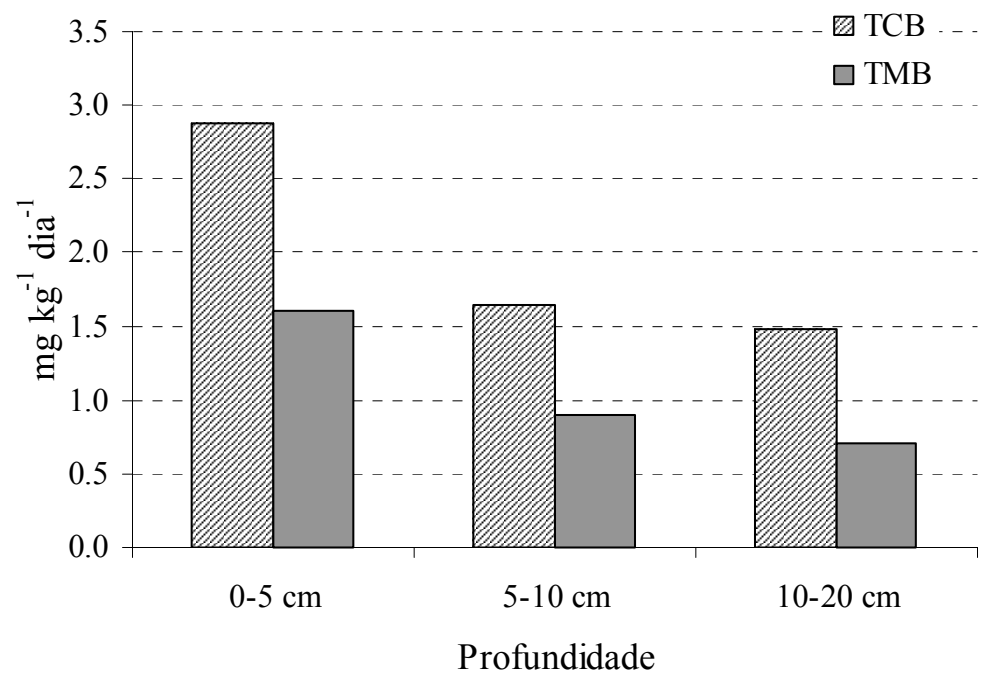

Figura 16. Mineralização bruta (TMB) e consumo bruto (TCB) de nitrogênio de solos sob lavoura convencional (LC), semeadura direta (SD) e pastagem (P) nas profundidades do solo de 0-5, 5-10 e 10-20 cm. (Os valores correspondem a médias de todos os manejo e umidade do solo).

Realizaram-se analises da variância separadas para cada profundidade, encontrando-se que a umidade (U), o manejo (M) e a interação $M \times U$ influíram significativamente nos resultados de TMB e TCB, nas três profundidades (Tabela 9).

As diferenças mais marcantes para TMB verificaram-se de 0-5 cm. A TMB da pastagem foi significativamente superior àquela dos tratamentos agrícolas, em todas as umidades. A TMB de $\mathrm{P}$ apresentou uma queda importante quando o conteúdo de umidade decresceu para 25\% MCR, enquanto a SD e LC não foram afetadas pelo conteúdo de umidade. A SD foi sempre superior a LC, com média de 1,0 e $0,56 \mathrm{mg} \mathrm{kg}^{-1}$ $\mathrm{dia}^{-1}$ respectivamente. Na profundidade de 5-10 $\mathrm{cm}$ a TMB de LC não apresentou diferenças com a umidade, enquanto que P e SD apresentaram TMB maiores em 65 e $80 \% \mathrm{MCR}$, respectivamente, sendo sempre $\mathrm{P}$ superior a $\mathrm{SD}$, exceto com $80 \% \mathrm{MCR}$ em que foram iguais. De uma forma geral, de 10 a $20 \mathrm{~cm}$ a TMB de P foi superior a SD e LC, mas os tratamentos agrícolas não foram diferentes entre eles; a P e SD apresentaram 
TMB máximas a 65 e 55\% MCR, enquanto que LC não apresentou reposta aos conteúdos de umidade.

A TCB foi, em geral, maior que a TMB em todas as situações de manejo e conteúdo de umidade do solo o que estaria indicando que os processos de imobilização e nitrificação, que são os que têm maior possibilidades de compor o consumo de amônio nestes solos, estariam ocorrendo ativamente utilizando praticamente todo o amônio que é liberado da matéria orgânica.

Tabela 9. Taxas de mineralização e de consumo de amônio do solo, sob lavoura convencional (LC), semeadura direta (SD) e pastagem (P), nas profundidades de 0-5, 5-10 e 10-20 cm e à temperatura de $35^{\circ} \mathrm{C}$, com as umidades de 25,55 , 65 e $80 \%$ da máxima capacidade de retenção de água (\% MCR).

\begin{tabular}{|c|c|c|c|c|c|c|c|}
\hline \multirow{3}{*}{$\begin{array}{l}\text { Umidade } \\
\% \text { MCR }\end{array}$} & \multirow{3}{*}{ Manejo } & \multicolumn{2}{|c|}{$0-5 \mathrm{~cm}$} & \multicolumn{2}{|c|}{$5-10 \mathrm{~cm}$} & \multicolumn{2}{|c|}{$10-20 \mathrm{~cm}$} \\
\hline & & TMB & TCB & TMB & TCB & TMB & $\mathrm{TCB}$ \\
\hline & & \multicolumn{6}{|c|}{$\mathrm{mg} \mathrm{kg}^{-1} \mathrm{dia}^{-1}$} \\
\hline 80 & $P$ & 3,85 a $A$ * & 4,40 a $B$ & 1,20 a $A$ & 1,90 a $A$ & 0,56 a B & 1,03 a $A$ \\
\hline & SD & $1,09 \mathrm{~b} \mathrm{~A}$ & $1,78 \mathrm{~b} \mathrm{~A}$ & 1,12 b A & 1,80 b A & 0,28 b BC & $0,88 \mathrm{~b} A C$ \\
\hline & LC & 0,79 с A & $1,44 \mathrm{c} \mathrm{A}$ & 0,49 c $A$ & 0,92 с A & 0,47 b A & 0,85 b A \\
\hline \multirow[t]{3}{*}{65} & $P$ & 3,76 a $A$ & 4,69 a $A B$ & 2,00 a $B$ & 2,36 a $A$ & 1,60 a $A$ & 2,26 a $B$ \\
\hline & SD & $1,23 \mathrm{~b} A$ & 2,57 b A & 0,99 b B & 1,94 b A & 1,02 b A & $1,55 \mathrm{~b} \mathrm{~B}$ \\
\hline & LC & 0,76 с A & $2,07 \mathrm{c} \mathrm{A}$ & 0,68 с $A$ & 1,74 c B & 0,78 b A & 1,49 b B \\
\hline \multirow[t]{3}{*}{55} & $\mathrm{P}$ & 3,46 a $A$ & 4,08 a $B$ & 1,39 a $A$ & 2,00 a $A$ & 1,27 a $A$ & 2,63 a $B$ \\
\hline & SD & $0,96 \mathrm{~b} A$ & $2,63 \mathrm{~b} \mathrm{~A}$ & $0,51 \mathrm{~b} B C$ & 1,72 b A & 0,73 b AB & 1,42 b BC \\
\hline & LC & $0,51 \mathrm{c} \mathrm{A}$ & $1,54 \mathrm{c} \mathrm{A}$ & $0,26 \mathrm{c} \mathrm{A}$ & $1,28 \mathrm{c} A B$ & 0,45 b A & 1,72 b B \\
\hline \multirow[t]{3}{*}{25} & $P$ & 1,88 a $B$ & 5,57 a $A$ & 1,43 a $A$ & 2,24 a $A$ & 0,61 a $B$ & 1,36 a $A$ \\
\hline & SD & $0,63 \mathrm{~b} A$ & $2,12 \mathrm{~b} A$ & 0,43 b BC & 0,71 b B & 0,17 b C & $0,74 \mathrm{~b} \mathrm{~A}$ \\
\hline & LC & 0,32 c $A$ & $1,56 \mathrm{cA}$ & $0,34 \mathrm{c} \mathrm{A}$ & $1,13 \mathrm{c} A \mathrm{~B}$ & 0,50 a $A$ & 1,85 c B \\
\hline \multicolumn{2}{|c|}{ Fonte de Variação } & \multicolumn{6}{|c|}{ Valores de probabilidade } \\
\hline \multicolumn{2}{|c|}{ Manejo (M) } & 0,0001 & 0,0001 & 0,0001 & 0,0001 & 0,0001 & 0,0001 \\
\hline \multicolumn{2}{|c|}{ Umidade (U) } & 0,0001 & 0,0518 & 0,0001 & 0,0007 & 0,0001 & 0,0001 \\
\hline \multicolumn{2}{|c|}{$\mathrm{M} \times \mathrm{U}$} & 0,0026 & 0,0268 & 0,0191 & 0,0125 & 0,0001 & 0,0001 \\
\hline \multicolumn{2}{|l|}{ SE } & 0,065 & 0,088 & 0,043 & 0,056 & 0,023 & 0,05 \\
\hline
\end{tabular}

* Letras minúscula diferentes indicam diferenças significativas entre manejos no mesmo nível de umidade, letras maiúscula diferentes indicam diferenças significativas entre umidades,no mesmo manejo, $(\mathrm{p}<0,05)$. 
A TMB e TCB (Tabela 9) estiveram positivamente correlacionadas $(\mathrm{r}=0,847) \mathrm{o}$ que confirma que o $\mathrm{N}$ mineralizado da $\mathrm{MO}$ foi o substrato dos processos de consumo de amônio. Na superfície, de uma forma geral, não se verificou efeito do conteúdo de umidade nas TCB, ocorrendo sim efeito do manejo e da interação $\mathrm{M} \times \mathrm{U}$; $\mathrm{P}$ foi significativamente maior que LC e SD a todos os conteúdos de água e os tratamentos agrícolas não diferiram entre si; a 55\% MCR também SD foi maior que LC. De 5-10 cm de profundidade, as TCB dos tratamentos de manejo se ordenaram na seguinte seqüência: P > SD > LC, apresentando os valores maiores entre 65 e 80\% MCR. De 10 a $20 \mathrm{~cm}$ de profundidade, o comportamento das TCB foi similar aquele de $5-10 \mathrm{~cm}$.

Nas situações em que foi verificado que a umidade afetou às taxas de mineralização bruta, foram realizados ajustes às linhas de tendência correspondentes. $\mathrm{O}$ comportamento da TMB, com valores máximos predominantemente entre 65 e $80 \%$ da $\mathrm{MCR}$, foi descrito geralmente com ajustes de tipo quadrático com o componente linear positivo e o quadrático negativo (Figura 17, 18 e 19).

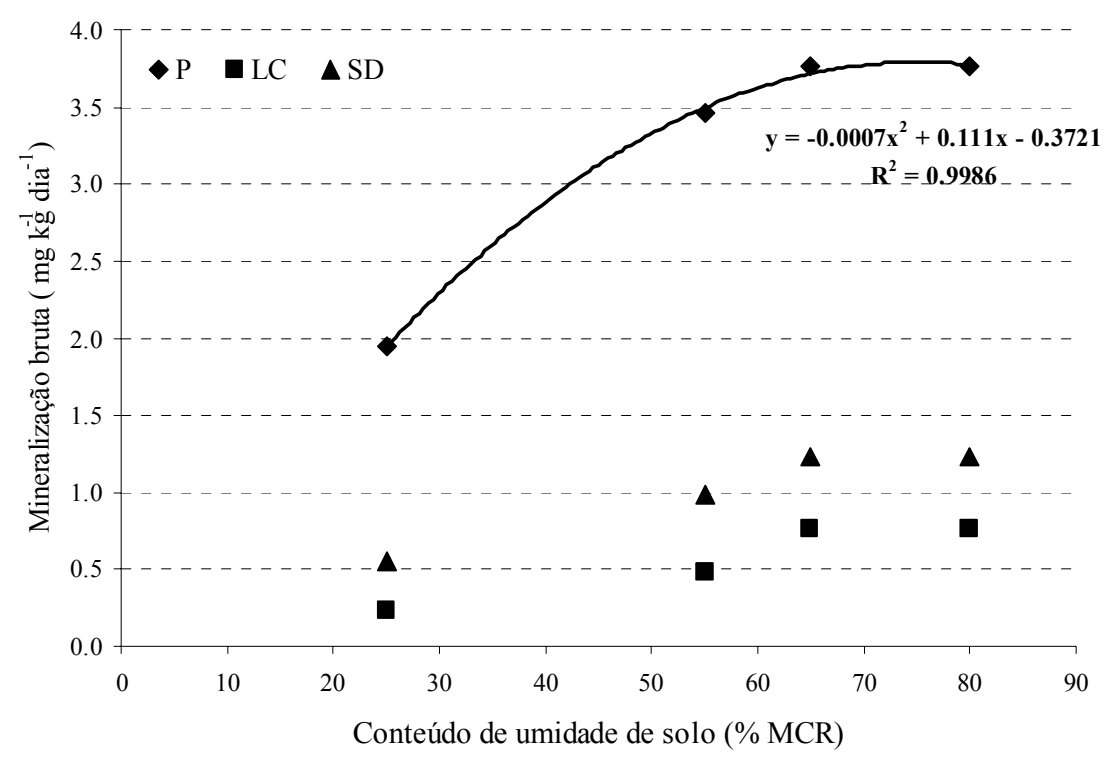

Figura 17. Variação da taxa de mineralização bruta (TMB) com a umidade do solo, expressa como porcentagem da máxima capacidade de retenção de água (\%MCR), na profundidade de $0-5 \mathrm{~cm}$, para pastagem $(\mathrm{P})$, semeadura direta (SD) e lavoura convencional (LC). 


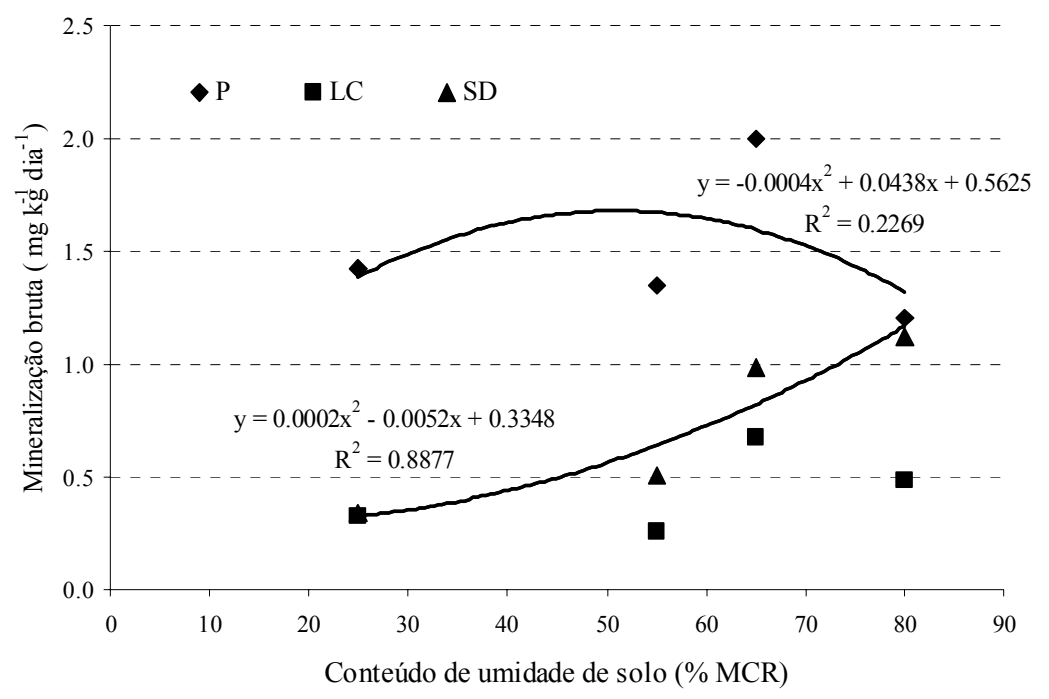

Figura 18. Variação da taxa de mineralização bruta (TMB) com a umidade do solo, expressa como porcentagem da máxima capacidade de retenção de água (\%MCR), na profundidade de 5-10 cm, para pastagem $(\mathrm{P})$, semeadura direta (SD) e lavoura convencional (LC).

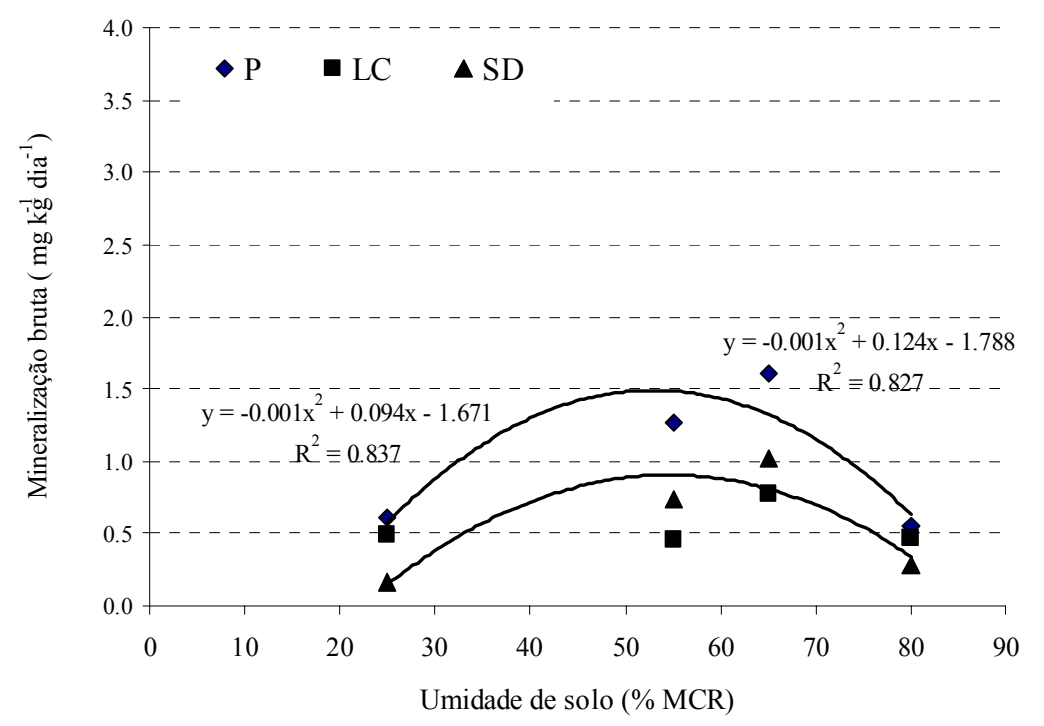

Figura 19. Variação da taxa de mineralização bruta (TMB) com a umidade do solo expressa como porcentagem da máxima capacidade de retenção de água (\%MCR), na profundidade de 10-20 cm, para pastagem $(\mathrm{P})$, semeadura direta (SD) e lavoura convencional (LC) 
De $0-5 \mathrm{~cm}$ de profundidade, a menor umidade ( $25 \%$ de MCR) representou uma restrição importante para os microrganismos quimiorganotróficos responsáveis pela conversão de $\mathrm{N}$ orgânico a $\mathrm{N}$ mineral, já que as TMB foram sensivelmente menores. Resultados similares foram obtidos por Gava et al. (2001) para um Oxisol de textura argilosa do Estado de São Paulo, Brasil, e por Pilbeam \& Warren (1995) num Ferrasol com $74 \%$ de areia do Quênia, mesmo com diferentes impactos na disponibilidade de $\mathrm{N}$ para as plantas. Ambos os solos sendo tropicais, possuem baixo conteúdo de C orgânico:

2,5 e 6,0 $\mathrm{g} \mathrm{kg}^{-1}$, respectivamente, para o solo do Brasil e do Quênia, e mostraram rápida resposta ao aumento de umidade. Este resposta estaria relacionada com a presencia de importantes proporções de C nas frações leves (Sá et al., 2001), as que apresentam altas taxas de reciclagem. Isto posto, ante um aumento no conteúdo de umidade do solo irá ocorrer rápida mineralização da $\mathrm{MO}$ leve, aportando uma importante quantidade de $\mathrm{N}$ às plantas e, inclusive, em algumas circunstâncias, determinando que os cultivos não apresentem resposta à fertilização nitrogenada (Pilbeam \& Warren, 1995).

Como diferença com os solos tropicais, o Molisol do presente experimento possui grande proporção de $\mathrm{MO}$ em frações de tamanhos $<50 \mu \mathrm{m}$ (Tabela 3), altamente humificadas e de lenta mineralização, não sendo afetados pelas condições ambientais. Como a distribuição da $\mathrm{MO}$ em frações granulométricas é modificada pelo manejo do solo, $\mathrm{P}$ deve possuir maior quantidade de $\mathrm{C}$ e $\mathrm{N}$ em frações leves e a SD manifestou uma tendência neste sentido, e, portanto, também a TMB será maior e mais alterada pelos conteúdos de umidade que solos sob LC.

\section{Experimento B}

$O$ efeito de estratificação das TMB e TCB neste experimento foi menos marcante que no experimento A o que estaria indicando que a umidade do solo teve maior efeito nos processos brutos do solo que a temperatura (Figura 20). 


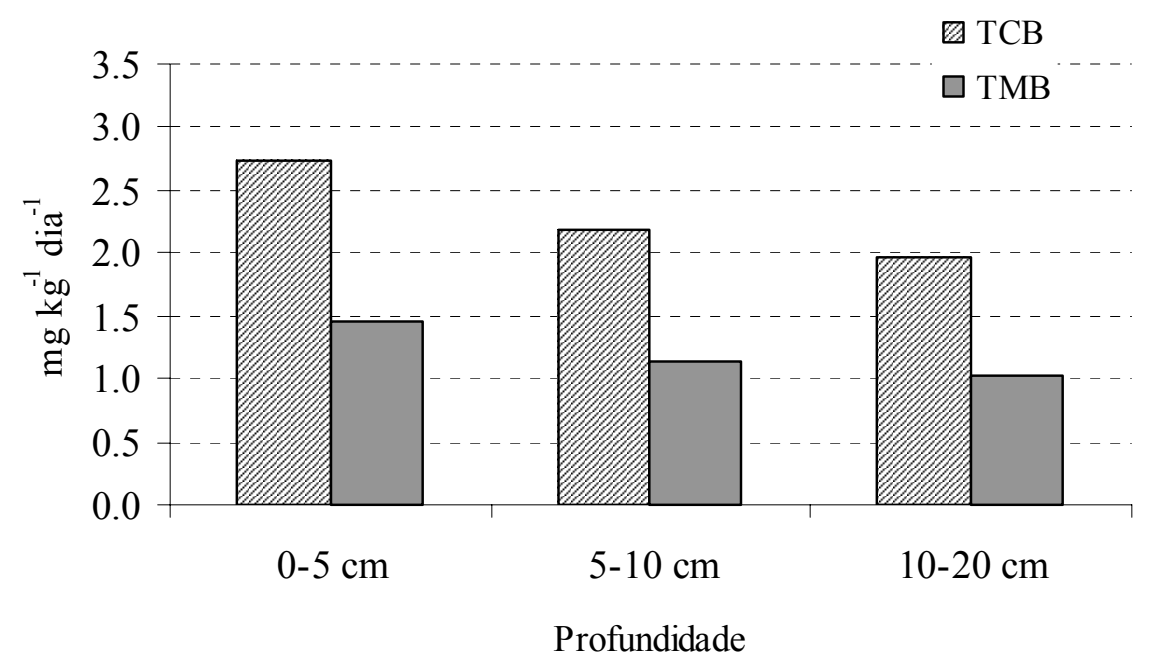

Figura 20. Mineralização bruta (TMB) e consumo bruto (TCB) de nitrogênio de solo sob lavoura convencional (LC), semeadura direta (SD) e pastagem (P) a profundidades de solo de 0-5, 5-10 e 10-20 cm. (Os valores correspondem a médias de manejo e temperatura)

A análise de variância em cada profundidade indicou efeito significativo do manejo (M) e da temperatura (T) nas TMB e TCB em todas as profundidades (Tabela 10), mas sem interação $M \times T$ na profundidade de 10-20 cm. De 0-5 cm de profundidade, a TMB de $\mathrm{P}$ foi maior a 25 e $35^{\circ} \mathrm{C}$ que a 5 e $15^{\circ} \mathrm{C}$; em LC a TMB não foi afetada pela temperatura, enquanto que $\mathrm{SD}$ apresentou menor $\mathrm{TMB}$ a $5^{\circ} \mathrm{C}$. De $5-10 \mathrm{~cm}$ de profundidade, $\mathrm{P}$ apresentou redução na $\mathrm{TMB}$ a $25^{\circ} \mathrm{C}$; $\mathrm{SD}$ apresentou um máximo a $15^{\circ} \mathrm{C}$ e LC não manifestou efeito de temperatura com uma taxa média de $0,54 \mathrm{mg} \mathrm{kg}^{-1} \mathrm{dia}^{-1}$ na TMB. De 10-20 cm as TMB de P foram significativamente maiores que em SD e LC, e nesses manejos as TMB foram iguais. $\mathrm{O}$ efeito geral da temperatura nesta profundidade foi uma diminuição significativa a $5^{\circ} \mathrm{C}$.

O comportamento da TCB apresentou mesmo padrão que o observado para TMB, mas com valores médios maiores. O maior valor médio de TMB de 4,42 $\mathrm{mg} \mathrm{kg}^{-1}$ $\mathrm{dia}^{-1}$ foi obtido na temperatura de $25^{\circ} \mathrm{C} \operatorname{com} 70 \% \mathrm{MCR}$ o que indicaria que são essas as 
condições ótimas para a mineralização bruta do nitrogênio nesse solo. Esse resultado concorda parcialmente com os de Sierra (1997) para solos temperados com características semelhantes, já que nesse trabalho foi verificado efeito de temperatura e umidade, mas foi a temperatura o fator que explicou principalmente a mineralização líquida do nitrogênio.

Tabela 10 Taxas de mineralização e de consumo de amônio de solo sob lavoura convencional (LC), semeadura direta (SD) e pastagem (P) medidas às temperaturas de $5,15,25$ e $35^{\circ} \mathrm{C}$ e a $70 \%$ da máxima capacidade de retenção de água (\% MCR) às profundidades de 0-5, 5-10 e 10-20 cm .

\begin{tabular}{|c|c|c|c|c|c|c|c|}
\hline \multirow{3}{*}{$\begin{array}{c} \\
\text { Temperatura } \\
{ }^{\circ} \mathrm{C} \\
\end{array}$} & \multirow{3}{*}{ Manejo } & \multicolumn{2}{|c|}{$0-5$} & \multicolumn{2}{|c|}{$5-10$} & \multicolumn{2}{|c|}{$10-20$} \\
\hline & & TMB & TCB & TMB & TCB & TMB & TCB \\
\hline & & \multicolumn{6}{|c|}{$\mathrm{mg} \mathrm{kg}^{-1} \mathrm{dia}^{-1}$} \\
\hline \multirow[t]{3}{*}{5} & $\mathrm{P}$ & 2,48 a $\mathrm{A} *$ & 4,02 a $A$ & $1,91 \mathrm{a} A B$ & 3,31 a $\mathrm{A}$ & 1,24 & 2,55 \\
\hline & SD & $0,26 \mathrm{~b} A$ & 1,99 b A & $0,56 \mathrm{~b} \mathrm{~A}$ & $1,82 \mathrm{~b} \mathrm{~A}$ & 0,71 & 1,75 \\
\hline & $\mathrm{LC}$ & $0,44 \mathrm{~b} \mathrm{~A}$ & $1,90 \mathrm{~b} \mathrm{~A}$ & $0,40 \mathrm{~b} \mathrm{~A}$ & $2,14 \mathrm{~b} \mathrm{~A}$ & 0,48 & 1,98 \\
\hline \multirow[t]{3}{*}{15} & $\mathrm{P}$ & 1,06 a B & 2,76 a B & 1,55 a $\mathrm{AB}$ & 2,01 a B & 1,21 & 1,69 \\
\hline & SD & 1,12 a B C & 2,69 a $\mathrm{A}$ & $2,16 \mathrm{~b} \mathrm{~B}$ & 2,60 a $A$ & 0,96 & 1,61 \\
\hline & $\mathrm{LC}$ & 0,84 a $\mathrm{A}$ & 2,01 a $\mathrm{A}$ & 0,59 с A & 0,95 b B & 1,00 & 1,43 \\
\hline \multirow[t]{3}{*}{25} & $\mathrm{P}$ & 4,42 a $C$ & 5,09 a $\mathrm{AC}$ & $1,43 \mathrm{ab} \mathrm{B}$ & 3,08 a $\mathrm{A}$ & 1,40 & 2,64 \\
\hline & SD & 0,54 a $B$ & $2,02 \mathrm{~b} \mathrm{~A}$ & $0,90 \mathrm{~b} \mathrm{~A}$ & $2,35 \mathrm{~b} \mathrm{~A}$ & 0,92 & 2,40 \\
\hline & LC & 0,60 a $\mathrm{A}$ & $2,16 \mathrm{~b} \mathrm{~A}$ & $0,51 \mathrm{c} \mathrm{A}$ & $1,81 \mathrm{c} \mathrm{A}$ & 0,83 & 2,26 \\
\hline \multirow[t]{3}{*}{35} & $\mathrm{P}$ & 3,76 a C & 4,69 Ac & 2,00 a $\mathrm{A}$ & 2,36 a B & 1,60 & 2,26 \\
\hline & SD & $1,23 \mathrm{~b} \mathrm{C}$ & $2,57 \mathrm{~b} \mathrm{~A}$ & 0,94 b A & 1,94 b A & 1,02 & 1,49 \\
\hline & $\mathrm{LC}$ & $0,76 \mathrm{~b} \mathrm{~A}$ & $2,07 \mathrm{~b} \mathrm{~A}$ & 0,68 b A & $1,74 \mathrm{~b} \mathrm{AB}$ & 0,78 & 1,49 \\
\hline \multicolumn{2}{|c|}{ Fonte de Variação } & \multicolumn{6}{|c|}{ Valores de probabilidade } \\
\hline \multicolumn{2}{|c|}{ Manejo (M) } & 0,0001 & 0,0001 & 0,0001 & 0,0001 & 0,0001 & 0,0035 \\
\hline \multicolumn{2}{|c|}{ Temperatura $(\mathrm{T})$} & 0,0001 & 0,0382 & 0,0017 & 0,0085 & 0,0091 & 0,0001 \\
\hline \multicolumn{2}{|c|}{$\mathrm{M} \mathrm{X} \mathrm{T}$} & 0,0001 & 0,0047 & 0,0001 & 0,0006 & 0,1392 & 0,6322 \\
\hline \multicolumn{2}{|l|}{ SE } & 0.0530 & 0,094 & 0,051 & 0,068 & 0.035 & 0,066 \\
\hline
\end{tabular}

* Letras minúscula diferentes indicam diferenças significativas entre manejos no mesmo nível de temperatura, letras maiúscula diferentes indicam diferenças significativas entre temperaturas, no mesmo manejo, $(\mathrm{p}<0,05)$. 
Zaman \& Chang (2004) encontraram um máximo para $\mathrm{TMB}$ a $40^{\circ} \mathrm{C}$ e foi a temperatura o fator que teve uma influência dominante nos processos microbianos do solo, incluída a mineralização bruta. Nos trabalhos de Sierra \& Marban (2000) com solos tropicais e Fisk et al. (1998) com solos de tundra, não foram encontrados efeitos da temperatura nem nas TM líquida como na TMB e a umidade do solo apareceu como o fator dominante na mineralização do N.

Franzluebbers et al. (2001), analisando o efeito do clima nas frações ativas da matéria orgânica do solo, encontraram resultados inconsistentes da umidade do solo na mineralização líquida (ML) a altas temperaturas, mesmo que nas mais elevadas temperaturas anuais tenham resultado em maior ML em regiões térmicas que em regiões frígidas. No presente trabalho, não foram avaliadas condições de baixas temperaturas com baixa umidade, representaria uma restrição maior para a atividade dos microrganismos do solo.

Os resultados indicaram que apesar de a temperatura e a umidade do solo sempre terem apresentado efeito significativo nas TMB e TCB, foi o manejo o fator que explicou sempre a maior parte da variabilidade. Os valores médios de $\mathrm{F}$ da análise de variância em cada profundidade no experimento A, para o manejo e para a umidade foram, respectivamente, de 89,3 e 26,5 (resultados não apresentados). Da mesma forma, no experimento B o valor médio de F para o efeito de manejo foi 91,04 e o de temperatura 10,45 (resultados não apresentados), confirmando que nos dois experimentos o manejo explica uma maior proporção da variabilidade nas TMB.

$\mathrm{O}$ manejo que apresentou maior resposta à temperatura e a umidade foi $\mathrm{P}$, enquanto que no extremo oposto, LC não mostrou respostas para temperatura e nem para umidade. É possível que a redução no conteúdo de matéria orgânica do solo explique este comportamento na LC. Esta redução afeta as frações mais ativas, ficando no solo, principalmente, matéria orgânica muito humificada e fisicamente protegida, com taxas de reciclagem muito lentas. 


\subsection{Conclusões}

A temperatura e a umidade do solo influíram nas TMB e TCB. O efeito da temperatura foi menor que o da umidade de solo, sendo que as maiores TMB e TCB ocorreram a $25^{\circ} \mathrm{C}$ e a $70 \% \mathrm{MCR}$.

O manejo do solo explicou a maior parte da variabilidade na TMB, sendo a pastagem e, principalmente, nos $5 \mathrm{~cm}$ superficiais, a situação de maior atividade biológica. A SD também resultou em recuperação da TMB e estratificação marcada nos $5 \mathrm{~cm}$ superficiais, mas os valores de TMB foram sempre menores que aqueles de $\mathrm{P}$.

A LC não apresentou resposta em temperatura e nem para umidade de solo.

A TCB foi sempre maior que a TMB, resultando em mineralização líquida negativa. 


\section{VARIAÇÕES TEMPORAIS NA MINERALIZAÇÃO BRUTA DE NITROGÊNIO EM UM MOLISOL DO SUDESTE DE BUENOS AIRES (ARGENTINA)}

\section{Resumo}

Estudou-se, em campo, a evolução das taxas de mineralização bruta (TMB) e de consumo bruto (TCB) de nitrogênio, em um Molisol do sudeste de Buenos Aires (Argentina) sob semeadura direta (SD) e lavoura convencional (LC), durante um cultivo de milho, e sob pastagem (P), após 17 anos de manejo desse solo sob LC. As TMB e TCB foram medidas mensalmente com a técnica da diluição do ${ }^{15} \mathrm{~N}$ e apresentaram grandes variações no tempo, influenciadas pelas flutuações da umidade do solo. TMB apresentou valores entre 0.18 e $2.41 \mathrm{mg} \mathrm{kg}^{-1} \mathrm{dia}^{-1}$ e TCB entre 0.21 a $3.52 \mathrm{mg} \mathrm{kg}^{-1} \mathrm{dia}^{-1}$. As TMB e TCB da pastagem foram geralmente maiores que as de LC e SD. A SD diferenciou-se de LC nos meses de fevereiro e março, tanto na TMB como na TCB. As TCB foram sempre maiores que as TMB. As quantidades mineralizadas e consumidas acumuladas por SD foram significativamente maiores às correspondentes no manejo LC, embora a cultura de milho não pode se beneficiar dessas diferenças, uma vez que a disponibilidade não coincidiu com os estágios de máxima demanda pela cultura do milho. 


\section{Summary}

Gross nitrogen mineralization (TMB) and consumption rates (TCB) were investigated in a field experiment with corn crop growing under no tillage (SD) and conventional tillage (LC) and pasture (P) during the same period. The soil was previously on conventional tillage for 17 years. TMB and TCB were estimated monthly with the dilution isotope ${ }^{15} \mathrm{~N}$ technique. Gross mineralization rates ranged between 0.18 and $2.41 \mathrm{mg} \mathrm{kg}^{-1} \mathrm{day}^{-1}$ and consumption rates between 0.21 and $3.52 \mathrm{mg} \mathrm{kg}^{-1} \mathrm{day}^{-1}$. Temporal high variations of TMB and TCB, associated with soil water contents were observed. Pasture TMB and TCB values were higher than LC and SD. TMB and TCB values of SD management system were higher than LC only on the February and March soil samplings. For all the management systems TCB was higher than TMB, being the total consumed amounts, higher than the mineralized ones. Total mineralized $\mathrm{N}$ was higher on SD than LC; however, the corn crop was not benefited since $\mathrm{N}$ availability did not meet the period of highest $\mathrm{N}$ demand.

\subsection{Introdução}

A matéria orgânica do solo (MOS) tem importante função na manutenção da fertilidade do solo por armazenar nutrientes, reduzindo o aporte de fertilizantes minerais, principalmente quando se pretende minimizar o impacto da agricultura na qualidade do meio ambiente.

O sistema de SD é uma alternativa de manejo de solo e culturas que por eliminar o revolvimento do solo, detém a redução da MOS. Os resultados da aplicação da SD são variáveis em função de diversos fatores, entre os quais se destaca o clima, a textura do solo, o manejo prévio da área e o numero de anos desde a implantação do sistema. Puget \& Lal (2004) realizaram uma avaliação de 28 estudos publicados envolvendo 56 experimentos em sistemas pareados de SD e LC, por meio de análise conjunta (meta-análise), e concluíram que a SD não teve efeito marcante no conteúdo 
total de matéria orgânica do solo, nem no seqüestro potencial de $\mathrm{N}$ em solos da ordem Molisol, mas verificaram incremento generalizado no teor de MO na camada de 0-5 cm, na conversão de LC para SD.

Na região SE da província de Buenos Aires, com clima temperado-úmido e solos de textura superficial franca a franco-arenosa, a SD não consegue melhorar os rendimentos das culturas com relação à $\mathrm{LC}$, mesmo com adição de grandes quantidades de nitrogênio ao solo (Domínguez et al., 2001; Echeverría \& Sainz Rozas, 2001; Aparicio et al., 2002), embora tenham sido obtidos indícios de melhora nas propriedades físicas (Ferreras et al., 2000) e bioquímicas do solo (Fabrizzi et al., 2003).

Estudos de longo prazo, analisando o efeito das lavouras na dinâmica da MOS, têm demonstrado que o revolvimento do solo produz uma importante redução no conteúdo de MOS e na mineralização do nitrogênio (Elliot, 1986; Six et al., 1999). É reconhecido que depois da conversão de LC a SD resulta em um aumento na quantidade de $\mathrm{N}$ nas frações lábeis, mas esse $\mathrm{N}$ tem menores taxas de reciclagem. Depois da instalação da SD teria lugar uma reconstrução da fração do $\mathrm{N}$ ativo do solo, aquela que na LC não se acumula, por ser continuamente mineralizada.

A implantação de pastagens após ciclos agrícolas com lavouras do tipo convencional é uma prática que também consegue recompor o conteúdo de matéria orgânica do solo e as suas propriedades físicas e biológicas (Studdert et al., 1997) conduzindo a uma estratificação da atividade radicular, de fungos e da fauna do solo (Haynes et al., 1991). Essas mudanças conduzem a modificações nos processos de mineralização no solo, que habitualmente são quantificadas por meio da mineralização líquida. Como a mineralização líquida é o resultado de combinações de taxas brutas dos processos que integram o ciclo do $\mathrm{N}$, medidas da TMB permitiriam melhorar a compreensão dos efeitos das práticas de manejo do solo, nos processos de ciclagem de nitrogênio.

O objetivo do presente trabalho foi estudar a evolução dos processos de mineralização e de consumo bruto de nitrogênio em condições de campo, em um 
Molisol sob SD e LC, durante um cultivo de milho, e sob pastagem, após 17 anos de manejo sob LC.

\subsection{Material e Métodos}

As determinações foram realizadas em experimento de campo como, descrito no Anexo B. Em 13 de outubro de 2003 foi semeado o milho, nos tratamentos SD e LC, com o híbrido Asgrow 160 MG, com distância entre linhas de 0,7 m, na densidade de 75.400 sementes por hectare. O preparo do solo na LC foi realizado em três operações, a saber: primeiro com grade de discos para misturar os resíduos vegetais da cultura anterior ao solo (agosto de 2003), seguido por arado de grade de $20 \mathrm{~cm}$ (agosto de 2003) e finalmente com grade de dentes (outubro de 2003). Foram realizadas duas aplicações de herbicidas antes da emergência, tanto nas parcelas de SD como nas de LC. Na LC o controle de plantas daninhas também foi realizado com cultivador de campo durante o crescimento da cultura do milho. Não se realizou fertilização mineral com $\mathrm{N}$ e $\mathrm{K}$, aplicando-se somente fósforo na dose de $50 \mathrm{~kg} \mathrm{ha}^{-1}$ de $\mathrm{P}_{2} \mathrm{O}_{5}$, na semeadura.

As determinações das taxas de mineralização e consumo bruto foram realizadas mensalmente, de outubro de 2003 a março de 2004. Em cada mês foram instalados 6 cilindros de PVC de $6 \mathrm{~cm}$ de diâmetro e $10 \mathrm{~cm}$ de profundidade em cada parcela (Figura 21). Ao solo de cada cilindro foi adicionado $14 \mathrm{~mL}$ de uma solução de sulfato de amônio com abundância de $10 \%$ em átomos de ${ }^{15} \mathrm{~N}$ em excesso, a uma taxa de $10 \mu \mathrm{g} \mathrm{g}^{-1} \mathrm{~N}$. A adição foi realizada utilizando-se de agulhas clínicas do tipo espinhal, com $10 \mathrm{~cm}$ de comprimento. As agulhas em número de 7 foram fixadas num disco de acrílico de igual diâmetro que os tubos de PVC. Uma vez inserido o conjunto de agulhas no solo, delas foi retirado o êmbolo interno que evitava a obstrução das mesmas com solo, conectandose, a seguir, o injetor que continha a solução de sulfato de amônio. A adição da solução foi feita ao mesmo tempo em que as agulha foram removidas do solo (Figura 22). 


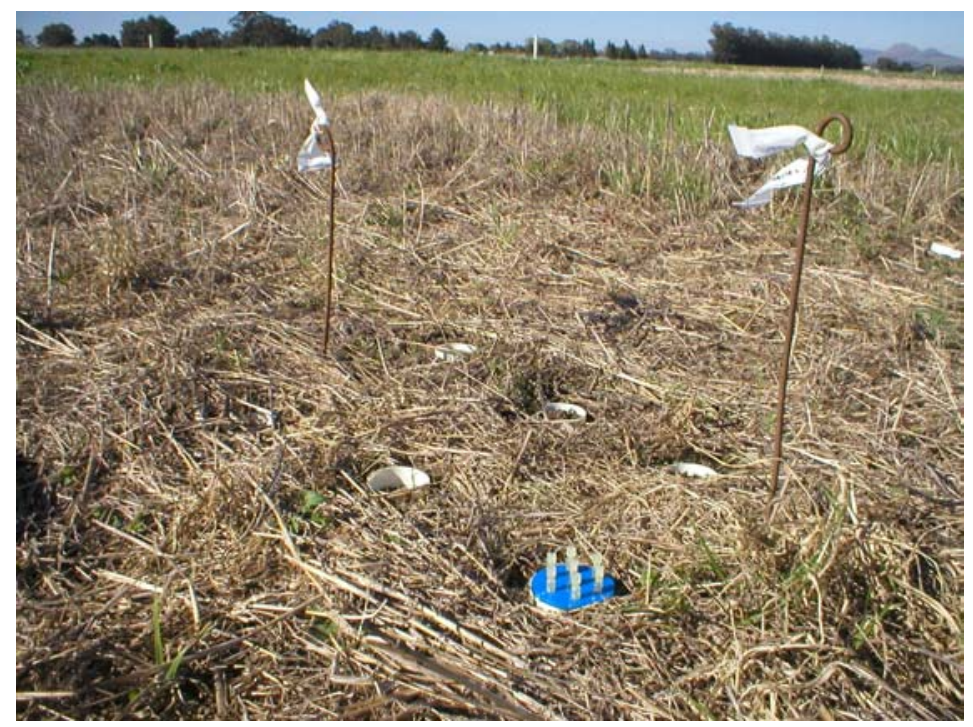

Figura 21. Distribuição dos cilindros para as determinações das taxas de mineralização bruta na pastagem e detalhe do disco de acrílico, contendo agulhas do tipo espinhal inseridas no solo.

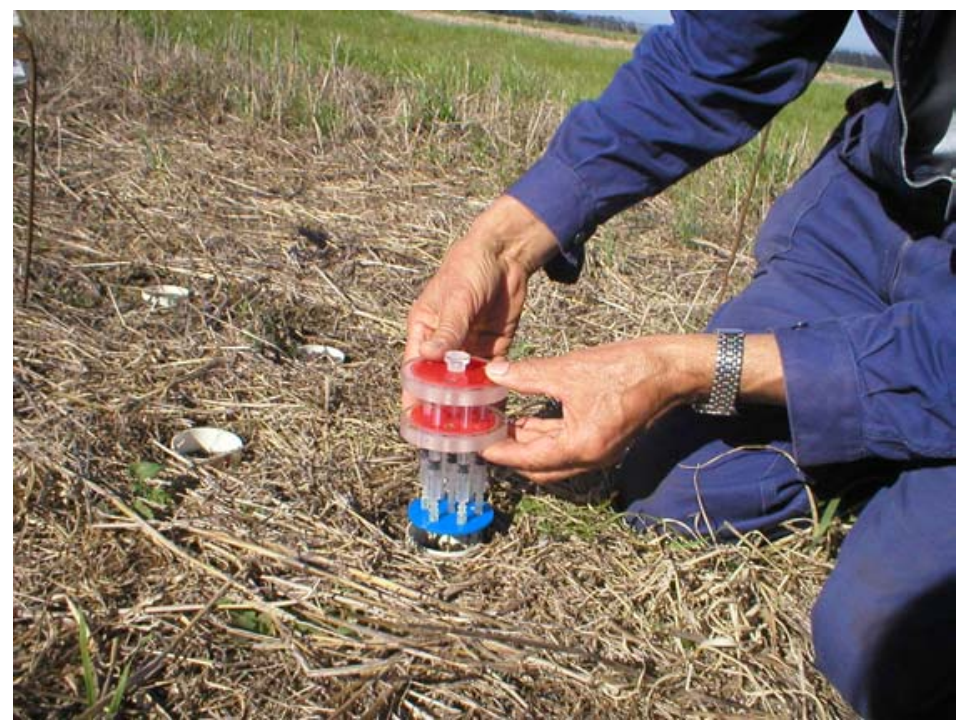

Figura 22. Adição de ${ }^{15} \mathrm{NH}^{+}{ }_{4}$ ao solo dos cilindros com injetor múltiplo e agulhas espinhais para a determinação das taxas de consumo e de mineralização bruta. 
Após 24 horas da adição de ${ }^{15} \mathrm{NH}_{4}{ }^{+}$, foram coletados a metade do número de cilindros de cada parcela e levados para o laboratório, onde foi obtida a massa total de solo por cilindro e realizada a extração com KCl, para determinar o conteúdo de $\mathrm{NH}_{4}^{+} \mathrm{e}$ o seu enriquecimento em ${ }^{15} \mathrm{~N}$. A extração foi realizada em aproximadamente $60 \mathrm{~g}$ de solo, com prévia homogeneização, usando-se $200 \mathrm{~mL}$ de solução de $\mathrm{KCl} 2 \mathrm{M}$, sob agitação, por $1 \mathrm{~h}$. $\mathrm{O}$ extrato contendo o $\mathrm{N}$-amônio foi filtrado antes das etapas de determinações Uma parte da massa de solo de cada cilindro foi utilizada para determinar o conteúdo de água por gravimetria, após secagem em estufa a $105^{\circ} \mathrm{C}$. O N-amônio dos extratos foi determinado por titulometria após microdestilação dos extratos por arraste de vapor na presença de $\mathrm{MgO}$ (Bremner, 1965). Uma alíquota de $60 \mathrm{~mL}$ de extrato foi preparada por microdifussão para a determinação de ${ }^{15} \mathrm{~N}$. A microdifussão foi realizada com o método de Sorensen \& Jensen (1991) e as determinações de ${ }^{15} \mathrm{~N}$ em um espectrômetro de massas da Europa Sc. ANCA-SL

Os cilindros restantes foram extraídos seis dias depois e seguiram o mesmo protocolo que os primeiros. Com os valores de enriquecimento da fração de amônio inicial e final foram calculadas as taxas de mineralização bruta (TMB) e as de consumo bruto de amônio (TCB) segundo as equações (2) e (3), respectivamente.

Nas parcelas a campo foi determinada a densidade aparente de solo pelo método do anel volumétrico (Blake \& Hartge, 1986) e o conteúdo de água à capacidade de campo (Gardner, 1986). Em cada parcela foi instalado um sensor de temperatura a 7,5 $\mathrm{cm}$ de profundidade. Estimou-se o balanço de água do solo usando um modelo simples que assume o solo como um reservatório, no qual o conteúdo de água varia entre os limites inferior e superior (Della Maggiora et al., 2003).

Antes da semeadura do milho colheram-se amostras compostas de solo em três profundidades 0-5, 5-10 e 10-20 cm. Nestas amostras foi determinado o conteúdo de C orgânico (Walkley \& Black, 1934) e o N total por digestão-destilação Kjelhdal.

Os valores obtidos de TMB e TCB foram submetidos à analise da variância segundo o modelo de classificação hierárquica (ou aninhada) com o fator tempo 
(medições mensais) aninhado ao manejo. Quando foram necessários, realizaram-se testes de Tukey para comparar as médias a um nível de probabilidade de 5\%.

\subsection{Resultados e Discussão}

O período de estudo apresentou temperaturas ambientes muito similares aos valores históricos da área, mas as precipitações foram maiores que os valores históricos para os meses de outubro a dezembro, e muito baixas em janeiro (Figura 23), o que condicionou o desenvolvimento da cultura de milho e da pastagem, como também, os processos microbianos no solo.

As plantas de milho sofreram déficit hídrico a partir do segundo decênio do mês de janeiro (Figura 24), em coincidência com o período em que é determinado o rendimento da cultura (Andrade \& Sadras, 2002).
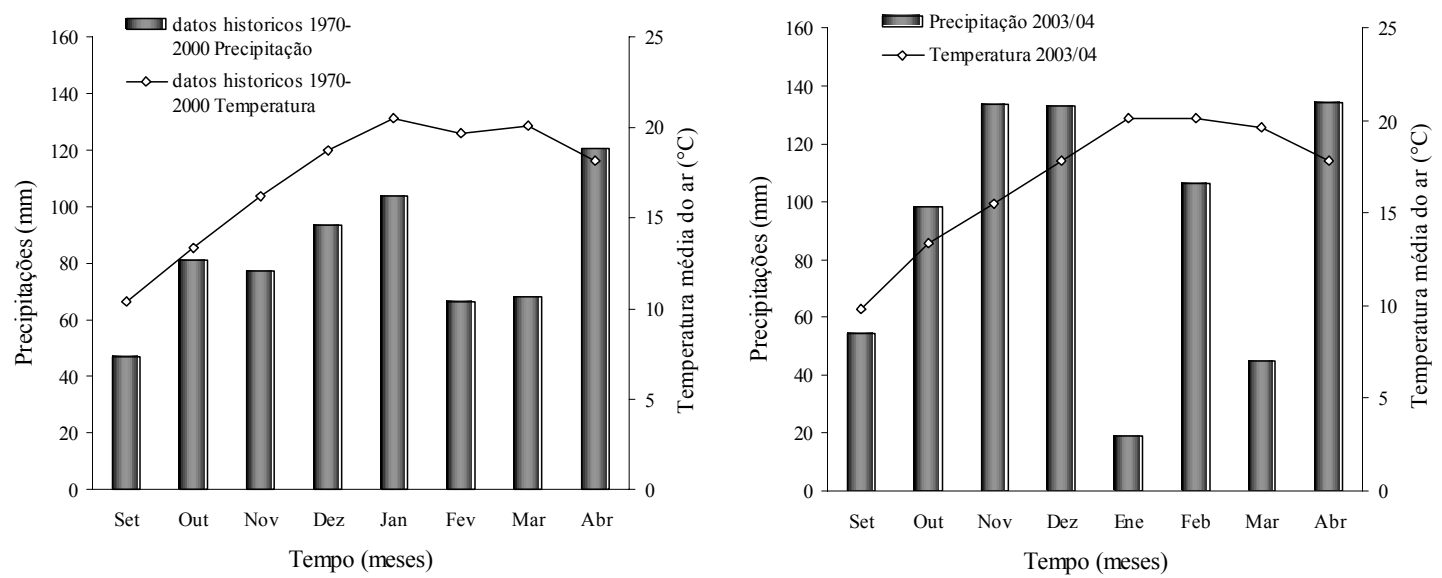

Figura 23. Precipitações e temperatura ambiente no período setembro-abril históricos (período 1970-2000) e em 2003-2004. 
Esta situação resultou em baixos rendimentos, tanto para a LC (6970 $\left.\mathrm{kg} \mathrm{ha}^{-1}\right)$ como para SD $\left(2720 \mathrm{~kg} \mathrm{ha}^{-1}\right)^{1}$. Esta diferença em rendimento entre os manejos foi a máxima encontrada em todos os anos, desde a instalação do experimento; nos anos anteriores as diferenças foram de no máximo $1150 \mathrm{~kg} \mathrm{ha}^{-1}$, geralmente em favor da SD, mais nem sempre foram significativas. No ciclo agrícola 2003-04 deve-se destacar que as condições meteorológicas fizeram que a aplicação de herbicidas em SD não fosse completamente efetiva, resultando em alta competição entre as plantas daninhas e a cultura do milho, fato esse que juntamente com o déficit hídrico, explicam a diferença de rendimento.

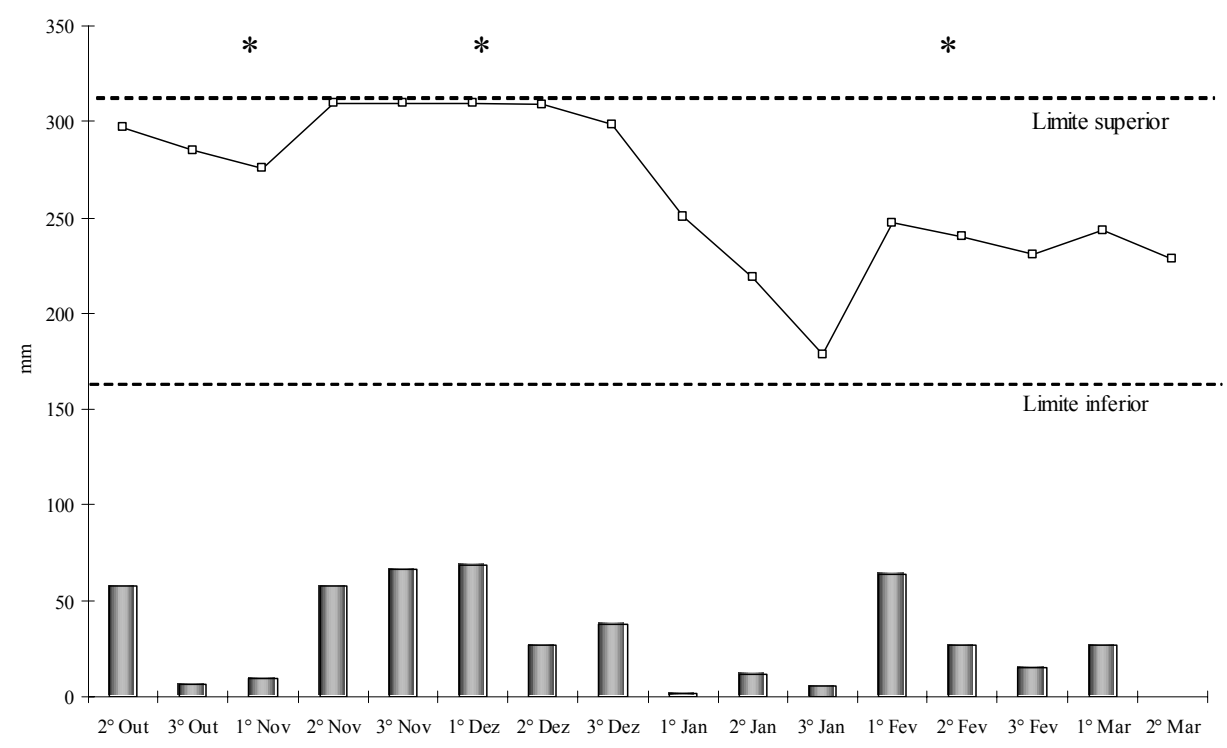

Figura 24. Precipitações (em colunas) e dinâmica de acumulação de água no solo para o cultivo de milho (linha continua) no período outubro de 2003 a março de 2004. Linhas de pontos indicam o limite superior e inferior da água disponível para as plantas; os asteriscos indicam as datas médias de emergência, V6, floração e maturação fisiológica.

\footnotetext{
${ }^{1}$ DOMÍNGUEZ, G., comunicação pessoal, 2004.
} 


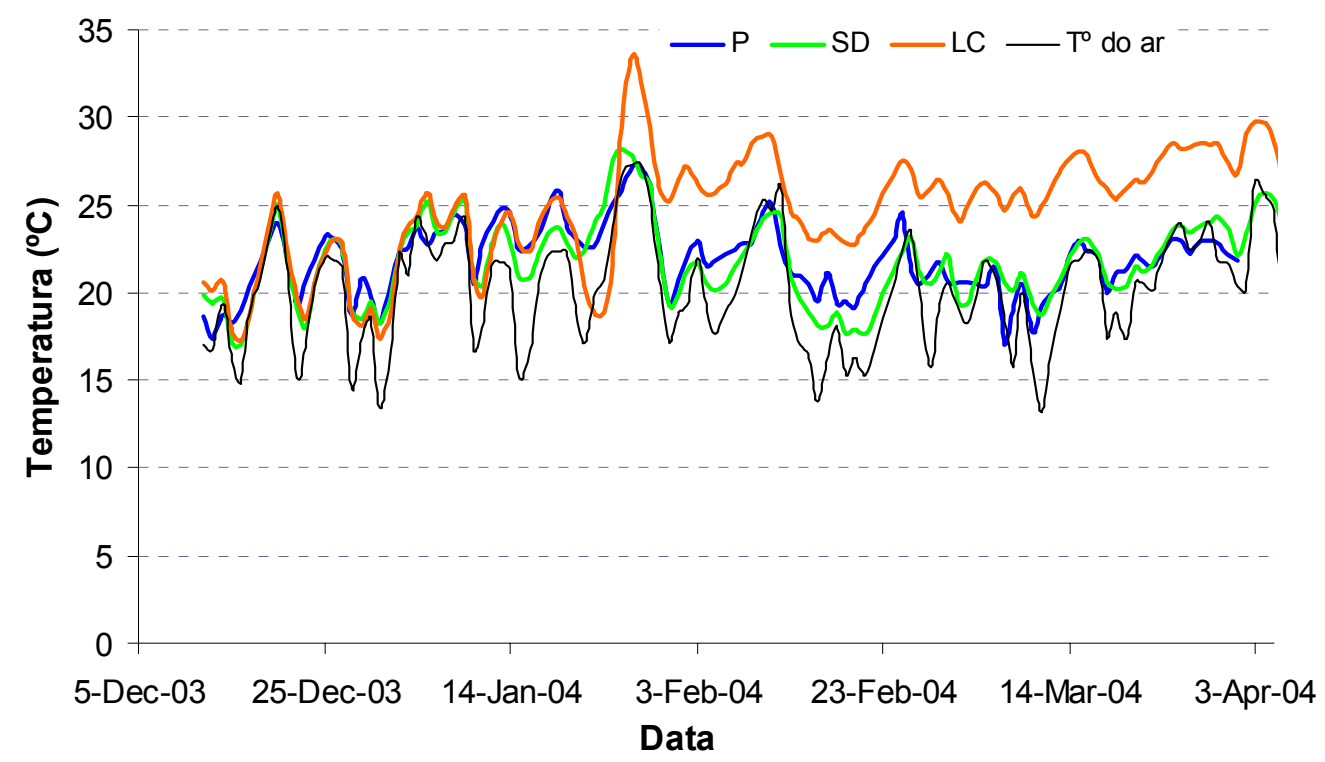

Figura 25. Temperatura de solo a 7,5 cm de profundidade nos tratamentos lavoura convencional (LC), semeadura direta (SD) e pastagem (P).

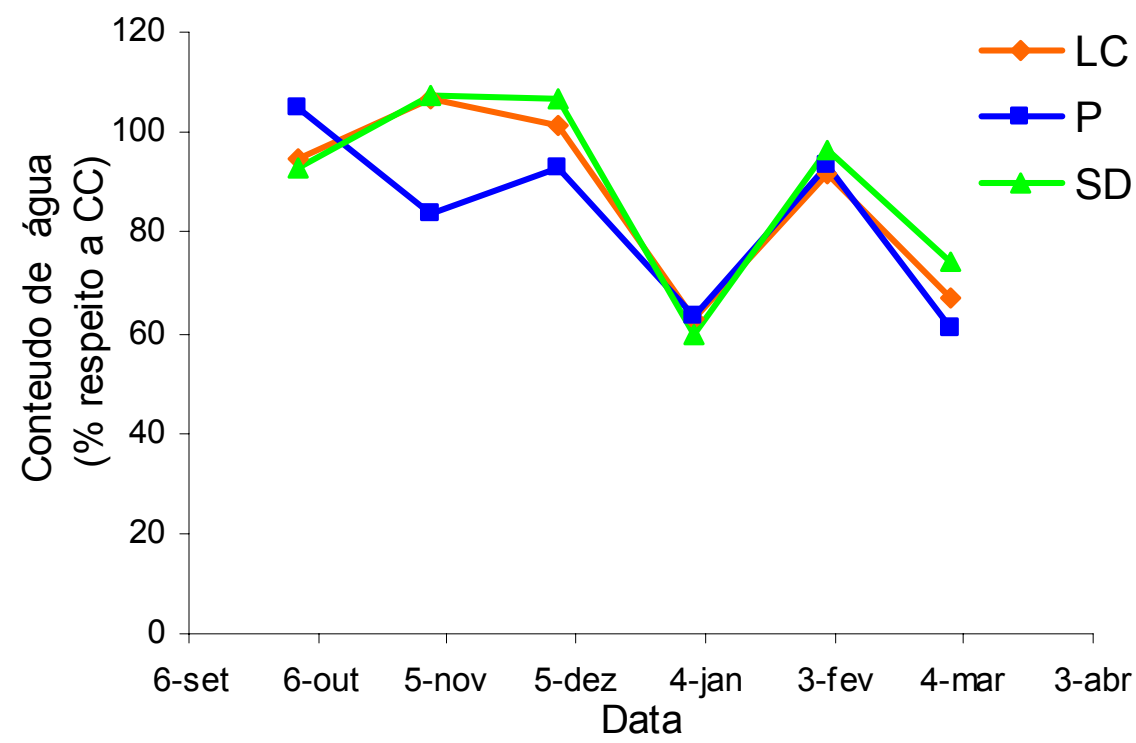

Figura 26. Conteúdo de água do solo no período de outubro 2003 a março 2004, nas parcelas sob lavoura convencional (LC), semeadura direta (SD) e pastagem (P). 
A temperatura do solo foi similar nos três manejos até o mês de janeiro, quando a temperatura da LC apresentou incrementos que se manifestaram, inclusive, até o momento da colheita (Figura 25). Apesar de as pequenas diferenças nos primeiros meses entre LC e SD, a emergência e o estágio V6 de SD ficou atrasados em três dias em relação à LC, enquanto na floração o atraso foi de 5 dias $^{2}$.

O conteúdo de água expresso como porcentagem da capacidade de campo foi geralmente maior em SD e LC que na pastagem, e apresentou uma importante redução em janeiro, alcançando, em média, valores próximos a 60\% (Figura 26).

\section{Conteúdo da fração amônio no solo e enriquecimento em ${ }^{15} \mathrm{~N}$}

Os conteúdos de amônio no solo apresentaram valores menores que $20 \mathrm{mg} \mathrm{kg}^{-1}$ durante todo o período de medidas, tanto nos tratamentos agrícolas quanto na pastagem (Tabela 11). Na primeira extração, após a adição de ${ }^{15} \mathrm{NH}^{+}{ }_{4}$, os valores flutuaram entre 7,15 e $14,7 \mathrm{mg} \mathrm{kg}^{-1}$ e na segunda extração entre 0,50 e $19,11 \mathrm{mg} \mathrm{kg}^{-1}$. Com exceção ao mês de outubro, quando aconteceu um pequeno aumento, nos outros meses verificou-se sempre redução nos conteúdos de amônio, entre a primeira e segunda extração, indicando que os processos que consomem o amônio estiveram ocorrendo muito ativamente no solo. É de se destacar que na pastagem, este consumo inclui a absorção de $\mathrm{N}$ pelas plantas desde o início, e que taxas de crescimento aumentam nesse período.

$\mathrm{O}$ enriquecimento inicial do amônio em ${ }^{15} \mathrm{~N}$ foi, em todos os meses, menor na pastagem que em SD e LC, indicando a ocorrência de atividade biológica maior neste manejo. Este comportamento estaria indicando que na $\mathrm{P}$ após $24 \mathrm{~h}$ de adicionado o marcador, aconteceu diluição isotópica como conseqüência da atividade microbiana.

${ }^{2}$ DOMÍONGUEZ, G., comunicação pessoal, 2004. 
Tabela 11. Conteúdo da fração amônio e enriquecimento em ${ }^{15} \mathrm{~N}$ depois da adição de ${ }^{15} \mathrm{NH}^{+}{ }_{4}$ nos manejos: lavoura convencional (LC), semeadura direta (SD) e pastagem $(\mathrm{P})$, nos meses de outubro a março. Valores médios para $\mathrm{n}=27$; desvios padrões entre parêntesis.

\begin{tabular}{|c|c|c|c|c|c|}
\hline \multirow[t]{2}{*}{ Mês } & \multirow[t]{2}{*}{ Manejo } & \multicolumn{2}{|c|}{$\mathrm{NH}_{4}^{+}\left(\mathrm{mg} \mathrm{kg}^{-1}\right.$ de $\left.\mathrm{N}\right)$} & \multicolumn{2}{|c|}{ Abundância de ${ }^{15} \mathrm{~N}$ (átomos em excesso) } \\
\hline & & inicial & final & inicial & final \\
\hline \multirow[t]{3}{*}{ Outubro } & $\mathrm{LC}$ & $10.15(1.71)$ & $15.51(2.73)$ & $7.11(0.27)$ & $7.40(0.42)$ \\
\hline & $\mathrm{P}$ & $12.92(2.36)$ & $17.09(0.74)$ & $4.62(0.09)$ & $5.99(0.49)$ \\
\hline & SD & $9.12(0.18)$ & 19.11(1.85) & $7.53(0.26)$ & $7.93(0.43)$ \\
\hline \multirow[t]{3}{*}{ Novembro } & LC & $14.20(3.18)$ & $9.32(1.98)$ & $7.60(0.45)$ & $7.24(0.45)$ \\
\hline & $\mathrm{P}$ & $12.66(3.44)$ & $9.43(0.25)$ & $6.65(0.40)$ & $6.29(0.41)$ \\
\hline & SD & $14.76(2.9)$ & $8.44(2.75)$ & $7.58(0.40)$ & $7.26(0.38)$ \\
\hline \multirow[t]{3}{*}{ Dezembro } & LC & $7.001 .18)$ & $1.69(0.40)$ & $8.47(0.08)$ & $3.22(1.12)$ \\
\hline & $\mathrm{P}$ & $12.89(2.32)$ & $5.12(1.21)$ & $6.78(0.26)$ & $0.75(0.03)$ \\
\hline & SD & $8.49(1.14)$ & $0.50(0.15)$ & $8.62(0.06)$ & $0.73(0.20)$ \\
\hline \multirow[t]{3}{*}{ Janeiro } & LC & $7.15(0.39)$ & $4.52(1.24)$ & $8.21(0.66)$ & $6.20(1.78)$ \\
\hline & $\mathrm{P}$ & $8.86(1.13)$ & $4.43(0.29)$ & $5.64(0.47)$ & $4.36(1.84)$ \\
\hline & SD & $7.70(1.93)$ & $4.20(1.80)$ & $6.59(1.62)$ & $6.32(0.24)$ \\
\hline \multirow[t]{3}{*}{ Fevereiro } & LC & $6.00(0.35)$ & $1.80(0.68)$ & $8.27(0.20)$ & $5.59(0.40)$ \\
\hline & $\mathrm{P}$ & $6.09(0.56)$ & $2.84(1.62)$ & $5.28(0.32)$ & $0.92(0.04)$ \\
\hline & SD & $7.52(0.98)$ & $2.04(1.05)$ & $6.78(0.37)$ & $1.89(0.72)$ \\
\hline \multirow[t]{3}{*}{ Março } & LC & $7.70(1.49)$ & $1.96(0.55)$ & $8.55(0.25)$ & $6.33(0.61)$ \\
\hline & $\mathrm{P}$ & $9.06(0.37)$ & $6.02(1.98)$ & $6.54(0.07)$ & $1.82(0.29)$ \\
\hline & SD & $8.16(0.97)$ & $2.37(1.28)$ & $8.37(0.29)$ & $1.82(0.67)$ \\
\hline
\end{tabular}

No mês de outubro, quando a extração final ocorreu $72 \mathrm{~h}$ após a adição do ${ }^{15} \mathrm{NH}_{4}^{+}$, apresentaram-se maiores valores médios finais de enriquecimento que os iniciais. Este resultado, com certeza, foi causado pela alta variabilidade espacial dos resultados, não sendo admissível que a matéria orgânica estivesse originalmente enriquecida, pelo fato que o solo do local não tinha sido utilizado em experimentos prévios com ${ }^{15} \mathrm{~N}$. A alta variabilidade pode ter sido causada pela distribuição não homogênea do marcador, devido a baixa umidade do solo $\left(0,175 \mathrm{~g} \mathrm{~g}^{-1}\right.$ para LC, 0,242 $\mathrm{g}$ $\mathrm{g}^{-1}$ para $\mathrm{P}$ e $0,17 \mathrm{~g} \mathrm{~g}^{-1}$ para SD). Esta condição levou a valores negativos de TMB e TCB, tratando-se de resultados sem valor real no sentido biológico, sendo pois descartados, 
permanecendo, somente, 39 valores de TMB e 22 de TCB. Esse baixo número de repetições põe em alerta à confiabilidade das inferências para este mês e fez com que nos meses seguintes fosse decidido por fazer a segunda extração após 6 dias, a fim de permitir a melhor difusão da solução marcadora pelo solo.

No mês de novembro, o enriquecimento final em ${ }^{15} \mathrm{~N}$ do amônio apresentou reduções muito pequenas, indicando baixa atividade biológica. Nos meses seguintes as quedas no enriquecimento do amônio foram maiores e com importantes diferenças como resposta ao manejo e às condições ambientais, determinantes da atividade dos microrganismos. Em geral, a P foi o manejo que apresentou maiores diluições na fração amônio, o que o que estaria indicando a mineralização mais ativa.

\section{Taxas de mineralização bruta.}

A TMB foi influenciada significativamente pelo fator tempo, enquanto que o manejo somente foi significativo a $10 \%$ de probabilidade; a interação tempoxmanejo revelou-se significativa. As maiores flutuações em TMB foram evidenciadas na pastagem, onde se obtiveram valores médios tão baixos como $0,21 \mathrm{mg} \mathrm{kg}^{-1} \mathrm{dia}^{-1} \mathrm{em}$ novembro, e tão altos como $2,41 \mathrm{mg} \mathrm{kg}^{-1} \mathrm{dia}^{-1}$ em dezembro.

No mês de outubro, não foram significativas as diferenças entre manejos, apesar da tendência de ter ocorrido mineralização mais ativa na pastagem (Figura 27). Em novembro, as TMB nos três manejos foram baixas, mas a LC apresentou valor significativamente maior. Em dezembro a pastagem teve TMB muito maior que os outros tratamentos. Em janeiro todas as taxas apresentaram valores muito baixos, certamente relacionados ao estresse hídrico, originado pela baixa pluviosidade nesse mês (19,2 mm), muito inferior à média histórica $(103,9 \mathrm{~mm})$. Em fevereiro e março manifestou-se uma recuperação nas $\mathrm{TMB}$ de $\mathrm{P}$ e $\mathrm{SD}$, mas LC apresentou os menores valores nesses meses. Somente nesses últimos meses, a TMB de SD foi significativamente maior àquela de LC. Os valores médios de TMB foram sensivelmente menores que os medidos no campo por Corre et al. (2002), em pastagem da Pensilvânia (USA), com composição botânica semelhante ao do presente trabalho, e que foram em

média de $6,52 \mathrm{mg} \mathrm{kg}^{-1} \mathrm{dia}^{-1}$, estimativas essas realizadas em diferentes estações no ano. 
Os valores deste trabalho foram da mesma ordem dos quantificados por Jamieson et al. (1999) em solos da Inglaterra com altos conteúdos de MO $\left(85 \mathrm{~g} \mathrm{~kg}^{-1}\right)$, e que variaram entre 0,36 e 2,36 $\mathrm{mg} \mathrm{kg}^{-1} \mathrm{dia}^{-1}$, com clara influência estacional em relação ao conteúdo de água e da temperatura.

\section{Taxa de consumo bruto}

As TCB apresentaram efeito significativo com o tempo e interação tempo $\times$ manejo. Em geral, a TCB foi menos variável que a TMB, mas também foi $\mathrm{P}$ o manejo que apresentou, em dezembro, o maior valor médio (3,52 $\left.\mathrm{mg} \mathrm{kg}^{-1} \mathrm{dia}^{-1}\right)$, enquanto que a SD apresentou o menor valor médio $\left(0,21 \mathrm{mg} \mathrm{kg}^{-1} \mathrm{dia}^{-1}\right)$. Na maioria das combinações tempo $\times$ manejo, a TCB foi maior que TMB, o que estaria indicando que a absorção de $\mathrm{N}$ pelas plantas é um processo que sempre deve competir com os processos microbianos de imobilização. Esse efeito dá uma idéia da grandeza entre a oferta e a demanda por N, como proposto por Pilbeam \& Warren (1996) e Gava (2003).

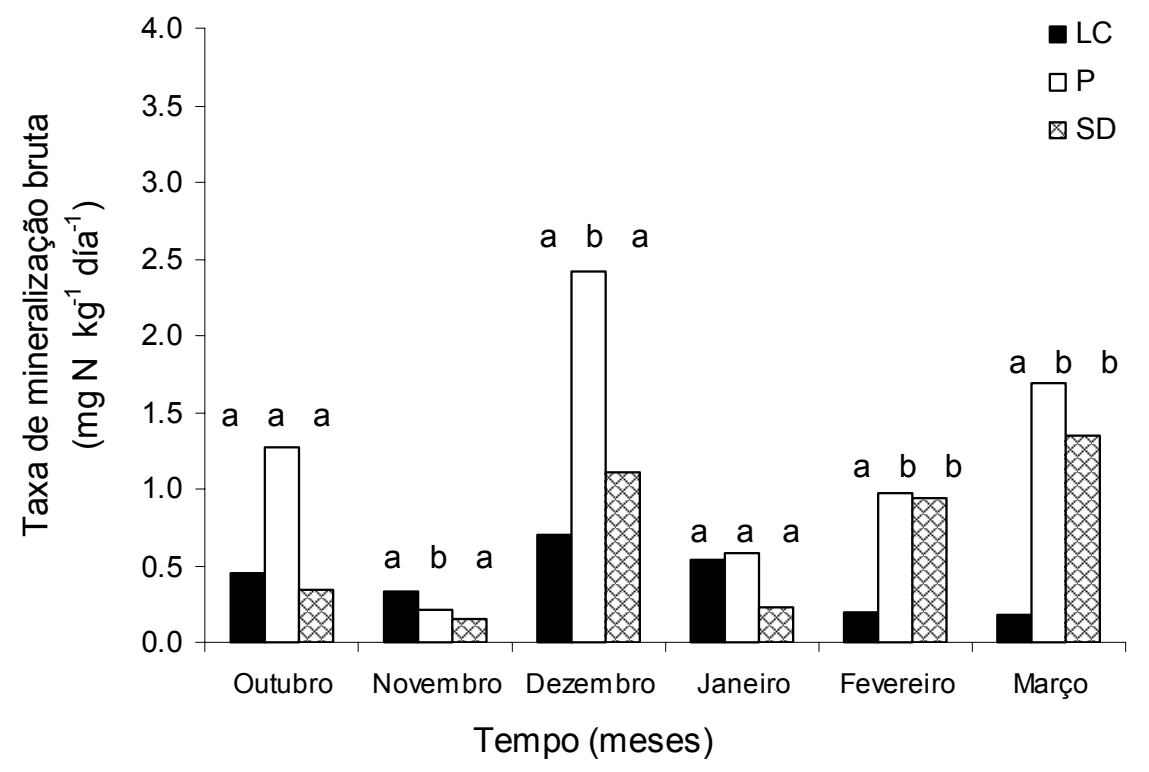

Figura 27. Taxa de mineralização bruta nos manejos lavoura convencional (LC), semeadura direta (SD) e pastagem (P) durante o ciclo agrícola do milho 2003-2004. 
Em outubro, devido à situação já discutida de aumento no enriquecimento entre a primeira e a segunda extração e com a diminuição no número de repetições, as TCB de $\mathrm{P}, \mathrm{SD}$ e LC não foram estatisticamente significativas, apesar que SD teve um valor médio, notavelmente, menor que LC e SD (Figura 28). Em novembro, as TMB também não apresentaram diferenças significativas entre manejos, mas todas foram maiores que TMB, com um valor médio de $1,45 \mathrm{mg} \mathrm{kg}^{-1} \mathrm{dia}^{-1}$.

Nos meses de dezembro e janeiro a TCB de $\mathrm{P}$ foi significativamente maior que LC e SD, alcançando valor médio de $3,52 \mathrm{mg} \mathrm{kg}^{-1} \mathrm{dia}^{-1}$ em dezembro, sendo esse o maior valor registrado em todo o experimento e coincidente com a maior TMB.

As TCB de janeiro também sofreram redução devido à baixa pluviometria, mas aumentaram em fevereiro e março. Nestes dois meses, o consumo de LC foi significativamente menor que o de SD e P.

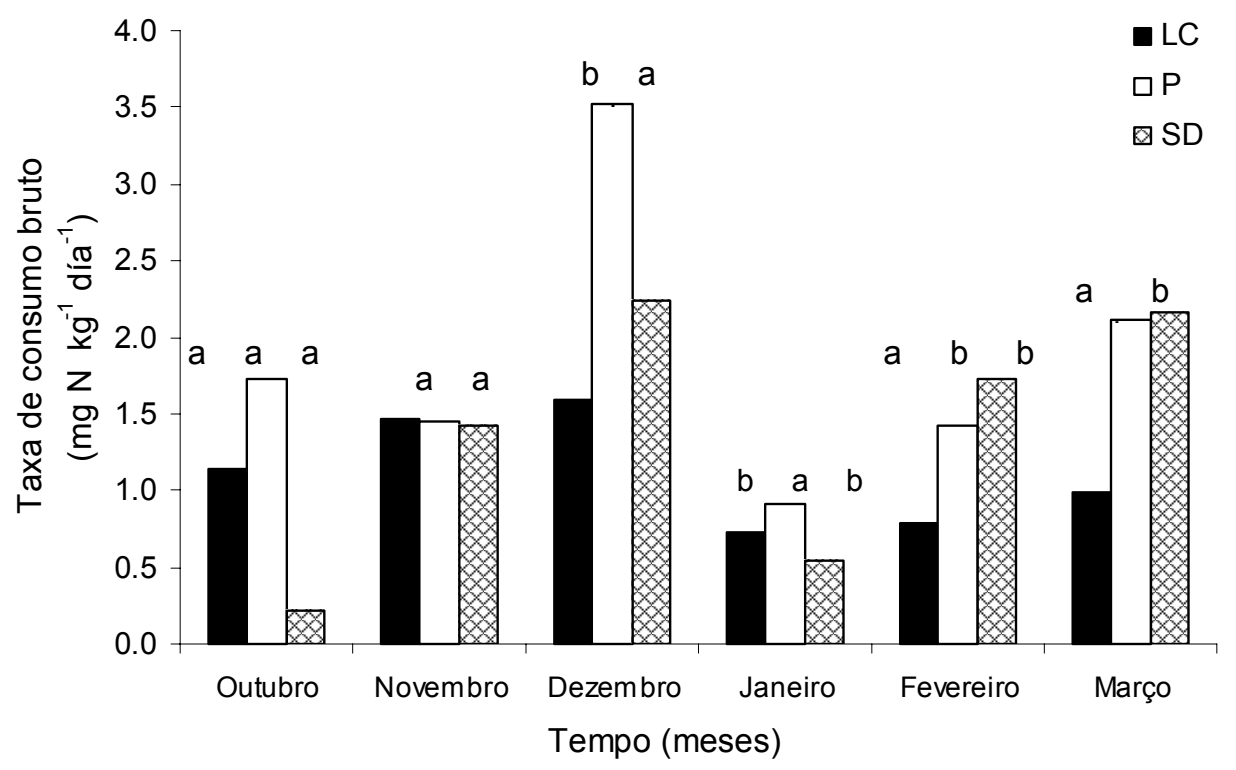

Figura 28. Taxa de consumo bruto nos manejos lavoura convencional (LC), semeadura direta (SD) e pastagem (P) durante o ciclo agrícola do milho 2003-2004. 


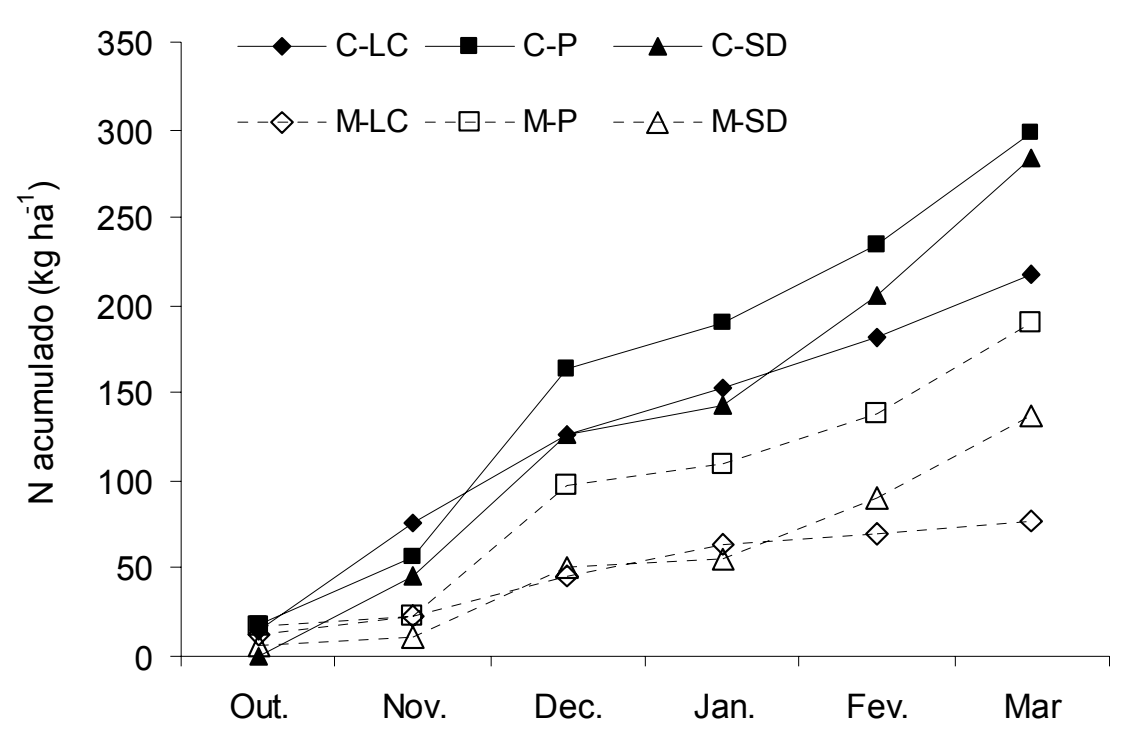

Figura 29. Acumulação de $\mathrm{N}$ mineralizado (M) e consumido (C) durante o período experimental outubro 2003 a março 2004 nos manejos lavoura convencional (LC), pastagem (P) e semeadura direta (SD).

As TMB e TCB apresentaram-se mais influenciadas pela umidade do solo que pela temperatura, como também verificado nos estudos do capítulo 6; é possível que a variação na temperatura não fosse muito ampla, pois o período amostrado só incluiu as estações de primavera e verão, com uma variação em média entre 13 e $25^{\circ} \mathrm{C}$.

Os valores determinados de densidade aparente do solo, na profundidade de 10 $\mathrm{cm}\left(1,21 \mathrm{Mg} \mathrm{m}^{-3}\right.$ para LC, 1,02 $\mathrm{Mg} \mathrm{m}^{-3}$ para $\mathrm{P}$ e 1,19 $\mathrm{Mg} \mathrm{m}^{-3}$ para SD), foram utilizados no cálculo das quantidades mineralizadas e consumidas que formam acumuladas durante o período experimental (Figura 29). De forma similar com os resultados apresentados na Figura 11, as quantidades acumuladas de $\mathrm{N}$ mineralizado foram, nos três manejos, inferiores às quantidades consumidas, mas, neste experimento, a LC foi o manejo em que as quantidades mineralizadas e consumidas de amônio foram menores ( 77 e $218 \mathrm{~kg}$ $\mathrm{ha}^{-1}$ respectivamente). A mineralização acumulada na pastagem foi de $190 \mathrm{~kg} \mathrm{ha}^{-1}$ e o consumo $299 \mathrm{~kg} \mathrm{ha}^{-1}$, enquanto que a $\mathrm{SD}$ indicou, como na maioria das situações 
estudadas, um comportamento intermédio entre LC e P, mineralizando $137 \mathrm{~kg} \mathrm{ha}^{-1} \mathrm{e}$ consumindo $283 \mathrm{~kg} \mathrm{ha}^{-1}$. As diferenças entre o $\mathrm{N}$ mineralizado e o $\mathrm{N}$ consumido foram menores na pastagem (109 $\left.\mathrm{kg} \mathrm{ha}^{-1}\right)$ e não apresentaram diferenças entre LC e SD (143 $\left.\mathrm{kg} \mathrm{ha}^{-1}\right)$. As quantidades mineralizadas acumuladas foram significativamente diferentes entre os três manejos $(\mathrm{p}<0,001)$ e as consumidas por $\mathrm{SD}$ e $\mathrm{P}$ foram maiores às consumidas por LC.

Os manejos LC e SD comportaram-se de forma similar até fevereiro. Como pode ser observado na Figura 29, as quantidades acumuladas de $\mathrm{N}$ mineralizado e consumido na $\mathrm{SD}$, começaram a se diferenciar dos correspondentes valores de LC no último período de medições, quando a TMB e TCB de SD foram muito elevadas e significativamente superiores às de LC. Esta maior quantidade de $\mathrm{N}$ mineralizado no final do ciclo do milho em SD, não seria aproveitado pela cultura na definição de rendimento, uma vez que nesse estádio tardio a taxa de absorção de $\mathrm{N}$ pelas plantas já deve ocorrer em taxas decrescentes (Andrade et al., 2002). Efetivamente, apesar de SD ter mineralizado uma quantidade maior de nitrogênio que LC, o rendimento em grãos da cultura de milho foi muito inferior em SD, podendo-se afirmar que a alta incidência de plantas daninhas em SD tenha atuado como um dreno do $\mathrm{N}$ mineralizado, impedindo a definição de maior rendimento da cultura pela diferença no aporte de $\mathrm{N}$.

As TMB do presente experimento para as parcelas cultivadas com milho são algo menores que as quantificadas por Nishio \& Fujimoto (1989) em solos (Andosols) do Japão, entre 1,15 e $3,77 \mathrm{mg} \mathrm{kg}^{-1} \mathrm{dia}^{-1}$. Para esses solos foram calculadas quantidades mineralizadas acumuladas, durante o período de crescimento do milho, da ordem de 521 e $808 \mathrm{~kg} \mathrm{ha}^{-1}$ de $\mathrm{N}$, valores esses elevados, mesmo tendo sido calculados para uma profundidade de solo de $35 \mathrm{~cm}$, se comparados aos obtidos neste trabalho de tese de doutorado. 


\subsection{Conclusões}

A metodologia da diluição do ${ }^{15} \mathrm{~N}$ foi adequada para a quantificação das TMB em campo.

As TMB e TCB apresentaram elevada variação no tempo, associada principalmente, às mudanças na umidade do solo.

As TMB e TCB da pastagem foram, geralmente, maiores que as de LC e SD. A SD diferenciou-se de LC nos meses de fevereiro e março, tanto na TMB como na TCB. As TCB foram sempre maiores que TMB.

As quantidades mineralizadas e consumidas, acumuladas em SD foram maiores às correspondentes de LC, embora a cultura de milho não tenha se beneficiado dessas diferenças, pela defasagem entre o estádio de máxima demanda por $\mathrm{N}$ pela cultura e a época de disponibilidade de $\mathrm{N}$ no solo. 


\section{CONCLUSÕES GERAIS}

A metodologia de diluição do isótopo ${ }^{15} \mathrm{~N}$ permitiu a determinação de taxas de mineralização e de consumo bruto em um Molisol do SE da Província de Buenos Aires sob diferentes sistemas de manejo, tanto em condições de laboratório, com amostras deformadas, quanto diretamente em campo, com amostras indeformadas. $\mathrm{Na}$ quantificação da taxa de nitrificação bruta, a marcação do solo com amônio- ${ }^{15} \mathrm{~N}$ não se mostrou adequado, levando a resultados muito variáveis, com evidencias de estimulação pelo substrato.

Quando foram quantificados os processos brutos em laboratório em período de 35 dias, com amostras deformadas na temperatura de $25^{\circ} \mathrm{C}$ e umidade de $60 \%$ da máxima capacidade de retenção de água do solo, a pastagem apresentou maiores TMB em amostras superficiais e nos primeiros dias de medição, enquanto que LC apresentou taxas maiores, de 10-20 cm de profundidade, após três semanas de incubação. A SD teve um comportamento semelhante à pastagem, mas com taxas menores. Verificou-se uma marcante estratificação nos processos brutos do nitrogênio, sendo maiores em superfície que em profundidade.

Em todos os experimentos, as taxas de consumo foram maiores que as de mineralização e as quantidades totais consumidas superaram àquelas mineralizadas.

Nos três manejos (LC, SD e P) mais que $80 \%$ do $\mathrm{C}$ e do $\mathrm{N}$ encontravam-se nas frações $<50 \mu \mathrm{m}$, indicando alta proteção física da matéria orgânica do solo. A P acumulou $112 \%$ mais $\mathrm{C}$ e $116 \%$ mais $\mathrm{N}$ nas frações leves $>50 \mu \mathrm{m}$ que LC. A SD não apresentou diferença com LC. O manejo não modificou as frações $<50 \mu \mathrm{m}$. 
Não se evidenciou um padrão simples relacionando TMB e TCB com as variáveis das frações granulométricas, indicando alta complexidade dos efeitos do manejo nos processos brutos do nitrogênio no solo. As equações de regressão múltiplas separadas para LC incluíram, freqüentemente, o $\mathrm{C}$ e $\mathrm{N}$ das frações mais finas, enquanto que nos modelos para $\mathrm{P}$ as frações leves $>50 \mu \mathrm{m}$ apareceram com maior freqüência, indicando recuperação da MO do solo.

A temperatura e a umidade do solo tiveram efeito nas TMB e TCB, sendo que as maiores $\mathrm{TMB}$ e $\mathrm{TCB}$ ocorreram a $25^{\circ} \mathrm{C}$ e na umidade de $70 \% \mathrm{MCR}$. A LC não apresentou resposta em temperatura e nem para umidade de solo.

Em campo, as TMB e TCB apresentaram variações no tempo, associadas, principalmente, às variações na umidade do solo. As TMB e TCB de pastagem foram geralmente maiores que as de LC e SD. As TMB e TCB de SD foram maiores que as de LC nos meses de fevereiro e março. As quantidades mineralizadas e consumidas acumuladas por SD foram maiores às correspondentes de LC, embora a cultura de milho não foi beneficiada por essas diferenças devido a disponibilidade não coincidir com os estádios de máxima demanda pelas plantas. 


\section{REFERÊNCIAS BIBLIOGRÁFICAS}

ACCOE, F.; BOECKX P.; BUSSCHAERT, J.; HOFMAN, G.; VAN CLEEMPUT. O. Gross transformations rates and net mineralisation rates related to the $\mathrm{C}$ and $\mathrm{N}$ contents of soil organic matter fractions in grasslands soils of different age. Soil Biology \& Biochemistry, v.36, p.2075-2087, 2004.

ALVAREZ, C.R.; ALVAREZ, R.; GRIGERA, M.S.; LAVADO, R.S. Associations between organic matter fractions and the active soil microbial biomass. Soil Biology \& Biochemistry, v.30, p.767-773, 1998.

ALVAREZ, R.; DÍAZ, R.; BARBERO, N.; SANTANATOGLIA, O.; BLOTTA, L. Soil organic carbon, microbial biomass and $\mathrm{CO} 2-\mathrm{C}$ production from three tillage systems. Soil and Tillage Research, v.33, p.17-28, 1995.

ANDERSEN, M.K.; JENSEN, L.S. Low soil temperature effects on short-term gross N mineralization-immobilisation turnover after incorporation of a green manure. Soil Biology \& Biochemistry, v.33, p.511-521, 2001.

ANDERSON, D.W.; PAUL, E.A. Organo-mineral complexes and their study by radiocarbon dating. Soil Science Society of America Journal, v.48, p.298-301, 1984.

ANDRADE, F.H.; ECHEVERRÍA, H.E.; GONZÁLEZ, N.S.; UHART, S.A. Requerimientos de nutrientes minerales. In: ANDRADE, F.H.; SADRAS, V.O. (Ed.) Bases para el manejo del maíz, el girasol y la soja. Balcarce: INTA, EEA, 2002. Cap.8, p.211-237. 
ANDRADE, F.H.; SADRAS, V. O. Efectos de la sequía sobre el crecimiento y rendimiento de los cultivos. In: Bases para el manejo del maíz, el girasol y la soja. Andrade, F.H.; Sadras, V.O. Eds. Balcarce, 2002. Cap. 7, p. 175-210.

ANDRIULO, A. Modellisation de l'evolution des matieres organiques des sols de la Pampa. Relation avec les systemes de culture. Paris: Institut National Agronomique Paris-Grignon, 1995. 143p. (These Doctorat).

APARICIO, V.; COSTA J.L.; ECHEVERRÍA, H.E.; CAVIGLIA, O. Evaluación de propiedades edáficas y crecimiento del maíz bajo diferentes sistemas de labranza en cuatro sitios del sudeste bonaerense. Revista de Investigaciones Agropecuarias, v.31, p.55-71, 2002.

ARSHAD, M.A.; FRANZLUEBBERS, A.J.; AZOOZA, R.H. Components of surface soil structure under conventional and no-tillage in northwestern Canada. Soil and Tillage Research, v.53, p.41-47, 1999.

BALESDENT, J.; CHENU, C.; BALABANE, M. Relationship of soil organic matter dynamics to physical protection and tillage. Soil and Tillage Research, v.53, p.215230,2000 .

BALESDENT, J.; MARIOTTI, A. Measurement of soil organic matter turnover using 13C natural abundance. In: BOUTTON, T.W.; YAMASAKI, S.-I. (Ed.) Mass spectrometry of soils. New York: Marcel Dekker, 1996. cap.3, p.83-111.

BALESDENT, J.; PETRAUD, J.P.; FELLER, C. Effet des ultrasons sur la distribution granulométrique des mattiéres organiques des sols. Science du Sol, v.29, p.95-106, 1991.

BARRACLOUGH, D. $15 \mathrm{~N}$ isotope dilution techniques to study soil nitrogen transformations and plant uptake. Fertilizer Research, v.42, p.185-192, 1995.

BARRACLOUGH, D. The use of mean pool abundances to interpret $15 \mathrm{~N}$ tracer experiments. I. Theory. Plant \& Soil, v.131, p.89-96, 1991. 
BARRACLOUGH, D. The direct or MIT route for nitrogen immobilization: A ${ }^{15} \mathrm{~N}$ mirror image study with leucine and glycine. Soil Biology \& Biochemistry, vol. 29, p.101-108, 1997.

BARRACLOUGH, D.; GEENS, E.L.; DAVIES, G.P.; MAGGS, J.M. Fate of fertilizer nitrogen. 3. The use of single and double labeled N-15 ammonium-nitrate to study nitrogen uptake by ryegrass. Journal of Soil Science, vol.36, p.593-603, 1985.

BARRACLOUGH, D.; PURI, G. The use of $15 \mathrm{~N}$ pool dilution and enrichment to separate the heterotrophic and autotrophic pathways of nitrification. Soil Biology \& Biochemistry, v.27, p.17-22, 1995.

BARRIE, A.; PROSSER, S.J. Automated analysis of light-element stable isotopes by isotope ratio mass spectrometry. In: BOUTTON, T.W.; YAMASAKI, S. (Eds.) Mass spectrometry of soils. New York: Marcel Dekker, 1996. p.1-46.

BARRIOS, E.; BURESH, R.J.; SPRENT, J.I. Nitrogen mineralization in density fractions of soil organic matter from maize and legume cropping systems. Soil Biology \& Biochemistry, v.28, p.1459-1465, 1996.

BATALLANEZ, E.E. Capacidad de almacenaje de humedad para cuatro series de suelos del S.E. de la provincia de Buenos Aires. Balcarce, 1972. 72p. Tesis de graduación Ing. Agr. Universidad Católica de Mar del Plata.

BEARE, M.H.; CABRERA, M.L.; HENDRIX, P.F.; COLEMAN, D.C. Aggegateprotectes and unprotectes organic matter pools in conventional-tillage and no-tillage soils. Soil Science Society of America Journal, v.58, p.787-795, 1994.

BERARDO, A. Aspectos generales de fertilización y manejo del trigo en el área de influencia de la Estación Experimental INTA-Balcarce. Balcarce: INTA, 1994. Boletín Técnico, 28.

BLAKE, G.R.; HARTGE, K.H. Bulk density. In: KLUTE, A. (Ed.) Methods of soil analysis. 2.ed. Madison: ASA, 1986. cap.2, p.363-375. 
BOUTTON T.W. Stable carbon isotope ratios of soil organic matter and their use as indicators of vegetation and climate change. In: BOUTTON T.W.; YAMASAKI, S.I. (Ed.) Mass spectrometry of soils. New York: Marcel Dekker, 1996. cap.2, p.4782, 1996.

BRADFORD, J.M.; PETERSON, G.A. Conservation tillage. In: SUMMER, M.E. (Ed.) Handbook of soil science. New York: CRC Press, 2000. p.G247-C298.

BRAY, R.H.; KURTZ, L. Determination of total, organic, and available forms of phosphorus in soils. Soil Science, v.59, p.39-45, 1945.

BREMNER, J.M. Inorganic forms of nitrogen. In: BLACK, C.A.; EVANS, D.D. (Ed.) Methods of soil analysis. Madison: ASA, 1965. pt.2, p.1149-1178. (Agronomy, 9).

BROOKES, P.D.; STARK, J.M.; MCINTEER, B.B.; PRESTON, D.T. Diffusion method to prepare soil extracts for automated nitrogen-15 analysis. Soil Science Society of America Journal, v.53, p.1707-1711, 1989.

CAMBARDELLA, C.A.; ELLIOT, E.T. Carbon and nitrogen dynamics of soil organic matter fractions from cultivated grassland soils. Soil Science Society of America Journal, v.58, p.123-130, 1994.

CAMBARDELLA, C.A.; ELLIOT, E.T. Particulate soil organic matter changes across a grassland cultivation sequence. Soil Science Society of America Journal, v.56, p.777-783, 1992.

CAMPBELL, C.A.; MYERS, R.J.K.; WEIER, K.L. Potentially mineralizable nitrogen decomposition rates and their relationship to temperature for five Queensland soils. Australian Journal of Soil Research, v.19, p.323-332, 1981.

CERRI, C.C.; FELLER, C.; BALESDENT, J.; VICTORIA, R.; PLENECASSAGNE, A. Application du traçage isotopique naturel em 13C à l'etude de la dynamique de la mattière organique dans les sols. Comptes Rendus de l'Academie de Science de Paris, Série 2, p.423-428,1985. 
CHEN J.; STARK, J.M. Plant species effects and carbon and nitrogen cycling in a sagebrush-crested wheatgrass soil. Soil Biology \& Biochemistry, vol 32, p.47-57, , 2000.

CHRISTENSEN, B.T. Physical fractionation of soil and organic matter in primary particle size and density separates. Advances in Soil Science, v.20, p.1-87, 1992.

COMPTON, J.E.; BOONE, R.D. Soil nitrogen transformations and the role of light fraction organic matter in forest soils. Soil Biology \& Biochemistry, vol.34, p.933943, 2002.

COOKSON, W.R.; MURPHY, D.V. Quantifying the contribution of dissolved organic matter to soil nitrogen cycling using $15 \mathrm{~N}$ isotopic pool dilution. Soil Biology \& Biochemistry, v.36, p.2097-2100, 2004.

CORRE, M.D.; SCHNABEL, R.R; STOUT, W.L. Spatial and seasonal variation of gross nitrogen transformations and microbial biomass in a Northeastern US grassland. Soil Biology \& Biochemistry, v.34, p.445-457, 2002.

COX, W.J.; ZOBEL, R.W.; VANES, H.M.; OTIS, D.J. Tillage effects on some soil physical and corn physiological-characteristics, Agronomy Journal, vol.82 , p. 806812, 1990.

DARWICH, N.A. Estado actual y manejo de los recursos naturales en la región pampeana húmeda sur. In: SEMINARIO JUICIO A NUESTRA AGRICULTURA. HACIA EL DESARROLLO DE UNA AGRICULTURA SOSTENIBLE, Buenos Aires, 1991. (Ed.) Buenos Aires: Ed. Hemisferio Sur, 1991. p.51-62.

DAVIDSON, E.A.; HART, S.C.; SHANKS, C.A.; FIRESTONE, M.K. Measuring gross mineralization, immobilization, and nitrification by $15 \mathrm{~N}$ isotopic pool dilution in intact soil cores. Journal of Soil Science, v.42, p.335-349, 1991.

DELlA MAGGIORA, A.I.; IRIGOYEN, A.I.; GARDIOL, J.M.; CAVIGLIA, O.; ECHARTE, L. Evaluación de un modelo de balance de agua en el suelo para el cultivo de maíz. Revista Argentina de Agrometeorología, v.2, n.2, p.167-176, 2002/03. 
DOMÍNGUEZ, G.; STUDDERT, G.; ECHEVERRÍA, H.; ANDRADE, F. Sistemas de cultivo y nutrición nitrogenada en maíz. Ciencia del Suelo, v.19, p.47-56, 2001.

DORAN, J.W. Microbial biomass and mineralizable nitrogen distributions in no-tillage and plowed soils. Biology and Fertility of Soils, v.5, p.68-75, 1987.

ECHEVERRÍA, H.E.; BERGONZI, R.; FERRARI, J.L. Un modelo para estimar la mineralización de nitrógeno en suelos del sudeste de la provincia de Buenos Aires (Argentina). Ciencia del Suelo, v.12, p.56-62, 1994.

ECHEVERRÍA, H.E.; FERRARI, J.L. Relevamiento de algunas características de los suelos agrícolas del sudeste bonaerense. Balcarce: INTA, Ce.R.B.A.S., 1993. Boletín Técnico ${ }^{\circ} 112$.

ECHEVERRÍA, H.E.; SAINZ ROZAS, H.R. Eficiencia de recuperación del nitrógeno aplicado al estadío de seis hojas del maíz bajo riego en siembra directa y labranza convencional. Ciencia del Suelo, v.19, p.57-66, 2001.

ECHEVERRÍA, H.E.; VIDELA, C.C. Eficiencia fisiológica y de utilización de nitrógeno en trigo en la Región Pampeana argentina. Ciencia del Suelo, v.16, p.8387, 1998.

EDWARDS A.P.; BREMNER J.M. Microaggregates in soils. Journal of Soil Science, v.18, p.64-73, 1967.

EIZA, M.J.; FIORITI, N.; STUDDERT, G.A.; ECHEVERRÍA, H.E. Fracciones de carbono orgánico en la capa arable: efecto de los sistemas de cultivo y de la fertilización nitrogenada. In: CONGRESO ARGENTINO DE LA CIENCIA DEL SUELO, 19, Entre Rios, 2004. Resumo expandido. Buenos Aires: INTA, 2004. 9p. CD-ROM.

ELLIOT, E.T. Aggregate structure and carbon, nitrogen and phosphorus in native and cultivated soils. Soil Science Society of America Journal, v.50, p.627-633, 1986. 
FABRIZZI, K.P.; MORÓN, A.; GARCÍA, F.O. Soil carbon and nitrogen organic fractions in degraded vs. Non-degraded Mollisols in Argentina. Soil Science Society of America Journal, v.67, p.1831-1841, 2003.

FALOTICO, J.L.; Studdert, G.A.; Echeverría, H.E. Nutrición nitrogenada del trigo bajo siembra directa y labranza convencional. Ciencia del Suelo, Vol.17, p. 9-20, 1999.

FELLER C. La matière organique dans les sols tropicaux à argile 1:1. Recherche de compartiments organiques fontionnels. Une approche granulométrique. Strasbourg, 1994. 393p.Thèse (Docteur) - Université Louis Pasteur.

FELLER, C.; BEARE M.H. Physical control of soil organic matter dynamics in the tropics. Geoderma, v.79, p.69-116, 1997.

FERRERAS, L.A.; COSTA, JL.; GARCÍA F.O.; PECORARI, C. Effect of no-tillage on some physical properties of a structural degradaded Petrocalcic Pleudoll of the southern "Pampas" of Argentina. Soil Tillage Research, vol.54, p.31-39, 2000.

FOLLET R.F.; SCHIMEL, D.S. Effect of tillage practices on microbial biomass dynamics. Soil Science Society of America Journal, v.53, p.1091-1096, 1989.

GARDNER, W.H. Water content. In: KLUTE, A. (Ed.) Methods of soil analysis. 2.ed. Madison: ASA, 1986. pt.1, p.493-544. (Agronomy, 9).

GAVA, G.J.C. Compartimentalização do nitrogênio no sistema solo-planta na implantação da semeadura direta no ciclo da cultura do milho. Piracicaba, 2003. 125p.Tese (Doutorado) - Centro de Energia Nuclear na Agricultura, Universidade de São Paulo.

GAVINELLI, E.; FELLER, C.; LARREÉ-LARROUY, M.C.; BACYE, B.; DJEGUI, N.; NZILA, J.D. A routine method to study soil organic matter by particle-size fractionation: examples for tropical soils. Communications in Soil Science \& Plant Analysis, v.26, p.1749-1760, 1995. 
GONZALEZ MONTANER, J.H.; MADDONI, G.A.; DINÁPOLI, M.R. Modelling grain yield and grain yield response to nitrogen in spring wheat crops in the Argentinean Southern Pampa. Field Crops Research, vol.51, p.241-252, 1997.

GREENLAND D.J. Interaction between clays and organic compounds in soils. Part I. Mechanisms of interaction between clays and defined organic compounds. Soil Fertility, v.28, p.415-425, 1965a.

GREENLAND D.J. Interaction between clays and organic compounds in soils. Part II. Adsorption of soil organic compounds and this effect on soil properties. Soil Fertility, v.28, p.521-532, 1965 b.

GUPTA, V.V.S.R.; ROPER, M.M.; KERKEGAAR, J.A.; ANGUS, J.F. Changes in microbial biomass and organic matter levels during the first year of modified tillage and stubble management practices on a red Earth. Australian Journal of Soil Research, v.32, p.1339-1354, 1994.

HART, S.C.; STARK, J.M.; DAVIDSON, E.A.; FIRESTONE, M.K. Nitrogen mineralization, immobilization and nitrification. In: KLUTE, A.; WEAVER, R.W.; MICKELSON, S.H.; SPARKS, D.L.; BARTELS, J.M. (Ed.) Methods of soil analysis. Part 2. Microbiological and Biochemical properties. Madison: SSSA, 1994. cap.42, p.985-1018. (Book Series, 5).

HATCH, D.J.; JARVIS, S.C.; PHILLIPS, L. Field measurement of nitrogen mineralization using soil core incubation and acetylene inhibition of nitrification. Plant and Soil, v.124, p.97-107, 1990.

HAYNES, R.J.; BEARE, M.H. Agregation and organic matter storage in neso-thermal humid soils. In: CARTER, M.R.; STEWART, B.A. (Ed.) Advances in soil science: structure and organic matter storage in agricultural soils. Boca Raton, CRC Lewis Publishers, 1996. p.213-262. 
HAYNES, R.J.; SWIFT, R.S. Stability of soil aggregates in relation to organics constituents and soil water content. Journal of Soil Science, v.41, p.73-83, 1990.

HAYNES, R.J.; SWIFT, R.S.; STEPHEN, R.C. Influence of mixed cropping rotations (pasture-arable) on organic matter content, water stable aggregation, and cold porosity in a group of soils. Soil Tillage Research, v.19, p.77-87, 1991.

HOOD, R.C.; WOOD, M. Estimating gross mineralization of Alnus glutinosa residues, using $15 \mathrm{~N}$ mirror image experimentation. In: VAN CLEEMPUT, O.; HOFMAN, G VERMOESEN, A. (EdS.). Progress in nitrogen cycling studies. Belgium, University of Ghent, 1996. p.53-56.

JAMIESON, N., MONHAGAN, R.; BARRACLOUGH, D. Seasonal trens of gross N mineralization in a natural calcareous grassland. Global Change Biology, vol.5, p.423-431, 1999.

JENKINSON, D.S. The turnover of organic matter in soil. In: WILD, A. (Ed.) Soil conditions and plant growth. London: Longman, 1988. p.564-607.

KIRKHAM, D.; BARTHOLOMEW, W.V.Equations for following nutrient transformations in soil, utilizing tracer data. Soil Science Society of America Proceedings, v.18, p.33-34, 1954.

KRISTENSEN H.L.; Mc CARTY, G.W.; MEISINGER, J.J. Effects of soil disturbance on mineralization of soil organic matter. Soil Science Society of America Journal, v.64, p.371-378, 2000.

LANDI, L.; BARRACLOUGH, D.; BADALUCCO, L.; GELSOMINO, A.; NANNIPIERI, P. L-Methionine-sulphoximine affects $\mathrm{N}$ mineralisationimmobilisation in soil. Soil Biology \& Biochemistry, v.31, p.253-259, 1999.

LUXHØI, J.; NIELSEN, N.E.; JENSEN, L.S. Influence of 15NH+4-application on gross N turnover rates in soil. Soil Biology \& Biochemistry, v.35, p.603-606, 2003.

MAHENDRAPPA, M.K.; SMITH, R.L.; KISTINSEN, T.A. Nitrifing organisms affected by climatic region in Western United States. Soil Science Society of America Proceedings, v.30, p.60-62, 1966. 
MALHI, S.S.; MC HILL, W.B. Nitrification in three Alberta soils: effect of temperature, moisture and substrate concentration. Soil Biology \& Biochemistry, v.14, p.393-399, 1982.

MEIJBOOM, F.W.; HASSINK, J.; VAN NOORDWIJK, M. Density fractionation of soil macroorganic matter using silica suspensions. Soil Biology \& Biochemistry, v.27, p.1109-1111, 1995.

MIELKE, L.N.; DORAN, J.W.; RICHARDS, K.A. Physical environment near the surface of plowed and no-tilled soils. Soil and Tillage Research, v.7, p.355-366, 1986.

MONAGHAN, R.; BARRACLOUGH, D. Contributions to gross N mineralization from

${ }^{15} \mathrm{~N}$-labelled soil macroorganic matter fractions during laboratory incubation. Soil Biology \& Biochemistry, vol.27, p.1623-1628, 1995.

MONHAGAN, R. Errors in estimates of gross rates of nitrogen mineralization due to non-uniform distributions of ${ }^{15} \mathrm{~N}$ label. Soil Biology \& Biochemistry, vol.27, p.855$859,1995$.

MONNIER, G.; TURC, L.; JEANSIN-LUUSINANG, C. Une méthode de fractionnament densimétrique par centrifugation des matières organiques $\mathrm{du}$ sol. Annales Agronomiques, v.13, p.55-63, 1962.

MORAES SÁ, J.C. Dinâmica da matéria orgânica do solo em sistemas de manejo convencional e plantio direto. Piracicaba, 2001. 141p.Tese (Doutorado) - Escola Superior de Agricultura "Luiz de Queiroz", Universidade de São Paulo.

MURPHY, D.V.; FILLERY, I.R.P.; SPARLING, G.P. Seasonal fluctuations in gross N mineralisation, ammonium consumption, and microbial biomass in a Western Australian soil under different land uses. Australian Journal of Agricultural Research, vol.49; p. 523-535, 1998.

MURPHY, D.V.; BHOGAL, A.; SHEPHERD, M.; GOULDING, K.W.T.; JARVIS, S. C.; BARRACLOUGH, D.; GAUNT, J. L. Comparison of ${ }^{15} \mathrm{~N}$ labelling methods to 
measure gross nitrogen mineralization. Soil Biology \& Biochemistry, vol.31, p.2015-2024, 1999.

MYERS, R.J.K. Temperature effects on ammonification and nitrification in tropical soils. Soil Biology \& Biochemistry, v.7, p.83-87, 1975.

MYROLD, D. Tracer basics. Applications to $\mathrm{N}$ cycle. http://cropandsoil.oregonstate.edu/classes/css523/w04/15N_tracer_files/frame.htm. (2004).

NAVARRO, C.A.; ECHEVERRÍA, H.E.; GONZÁLEZ, N.S.; IGLESIAS, M.A. Cinética de las reacciones de amonificación y nitrificación en los suelos del sudeste bonaerense. In: IX REUNIÓN ARGENTINA DE LA CIENCIA DEL SUELO, Paraná, Entre Ríos, 1980. Actas. Tomo II, p.431-437, 1980.

NISHIO, T.; KANAMORI,T.; FUJIMOTO, T. Nitrogen transformations in an anaerobic soil as determined by ${ }^{15} \mathrm{NH}_{4}$ dilution technique. Soil Biology \& Biochemistry, vol.17, p.149-154.

NISHIO, T.; FUJIMOTO, T. Mineralization of soil organic nitrogen in uplands fields as determined by ${ }^{15} \mathrm{NH}_{4}$ dilution technique. Soil Biology \& Biochemistry, vol.21, p.661-665, 1989.

O'DOWD, R.W.; BARRACLOUGH, D.; HOPKINS, D.W. Nitrogen and carbon mineralization in soil amended with D- and L-leucine. Soil Biology \& Biochemistry, v.31, p.1573-1578, 1999.

OLIVEIRA, F.H.T.; NOVAIS, R.F.; ALVAREZ, V.H.; CANTARUTTI, V.R.B.; BARROS, N.F. Fertilidade do solo no sistema plantio direto. In: ALVAREZ, V.H.; SCHAEFER, C.E.G.R.; BARROS, N.F.; de MELLO, J.W.V.; da COSTA, L.M. (Ed.) Tópicos em ciência do solo. Viçosa: SBCS, 2002. v.2, p.393-486.

ORCHARD, V.A.; COOK, F.J. Relationship between soil respiration and soil moisture. Soil Biology \& Biochemistry, v.15, p.447-453, 1983. 
PEIRETTI, R. Consideraciones sobre el sistema agrícola argentino: Desafíos y oportunidades frente al escenario actual. X Congreso Nacional de AAPRESID, 13-26 de agosto. Rosario, Santa Fe, Argentina, p.47-71, 2002.

PICONE, L.I. Importancia de la contribución del amonio fijado en forma no intercambiable para la nutrición de las plantas y microorganismos. Balcarce, 1978. 81p. Tesis (Graduación) - FCA, Universidad Nacional de Mar del Plata.

PICONE, L.; VIDELA, C.; GARCÍA, F. Desnitrificación durante el cultivo de trigo en un Argiudol típico bajo siembra directa y labranza convencional. Ciencia del suelo, vol.15, p.53-58, 1997.

PILBEAM, C.J.; WARREN, G.P. Use of $15 \mathrm{~N}$ for fertilizer $\mathrm{N}$ recovery and $\mathrm{N}$ mineralization studies in semiarid Kenya. Fertilizer Research, v.42, p.123-128, 1995.

PUGET, P.; LAL, R. Soil organic carbon and nitrogen in a Mollisol in central Ohio as affected by tillage and land use. Soil and Tillage Research, In Press, Corrected Proof, Available online 2 July 2004 13p.,

PURI, G.; ASHMAN, M.R. Relationship between soil microbial biomass and gross N mineralization. Soil Biology \& Biochemistry, vol.30, p.251-256, 1998.

RECOUS, S.; AITA, C.; MARY, B. In situ changes in gross N transformations in bare soil after addition of straw. Soil Biology \& Biochemistry, v.31, p.119-133, 1999.

RENAULT, P.; SIERRA, J. Modelling oxygen diffusion in aggregated soils: II Anaerobiosis in topsoil layers. Soil Science Society of America Journal, v.58, p.1023-1030, 1994.

RICE, C.W.; SMITH, M.S.; BLEVINS, R.L. Soil nitrogen availability after long term continuous no-tillage and conventional tillage corn production. Soil Science Society of America Journal, vol.50, p.1206-1210, 1986.

RICHARDS, L.A.; FIREMAN, M. Pressure plate apparatus for measuring moisture sorption and transmission by soils. Soil Science, v.56, p.395-404, 1943. 
SA, J.C. de M.; CERRI, C.C.; DICK, W.A.; RATTAN LAL; VENSKE, S.; PICCOLO, M.C.; FEIGL B.E. Organic matter dynamics and carbon sequestration rates for a tillage chronosequence in a Brazilian oxisol. Soil Science Society of America Journal, v.65, p.1486-1499, 2001.

SCHIMEL, D.S. Carbon and nitrogen turnover in adjacent grassland and cropland ecosystems. Biogeochemistry, vol.2, p.345-357, 1986.

SIX, J.; ELLIOT, E.T.; PAUSTIAN, K. Aggregate and soil organic matter dynamics under conventional and no-tillage systems. Soil Science Society of America Journal, v.63, p.1350-1358, 1999.

SIX, J.; PAUSTIAN, K.; ELLIOT, E.T.; COMBRINK, C. Aggregate and soil organic matter dynamics under conventional and no-tillage systems. Soil Science Society of America Journal, v.64, p.681-689, 2000.

SIX, J.; CONANT, R.T.; PAUL, E.A.; PAUSTIAN K. Stabilization mechanisms of soil organic matter: implications for c-saturation of soils. Plant and Soil, vol. 241, p.155$176,2002$.

SKOPP, J.; JAWSON, M.D.; DORAN, JW. Steady-state aerobial microbial activity as a function of soil water content. Soil Science Society of America Journal, v.54, p.1619-1625, 1990.

SOLLINS, P.; SPYCHER, G.; GLASSMANN, C.A. Net nitrogen mineralization from light and heavy-fraction forest soil organic matter. Soil Biology \& Biochemistry, v.16, p.31-37, 1984.

SORENSEN, P.; JENSEN, E.S. Sequential diffusion of ammonium and nitrate from soil extracts to a polytetraethylene trap for ${ }^{15} \mathrm{~N}$ determination. Analytica Chimica Acta, v.252, p.201-203, 1991.

SPARLING, G.P.; MURPHY, D.V.; THOMPSON, R.B.; FILLERY, I.R.P. Short-term net mineralization from plant residues and gross and net $\mathrm{N}$ mineralization from soil organic matter after rewetting of a seasonally dry soil. Australian Journal of Soil Research, v.33, p.961-973, 1995. 
SPARLING, G.P.; ROSS, D.J. Biochemical methods to estimate soil microbial biomass: current developments and applications. In: MULONGOY, K.; MERCKX, R. (Ed.) Soil organic matter dynamics and sustainability of tropical agriculture. Leuven: Wiley Sayce, 1993. p.21-27.

STANFORD, G.; FRERE, M.H.; SCHWANINGER, D.H. Temperature coefficient of soil nitrogen mineralization. Soil Science, v.115, p.321-323, 1973.

STARK, J.M.; HART, S.C. High rates of nitrification and nitrate turnover in undisturbed coniferous forest. Nature, v.385, p.61-64, 1997.

STENGER, R.; PRIESACK, E.; BEESE, F. Rates of net nitrogen mineralization in disturbed and undisturbed soils. Plant \& Soil, v.171, p.323-332, 1995.

STUDDERT, G.A.; ECHEVERRÍA, H.E. Crop rotations and nitrogen fertilization to manage soil organic carbon dynamics. Soil Science Society o America Journal, v.64, p.1496-1503, 2000.

STUDDERT, G.A.; ECHEVERRÍA, H.E.; CASANOVAS, E.M. Crop-pasture rotation for sustaining the quality and productivity on a Typic Argiudoll. Soil Science Society of America Journal, v.61, p.1466-1472, 1997.

TISDALL, J.M.; OADES, J.M. Organic matter and water stable aggregates in soils. Journal of Soil Science, v.33, p.141-163, 1982.

UNKOVICH, M.; JAMIESON, N.; MONHAGAN, R.; BARRALOUGH, D. Nitrogen mineralisation and plant nitrogen acquisition in a nitrogen-limited calcareous grassland. Environmental and Experimental Botany, v.40, p.209-219, 1998.

VAN VEEN, J.A.; KUIKMAN, P.J. Soil structural aspects of decomposition of organic matter by micro-organisms. Biogeochemistry, v.11, p.213-233, 1990.

VIDELA, C.; TRIVELIN, P.C.; STUDDERT, G.A.; BENDASSOLLI, J.A.; ECHEVERRÍA, H.E. Tempo de incubaçâo em experimentos de mineralização bruta do nitrogênio em solos Argiudoles típicos da Argentina. In: ENCONTRO 
CIENTÍFICO DOS POS-GRADUANDOS DO CENA-USP, 7., Piracicaba, 2001. Resumos. Piracicaba: CENA/USP, 2001.

VIDELA, C.; TRIVELIN, P.C.; STUDDERT, G.A.; ECHEVERRÍA, H.E.; BENDASOLLI, J.A. Mineralização bruta do nitrogênio em solos de alta fertilidade. Efeito do manejo e da profundidade de amostragem. In: INTERNATIONAL NUCLEAR ATLANTIC CONFERENCE, 6., Rio de Janeiro, 2002. Anais. Rio de Janeiro, 2002. CD-Rom.

VIDELA, C.C. La volatilización de amoníaco: una vía de pérdida de nitrógeno en sistemas agropecuarios. Boletín Técnico INTA, n.131, p.1-16, 1994.

WALKLEY, A.; BLACK, I.A. An examination of the Dgtjareff method for determining soil organic matter and a proposed modification of the chromic acid titration method. Soil Science, v.37, p.29-37, 1934.

WANG, W.J.; CHALK, P.M.; CHEN, D.; SMITH C.J. Nitrogen mineralization, immobilization and loss, and their role in determining differences in net nitrogen production during waterlogged and aerobic incubation of soils. Soil Biology \& Biochemistry, vol.33, p. 1305-1315, 2001.

WATSON, C.J.; MILLS, C.L. Gross nitrogen transformations in grassland soils as affected by previous management intensity. Soil Biology \& Biochemistry, vol.30, p. 743-753.

YONEYAMA, T. Characterization of natural $15 \mathrm{~N}$ abundant in soils. In: BOUTTON, T.W.; YAMASAKI, S. (Ed.) Mass spectrometry of soils. New York: Marcel Dekker, 1996. cap.8, p.205-224.

ZAMAN, M.; CHANG, S.X. Substrate type, temperature, and moisture content affect gross and net mineralization and nitrification rates in agroforestry systems. Biology and Fertility of Soils, vol.39, p.269-279, 2004. 


\begin{abstract}
ANEXO A
CARACTERIZAÇÃO DA ÁREA EXPERIMENTAL E DO SOLO

O experimento, denominado de Ensayo de Lavouras e Rotações mistas, foi implantado no campo Experimental do Instituto Nacional de Tecnología Agropecuaria (INTA), localizado em Balcarce, Província de Buenos Aires, Argentina, (37 $45^{\circ} \mathrm{S}, 58^{\circ}$ $18^{\prime} \mathrm{W}, 130 \mathrm{~m}$ sobre o nível do mar, $870 \mathrm{~mm}$ de precipitação media anual, $13,7^{\circ} \mathrm{C}$ de temperatura média anual). A área experimental possui um complexo de solos Paleudol petrocálcico - Argiudol típico, com $2 \%$ de declividade (sem erosão), cujas características determinadas em amostras colhidas em 1994 constam na Tabela 12. O solo foi manejado com rotações agrícolas sob plantio convencional durante 18 anos, na seqüência de culturas indicadas na Tabela 13.

Em 1994 foram instalados três diferentes manejos: lavoura convencional (LC), semeadura direta (PD) e pastagem permanente (P) dispostos em um desenho experimental em blocos ao acaso com 3 repetições, cuja seqüência de culturas se apresenta na tabela 14. A seqüência de culturas utilizada é composta por milho (Zea mays L.) - soja (Glycine Max L.) - trigo (Triticum aestivum L.). A pastagem está composta por uma mistura de Festuca arundinácea Schreb. e Trifolium repens L. O tamanho das parcelas é de $20 \times 35 \mathrm{~m}$.
\end{abstract}


Tabela 12. Propriedades do complexo de solos Paleudol petrocálcico - Argiudol típico, depois de 18 anos de agricultura sob plantio convencional na Estação Experimental Balcarce do INTA-Argentina. Amostras colhidas a $18 \mathrm{~cm}$ de profundidade

\begin{tabular}{lc}
\hline $\mathrm{pH}\left(1: 2,5\right.$ relação solo: $\left.\mathrm{H}_{2} \mathrm{O}\right)$ & 6,3 \\
CTC $(\mathrm{cmol} \mathrm{kg}$ & -1 \\
Textura & 33,1 \\
$\quad$ Argila $\left(\mathrm{g} \mathrm{kg}^{-1}\right)$ & franca \\
$\quad$ Silte $\left(\mathrm{g} \mathrm{kg}^{-1}\right)$ & 265 \\
$\quad$ Areia $\left(\mathrm{g} \mathrm{kg}^{-1}\right)$ & 337 \\
P disponível, Bray e Kurtz $\left(\mathrm{mg} \mathrm{kg}^{-1}\right)$ & 398 \\
\hline
\end{tabular}

Tabela 13. Seqüência de cultivos prévios à instalação do experimento na Estação Experimental do INTA Balcarce-Argentina.

\begin{tabular}{|c|c|c|c|c|c|c|c|c|c|c|c|c|c|c|c|c|c|c|c|c|}
\hline \multirow{3}{*}{$\frac{\text { Seqüência }}{1 \text { (a) }}$} & \multicolumn{20}{|c|}{ ANOS } \\
\hline & 76 & 77 & 78 & 79 & 8 & & 81 & 82 & 83 & 84 & & 85 & 86 & 87 & 88 & 89 & 90 & 91 & 92 & 93 \\
\hline & B & $\mathrm{T}$ & A & $\mathrm{T}$ & A & B & $\mathrm{T}$ & A & $\mathrm{T}$ & A & B & $\mathrm{T}$ & A & $\mathrm{T}$ & A & $\mathrm{T}$ & A $B$ & $\mathrm{~T}$ & A & $\mathrm{T}$ \\
\hline 2 & B & $\mathrm{T}$ & Av B & $\mathrm{T}$ & Av & B & $\mathrm{T}$ & Av $\quad$ B & $\mathrm{T}$ & $\mathrm{Av}$ & B & $\mathrm{T}$ & Av $\quad$ B & $\mathrm{T}$ & Av B & $\mathrm{T}$ & $\mathrm{Av}$ & $\mathrm{T}$ & $\mathrm{A} \operatorname{Tr} \mathrm{A}$ & $\operatorname{Tr}$ \\
\hline 3 & $\mathrm{P}$ & $\mathrm{P}$ & B & $\mathrm{T}$ & A & B & $\mathrm{T}$ & $\mathrm{P}$ & $\mathrm{P}$ & B & & $\mathrm{T}$ & A B & $\mathrm{T}$ & $\mathrm{P}$ & $\mathrm{P}$ & B & $\mathrm{T}$ & A B & $\mathrm{T}$ \\
\hline
\end{tabular}

(a) As seqüências 1,2 e 3 foram repetidas em três blocos casualizados e nelas instaláram-se no ano 1994 os manejos $\mathrm{Sd}, \mathrm{LC}$ e $\mathrm{P}$, respectivamente.

$\mathrm{B}=$ batata, $\mathrm{T}=$ trigo, $\mathrm{A}=$ aveia, $\mathrm{Av}=$ avena+vicia, $\mathrm{Atr}=$ avena+trébol rojo, $\mathrm{P}=$ pastagem.

Tabela 14. Seqüência de culturas após à instalação do experimento na Estação Experimental do INTA Balcarce-Argentina.

\begin{tabular}{|c|c|c|c|c|c|c|c|c|c|c|c|}
\hline \multirow[b]{2}{*}{ Manejo } & \multicolumn{11}{|c|}{ ANOS } \\
\hline & 94 & 95 & 96 & 97 & 98 & 99 & 00 & 01 & 02 & 03 & 04 \\
\hline SD & $M$ & $\mathrm{~S}$ & $\mathrm{~T}$ & $\bar{M}$ & $\mathrm{~S}$ & $\mathrm{~T}$ & $\bar{M}$ & $\mathrm{~S}$ & $\mathrm{~T}$ & $\bar{M}$ & $\mathrm{~S}$ \\
\hline LC & $M$ & $S$ & $\mathrm{~T}$ & $M$ & $S$ & $\mathrm{~T}$ & $M$ & $S$ & $\mathrm{~T}$ & $M$ & $S$ \\
\hline $\mathrm{P}$ & $\mathrm{P}$ & $\mathrm{P}$ & $\mathrm{P}$ & $\mathrm{P}$ & $\mathrm{P}$ & $\mathrm{P}$ & $\mathrm{P}$ & $P$ & $\mathrm{P}$ & $\mathrm{P}$ & $\mathrm{P}$ \\
\hline
\end{tabular}

$\mathrm{M}=$ milho, $\mathrm{S}=$ soja, $\mathrm{T}=$ trigo, $\mathrm{P}=$ pastagem. 


\begin{abstract}
ANEXO B

\section{AJUSTE METODOLÓGICO PARA A DETERMINAÇÃO DO TEMPO DE AMOSTRAGEM NA DETERMINAÇÃO DA TMB}

A equação apresentada por Barraclough et al. (1985) utilizada neste trabalho, é uma adaptação da proposta por Kirkham \& Bartholomew (1954) e o seu uso deve atender as suposições descritas em 2.2 .

Com o objetivo de conhecer o tempo adequado para fazer as extrações após da marcação do "pool" de amônio com ${ }^{15} \mathrm{~N}$ cumprindo com a suposição de cinética de ordem zero e a não ocorrência da remineralização, realizou-se um experimento totalmente casualizado em laboratório $\left(22^{\circ} \mathrm{C}\right)$ utilizando solo do tratamento Pastagem $(\mathrm{P})$ da camada de $0-10 \mathrm{~cm}$. Foram adicionados $100 \mathrm{~g}$ de solo seco ao ar, passado por peneira de $2 \mathrm{~mm}$ de malha em cilindros de PVC, de $7 \mathrm{~cm}$ de diâmetro e $5 \mathrm{~cm}$ de altura, contendo malha porosa na parte inferior. Os solos dos cilindros foram molhados até $60 \%$ da capacidade máxima de retenção de água $\left(234 \mathrm{~g} \mathrm{~kg}^{-1}\right)$, evitando-se perda de umidade com coberta de Parafilm ${ }^{\circledR}$, e pré-incubados na temperatura de $20^{\circ} \mathrm{C}$ durante uma semana. Após esse período, adicionou-se ${ }^{15} \mathrm{NH}_{4}^{+}$em dose de $10 \mathrm{mg} \mathrm{N} \mathrm{g}^{-1}$ de solo, num volume de $3,5 \mathrm{~mL}$, como $\left({ }^{15} \mathrm{NH}_{4}\right)_{2} \mathrm{SO}_{4}$, com abundância de $10 \%$ de ${ }^{15} \mathrm{~N}$ em excesso. A adição foi realizada com um injetor múltiplo com sete seringas. Após $24,48,72,96$ e $120 \mathrm{~h}$ da adição de ${ }^{15} \mathrm{NH}_{4}^{+}$, fizeram-se extrações com $400 \mathrm{~mL}$ de $\mathrm{KCl}$ 1M, 60 min. de agitação. Nos extratos filtrados determinou-se o conteúdo de $\mathrm{N}-\mathrm{NH}^{+}{ }_{4}$ por microdestilação por arraste de vapor e titulação (Bremner, 1965) e a abundância isotópica do $\mathrm{N}^{-\mathrm{NH}^{+}}{ }_{4}$ em espectrômetro de massas Europa Sc. ANCA-SL. As taxas de mineralização bruta (TMB) foram calculadas com a equação 
de Barraclough (1991), utilizando como primeira extração ( $\mathrm{t}=0)$, os valores obtidos após $24 \mathrm{~h}$ da adição do ${ }^{15} \mathrm{NH}^{+}{ }_{4} \mathrm{e}$ os dos dias seguintes: 2, 3, 4 e 5, como a segunda extração, resultando em quatro valores de taxas de mineralização. Para cada determinação foram obtidas 9 repetições.

Os resultados de tamanho e enriquecimento isotópico da fração de amônio e as TMB calculadas foram analisados estatisticamente por analise da variância e, quando for necessário, foram realizadas provas de diferenças de médias com o teste de Tukey ao nível de probabilidade de 0,05 .

Resultados

O conteúdo de $\mathrm{N}$-amônio foi elevado durante todo o período de medições, mas não apresentou variações significativas, com valores entre 101,2 e 129,9 mg N kg${ }^{-1}$ de solo (Figura 30). O enriquecimento isotópico do amônio apresentou valores muito semelhantes durante as medições, com valores que flutuaram entre 7,81 e $8,84 \%$ em excesso de átomos de ${ }^{15} \mathrm{~N}$. Só no segundo dia, o valor de enriquecimento foi significativamente diferente dos demais. É pertinente destacar, ainda, que os valores de enriquecimento não diminuiriam significativamente, a diluição do "pool" de amônio proveniente da mineralização da matéria orgânica foi suficiente para permitir a quantificação das taxas de mineralização bruta.

Tabela 15. Taxas de mineralização bruta do solo Argiudol típico sob pastagem no Sudeste da província de Buenos Aires (Argentina) calculadas com diferentes intervalos de tempo entre a primeira e segunda extração $(n=9)$.

\begin{tabular}{ccc}
\hline $\begin{array}{l}\text { Dias entre } 1^{\mathbf{o}} \text { e } 2^{\mathbf{o}} \\
\text { extração }\end{array}$ & \multicolumn{2}{c}{ Taxa de mineralização bruta } \\
& \multicolumn{2}{c}{$\mathrm{mg} \mathrm{N} \mathrm{kg}^{-1} \mathrm{dia}^{-1}$} \\
\hline & Media & DPM \\
2 & $-14,256 \mathrm{~B}$ & 6,246 \\
3 & $2,874 \mathrm{~A}$ & 0,372 \\
4 & $1,011 \mathrm{~A}$ & 0,731 \\
\hline
\end{tabular}


As taxas de mineralização bruta calculadas (Tabela 15) apresentaram diferenças significativas para tempo (dias após a adição). As letras maiúsculas após as médias na Tabela 4 indicam diferenças significativas ao nível $p=0,0001$.

O resultado de TMB (Tabela 15) para o primeiro intervalo de tempo após a primeira extração apresentou grande variabilidade, com valor médio negativo o que é biologicamente impossível. A análise dos resultados com eliminação dos valores correspondentes ao intervalo de tempo de 0 a 1 dia, apresentaram alta significância. Considerado o tempo inicial $(\mathrm{t}=0)$ a amostragem feita no dia 1 , o resultado de TBM do dia 2 (intervalo 1 a 2 dias) diferenciou-se do dia 3 e 4, podendo concluir que entre os dias 3 e 4 as taxas de mineralização calculadas permaneceram estabilizadas (Figura 31). Pode inferir destes resultados que os processos estão acontecendo com cinética de ordem zero (taxas constantes), e o $\mathrm{N}$ mineralizado da matéria orgânica está com abundância natural $\left(0,366 \%\right.$ de átomos de $\left.{ }^{15} \mathrm{~N}\right)$, já que no período analisado não se verificou uma redução indefinida das taxas de mineralização no tempo, como aconteceria se estivesse ocorrendo remineralização do ${ }^{15} \mathrm{NH}^{+}{ }_{4}$ imobilizado (Barraclough, 1997).

a)

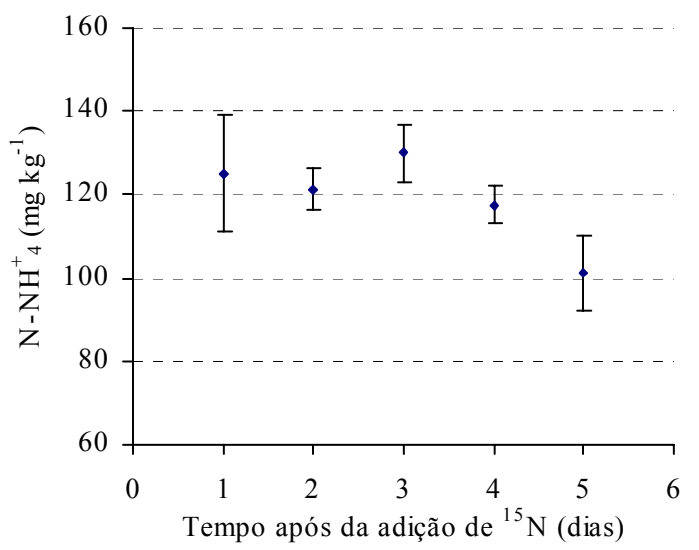

b)

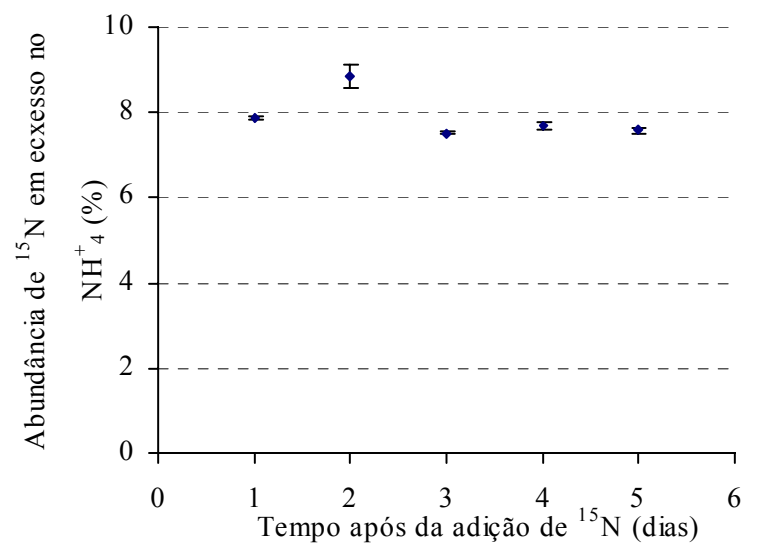

Figura 30. Conteúdo e enriquecimento em ${ }^{15} \mathrm{~N}$ da fração amônio após a adição de sulfato de amônio- ${ }^{15} \mathrm{~N}$ (barras significam o desvio padrão para $\mathrm{n}=9$ ). 

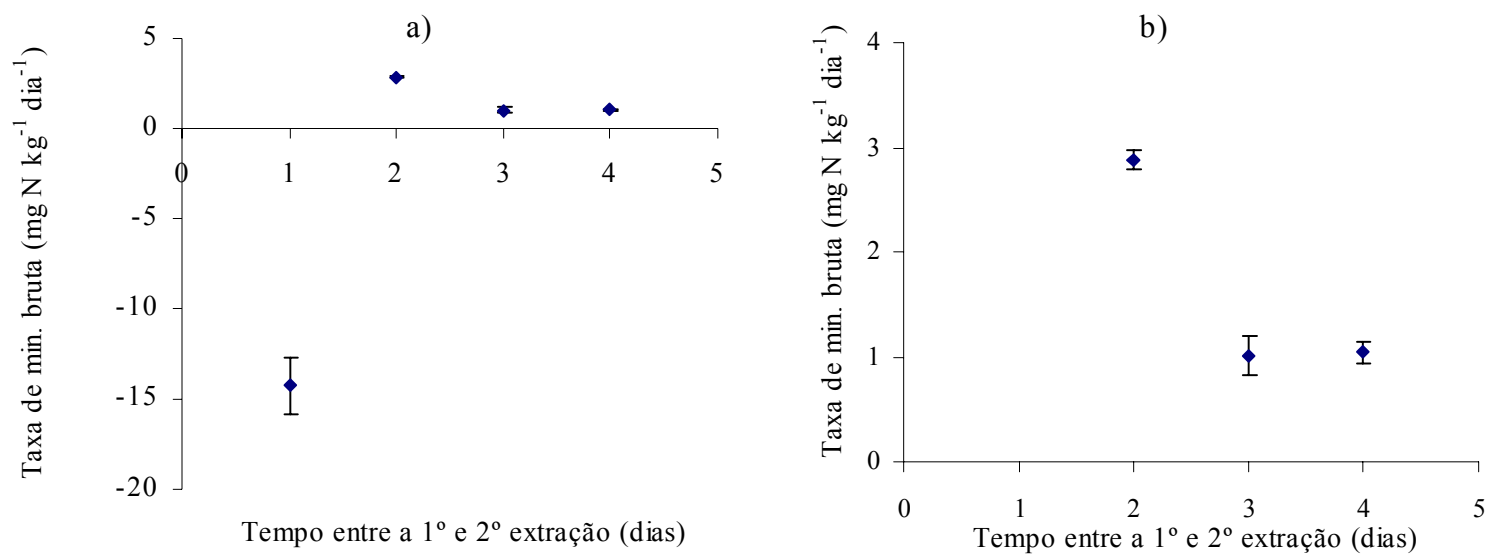

Figura 31. Taxas de mineralização bruta do solo sob pastagem, incluindo tempo de 1 dia (a) e com eliminação desse tempo (b). As barras verticais representam os desvios padrões da média para $n=9$.

A conclusão deste experimento prévio foi que para o solo testado é recomendável determinar-se a taxa de mineralização bruta utilizando um período de 3 a 4 dias entre a primeira e a segunda extração. Com efeito, o período de 3 a 4 dias foi utilizado nos experimentos de mineralização bruta realizados neste trabalho de tese. 